\title{
SHEAR AND FLEXURAL BEHAVIOUR OF LIGHTWEIGHT SELF-CONSOLIDATING CONCRETE BEAMS
}

\author{
By: \\ Kokilan Sathiyamoorthy \\ BEng, University of Moratuwa, Srilanka, 2008
}

\author{
A Thesis \\ Presented to Ryerson University \\ In Partial Fulfillment of the \\ Requirements for the Degree of \\ Master of Applied Science \\ In the Program of \\ Civil Engineering \\ Toronto, Ontario, Canada, 2016 \\ (C) Kokilan Sathiyamoorthy 2016
}




\section{AUTHOR'S DECLARATION}

I hereby declare that I am the sole author of this thesis. This is a true copy of the thesis, including any required final revisions, as accepted by my examiners.

I authorize Ryerson University to lend this thesis to other institutions or individuals for the purpose of scholarly research.

I further authorize Ryerson University to reproduce this thesis by photocopying or by other means, in total or in part, at the request of other institutions or individuals for the purpose of scholarly research.

I understand that my thesis may be made electronically available to the public. 


\title{
SHEAR AND FLEXURAL BEHAVIOUR OF LIGHTWEIGHT SELF-CONSOLIDATING CONCRETE BEAMS
}

\author{
Kokilan Sathiyamoorthy, Master of Applied Science, 2016 \\ Department of Civil Engineering \\ Ryerson University, Toronto, Canada
}

\begin{abstract}
Shear and flexural behaviour of lightweight self-consolidating concrete (LWSCC) beams made of slag aggregates were investigated. Shear reinforced LWSCC beams showed similar shear behaviour compared to their non-shear reinforced counterparts until the formation of diagonal cracks but higher ultimate shear resistance and ductility. Compared to normal weight selfconsolidating concrete (SCC) ones, non-shear reinforced LWSCC beams showed lower postcracking shear resistance. Shear strength of LWSCC/SCC beams increased with the decrease of shear span to depth ratio. LWSCC beams showed higher number of cracks and wider crack width at failure than their SCC counterparts. LWSCC beams developed higher number of cracks with wider crack width at failure compared with their SCC counterparts. American, Canadian and British Codes were conservative in predicting shear strength of shear/non-shear reinforced LWSCC beams. LWSCC beams (with slag aggregate) showed good shear resistance compared with those made of other types of aggregates besides satisfactory flexural performance.
\end{abstract}




\section{ACKNOWLEDGEMENTS}

I would like to express my deepest gratitude to my supervisor, Dr. Khandaker. M. Anwar Hossain, for his excellent guidance, support and patience during the development of this research. He provides me countless opportunities to learn while gaining experience through his effective training. Without his time and countless efforts, this thesis would not have been completed. I consider myself very fortunate to have the opportunity to work with him. Aside engineering principles, he has taught me life learning lessons that I will carry through my life.

Special thanks are extended to Dr. Abdurrahman Lofty for his guidance and supplying furnace slag lightweight aggregates from Lafarge Canada. Financial support from National Science and Engineering Research Council (NSERC) of Canada as well as in-kind donations from Lafarge Canada are also acknowledged.

I am also deeply grateful to PhD Candidate Mohammed Sherir and Ehsani Yeaginah Ali for helping me in casting test specimens despite his busy schedule. Their helps and suggestions were instrumental for successful completion of the tests. I also would like to thank Mr. Nidal Jaalouk, and Mr. Min Yao, for assisting me in casting and testing in the concrete and structural laboratories.

I also extend my special thanks to examining committee members: Dr. Shehata and Dr. Liu for their feedbacks.

Finally, heartiest appreciations to my wife and parents who always supported and encouraged me in every moment of my life. 


\section{DEDICATIONS}

To My Brother

Who passed away during my preparation of thesis. 


\section{TABLE OF CONTENTS}

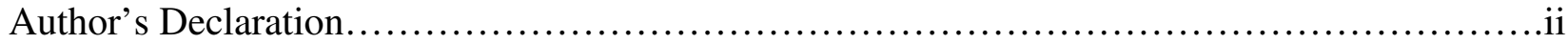

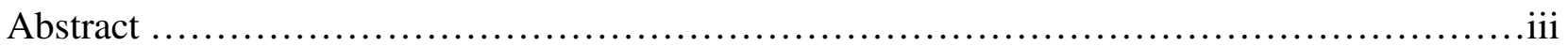

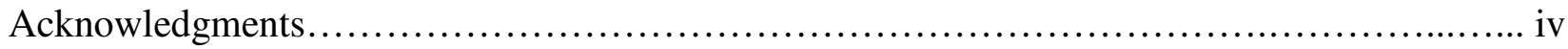

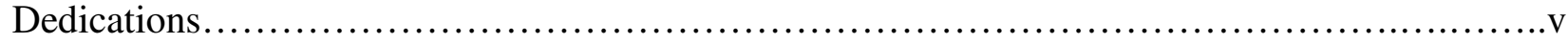

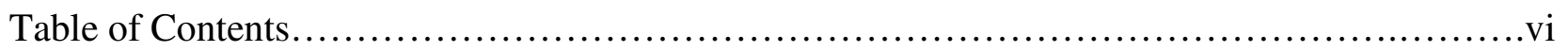

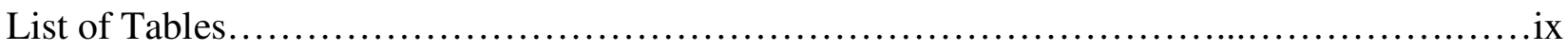

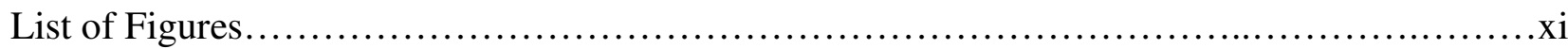

List of Symbols and Abbreviations............................................................

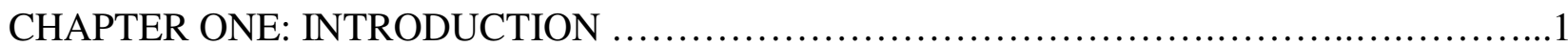

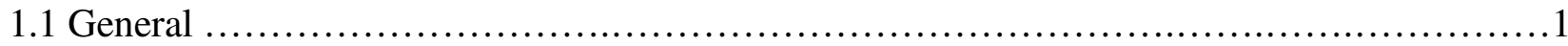

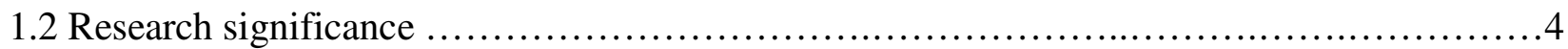

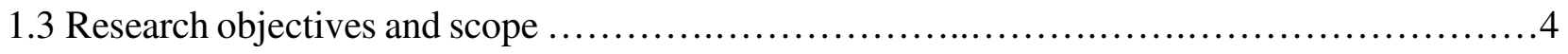

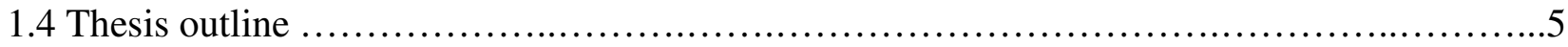

CHAPTER TWO: LITERATURE REVIEW ............................................

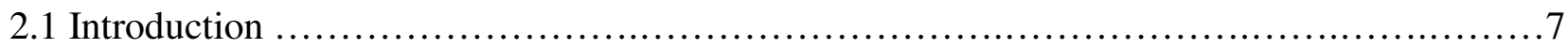

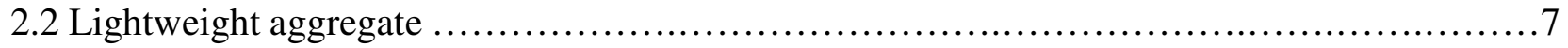

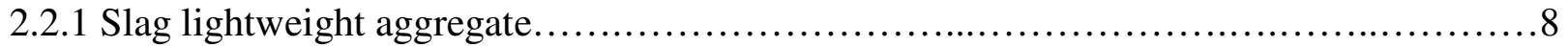

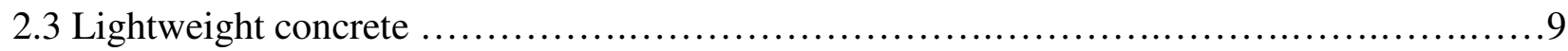

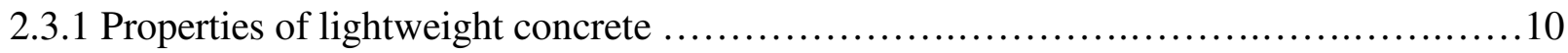

2.3.2 Compressive strength of lightweight concrete …................................... 10

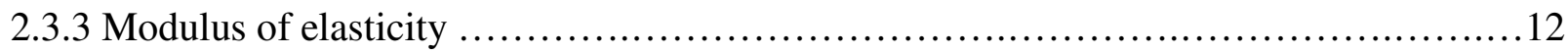

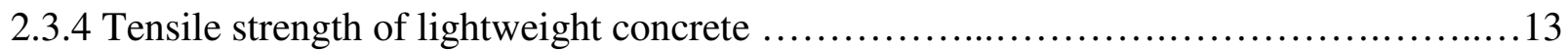

2.3.4 Examples of some research studies illustrating properties of lightweight concrete........13

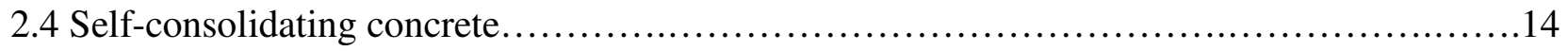

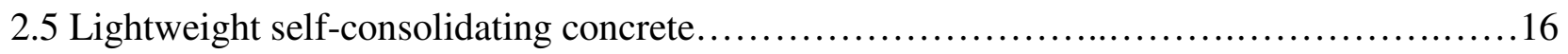

2.5.1 Examples of some studies on lightweight self-consolidating concrete with details........17

2.6 Analysis of reinforced concrete member in shear...................................... 18

2.6.1 Basic shear transfer mechanism in beams without shear reinforcement..................18

2.6.2 Shear transfer mechanism beams with shear reinforcement ..........................20

2.6.3 Code based shear prediction ......................................................... 20 
2.6.4 Shear strength of reinforced lightweight concrete members.......................22

2.6.5 Previous studies on shear behavior of reinforced concrete beams.....................23

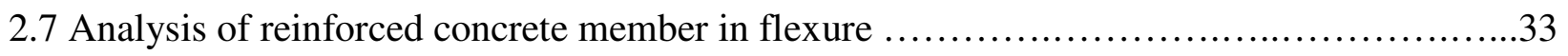

2.7.1 Theoretical ultimate moment of the LWSCC flexural beams ..........................34

2.7.2 Some previous studies of flexural behavior of lightweight concrete beams..............36

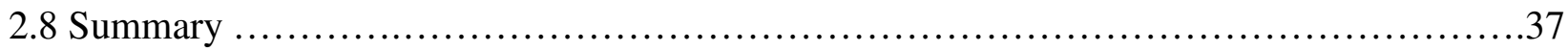

CHAPTER THREE: EXPERIMENTAL PROGRAM................................... 38

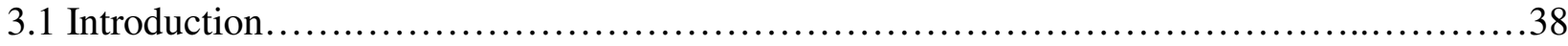

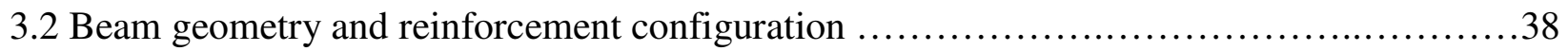

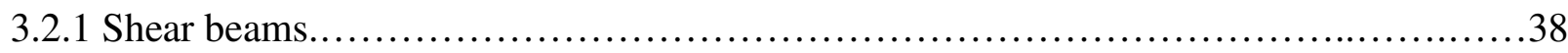

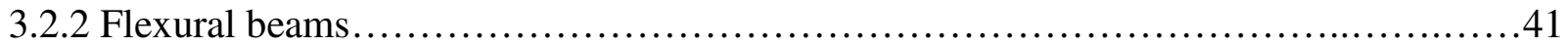

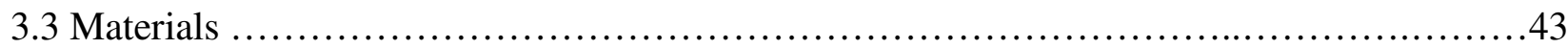

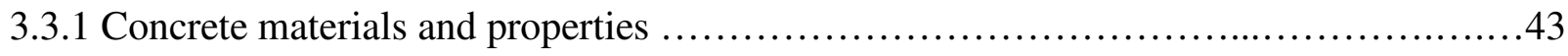

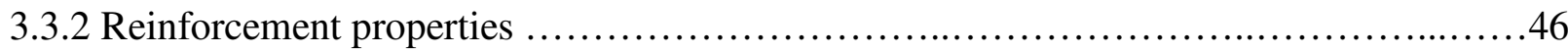

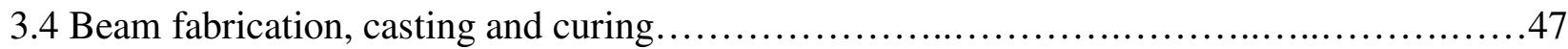

3.5 Experimental set up and instrumentation ......................................... 50

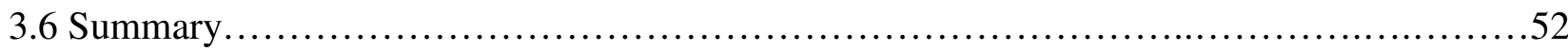

CHAPTER FOUR: EXPERIMENTAL RESULTS AND DISCUSSION .....................53

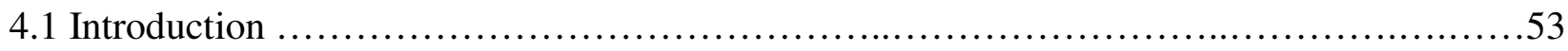

4.2 LWSCC and SCC shear beams without shear reinforcement .........................53

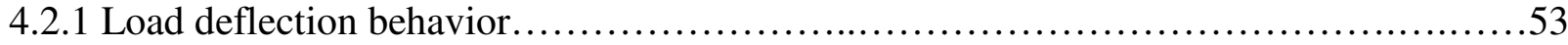

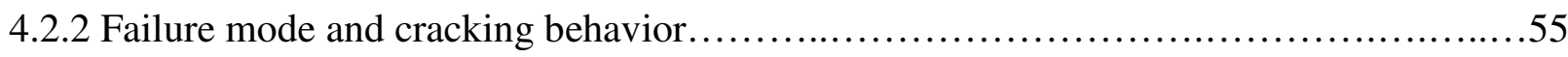

4.2.3 Influence of the shear span to depth ratio $(\mathrm{a} / \mathrm{d})$ on concrete shear resistance..............58

4.2.4 Post cracking shear resistance, ductility and energy absorption.....................59

4.3 LWSCC shear beams with shear reinforcement.....................................62

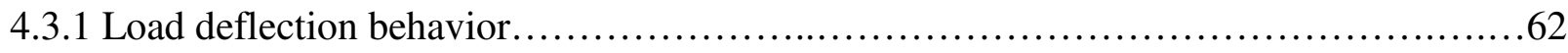

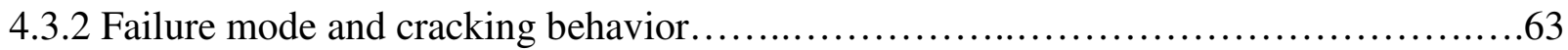

4.3.2 Strain development in the flexural and shear reinforcement.......................65

4.3.3 Influence of the shear span to depth ratio $(\mathrm{a} / \mathrm{d})$ on concrete shear resistance.............68

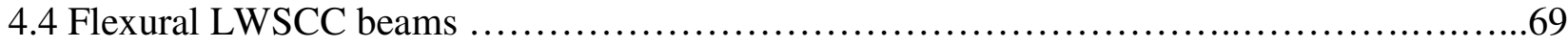

4.4.1 General.................................................................69 
4.4.2 Load deflection behavior.

4.4.3 Failure mode, crack pattern and ultimate load capacity..............................71

4.4.4 Strain development in concrete and flexural/shear reinforcements...................74

4.4.5 Bending moment and beam end rotation development.............................77

4.4.6 Ductility behavior of LWSCC flexural beams.................................. 77

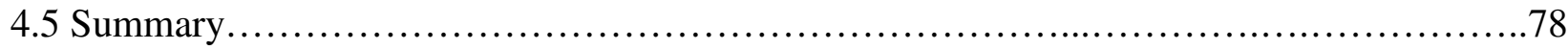

CHAPTER FIVE: THEORITICAL ANALYSIS OF SHEAR AND FLEXTURAL CAPASITIES

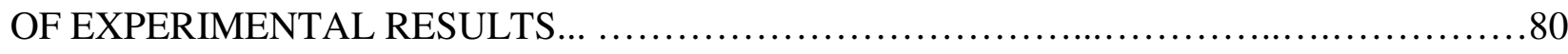

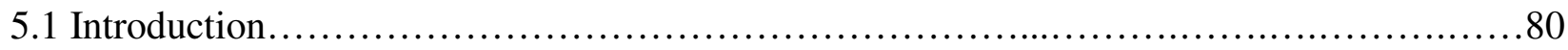

5.2 Codes and the prediction of shear capacity of beams ................................. 80

5.2.1 Shear strength prediction of slag aggregate beams without shear reinforcement.........82

5.2.2 Shear strength prediction of slag aggregate LWSCC beams with shear reinforcement....83

5.3 Analysis of previous experimental studies on shear resistance of lightweight concrete beams

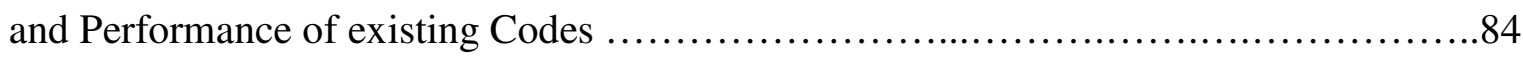

5.3.1 Analysis of the influence of aggregate type on the post-cracking and ultimate shear

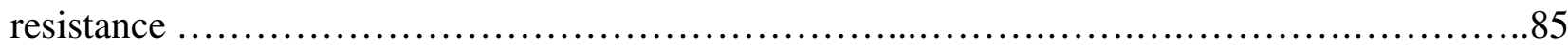

5.3.2 Code based analyses of LWC beams and performance of codes......................89

5.4 Code based prediction of flexural capacity of LWSCC beams.........................92

5.4.1 Theoretical cracking moment of the LWSCC flexural beams......................92

5.4.2 Theoretical ultimate moment of the LWSCC flexural beams .......................92

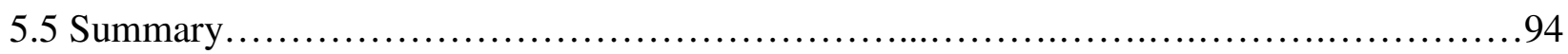

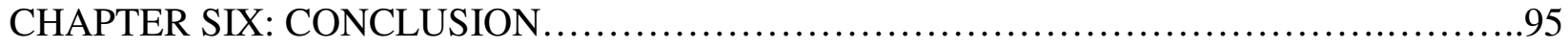

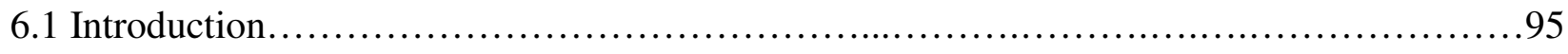

6.2 Shear resistance of LWSCC beams........................................... 95

6.3 Flexural LWSCC beams....................................................... 97

6.4 Recommendations for future research studies.................................... 97

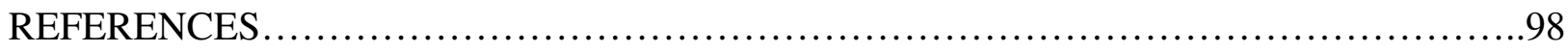




\section{LIST OF TABLES}

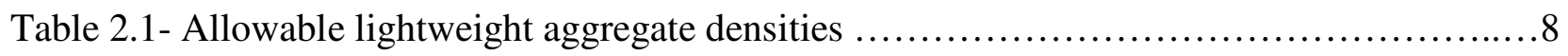

Table 2.2-Inductive values for compressive strength and modulus of elasticity..................11

Table 2.3-Details of lightweight concrete beams tested by Adom and Afrifa....................24

Table 2.4 - Details of lightweight concrete beams tested by Mohammed et al....................25

Table 2.5- Details of lightweight concrete beams tested by Alengaram et al .....................26

Table 2.6 - Details of lightweight concrete beams tested by Gunasekara et al. ..................27

Table 2.7 - Details of lightweight concrete beams tested by Juan ............................29

Table 2.8- Details of lightweight concrete beams tested by Ahmed ............................. 31

Table 3.1 - Shear beams geometry and reinforcement configuration...........................39

Table 3.2 - Flexural beams geometry and reinforcement configuration........................42

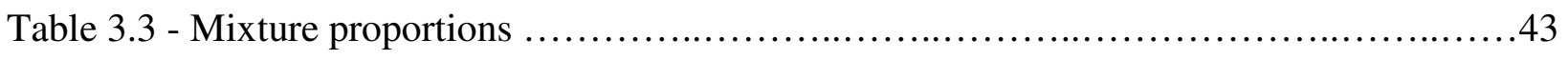

Table 3.4- Chemical and physical properties of cementing material............................44

Table 3.5- Lightweight slag aggregate gradation ............................................ 45

Table 3.6 - Rebar stress-strain response table............................................ 47

Table 3.7- Concrete compressive strength, flexural strength and density at 28 days. ..............50

Table 4.1- Experimental summary for shear beams without shear reinforcement.....................56

Table 4.2- Shear resistance and ductility factor for the shear beams without shear reinforcement60

Table 4.3 - Experimental results summary for tested shear beams with shear reinforcement .....64

Table 4.4- Experimental strain values of tested shear beams with shear reinforcement............68

Table 4.5- Summary of loads, moment and failure modes of LWSCC flexural beams..............72

Table 4.6- Yield load, ultimate load/moment and strain at different ages for flexural beams......76

Table 4.7-Curvature ductility index of LWSCC flexural beams...............................78

Table 5.1- Shear resistance of beams without shear reinforcement from experiment and code

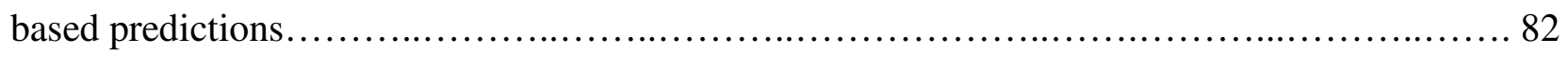

Table 5.2- Shear resistance of beams shear reinforcement from experiment and code based

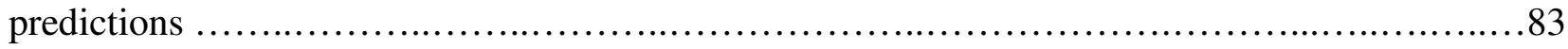

Table 5.3- Data summary for the lightweight concrete beams................................ 85

Table 5.4- Shear resistance factor and nominalized shear stress for beams without shear

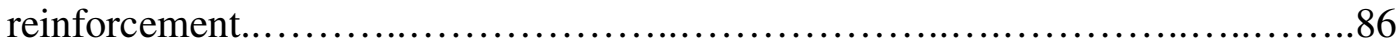


Table 5.5 - Shear resistance of lightweight concrete beams without shear reinforcement- experiment

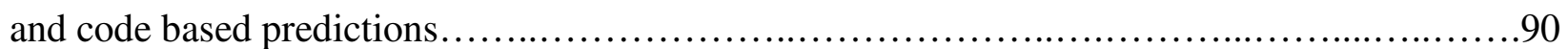

Table 5.6- Shear resistance of lightweight concrete beams with shear reinforcement- experiment

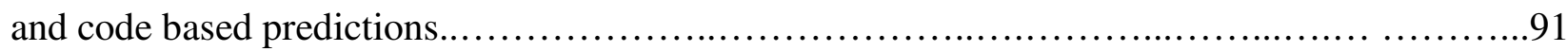

Table 5.7 - Experimental and theoretical cracking moment comparison........................92

Table 5.8- Comparison of experimental and theoretical ultimate moments of LWSCC beans......93 


\section{LIST OF FIGURES}

Figure 2.1- Internal pore structure of the lightweight aggregate...........................

Figure 2.2 -Lightweight concrete.................................................. 11

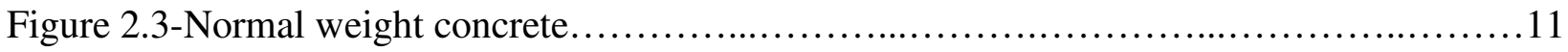

Figure 2.4 -Stress-strain curves for lightweight and normal weight concrete..................12

Figure 2.5 -.Self consolidating concrete construction.................................... 15

Figure 2.6 -Shear transfer mechanism of slender beams................................. 19

Figure 2.6(a) -Beam details of lightweight concrete beams tested by Adom and Afrifa..........24

Figure 2.6(b) -The experimental set-up for the beams tested by Mohammed et al..............25

Figure 2.6(c) -Reinforcement details of the beams tested by Alengaram et al....................26

Figure 2.6(d) -Reinforcement details of the beams tested by Gunasekara et al.................28

Figure 2.6(e) -Geometry details of the beams tested by Gunasekara et al.......................30

Figure 2.6(f) - Experimental set-up of the beams tested by Gunasekara et al ...................30

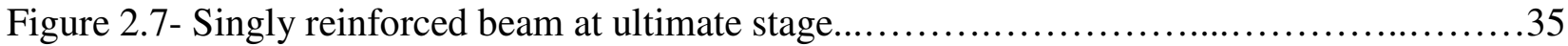

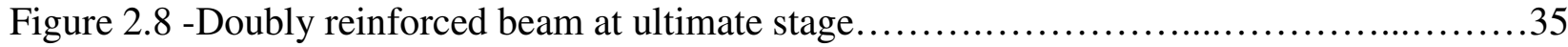

Figure 3.1- Shear beam cross-sections without shear reinforcement $\ldots \ldots \ldots \ldots \ldots \ldots \ldots \ldots \ldots \ldots . \ldots 40$

Figure 3.2- Shear beams without shear reinforcement showing four point loading..............40

Figure 3.3- Shear beams cross section with shear reinforcement $\ldots \ldots \ldots \ldots \ldots \ldots \ldots \ldots \ldots \ldots \ldots . \ldots \ldots$

Figure 3.4- Shear beams with shear reinforcement showing four point loading................41

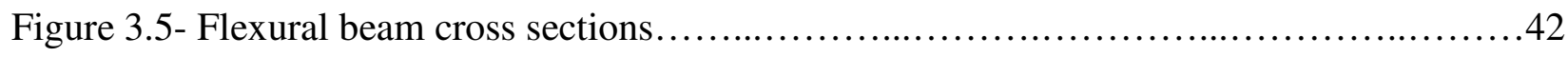

Figure 3.6 - Flexural beams showing four point loading................................43 


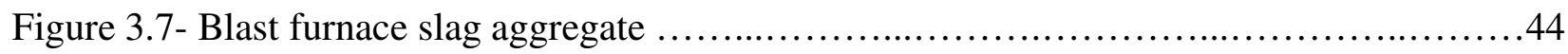

Figure 3.8- Slag aggregates -72 hours pre-soaking.................................... 45

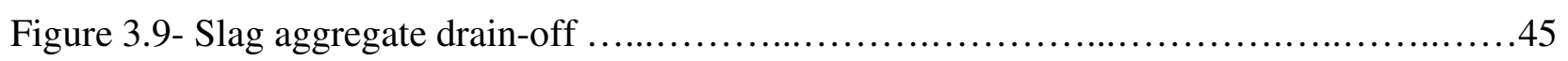

Figure 3.10 - Stress-strain response of reinforcement bars.............................. 46

Figure 3.11(a) - Mould or formwork showing reinforcement casing $\ldots \ldots \ldots \ldots \ldots \ldots \ldots \ldots \ldots \ldots . . .48$

Figure 3.11(b) -Beam casting showing concrete pouring and casted beams......................48

Figure 3.11 (c)- Beam formwork and casted beam...................................49

Figure 3.12- Moist curing of beams and control specimens...............................49

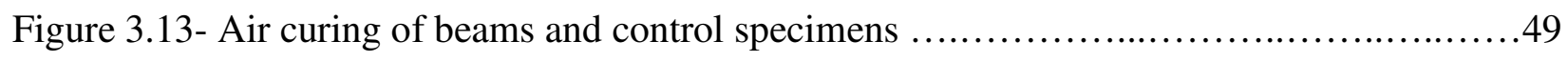

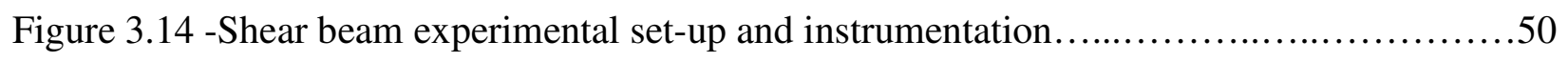

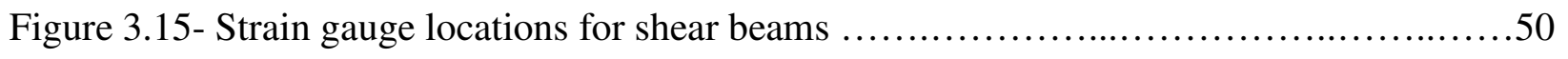

Figure 3.16 - Experimental set-up and instrumentation for flexural beams......................51

Figure $3.17-$ Strain gauge locations in flexural beams................................... 52

Figure 4.1 (a) - Load-deflection response for LWSCC shear beams without shear reinforcement54

Figure 4.1 (b) - Load-deflection response for SCC shear beams without shear reinforce.........57

Figure 4.2(a) - Failure modes tested shear LWSCC beams without shear reinforcement..........57

Figure 4.2(b) - Failure modes tested shear SCC beams without shear reinforcement.............58

Figure 4.3- Influence of shear span to effective depth ratio on concrete shear resistance.........59

Figure. 4.4- Normalized shear load-deflection responses for shear beams without shear

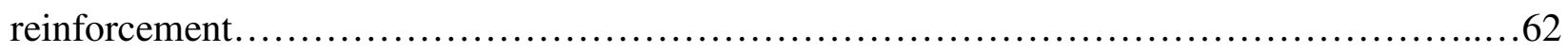

Figure 4.5-Load-mid span deflection responses for beams with shear reinforcement............63

Figure 4.6- Failure modes of tested shear beams with shear reinforcement...................65 
Figure 4.7(a) - Load-rebar strain curves for shear beams with shear reinforcement.............66

Figure 4.7(b) - Load-rebar strain curves for shear beams with shear reinforcement..............67

Figure 4.7(c) - Load-rebar strain curves for shear beams with shear reinforcement.............67

Figure 4.8- Influence of shear span to effective depth ratio on concrete shear resistance of beams

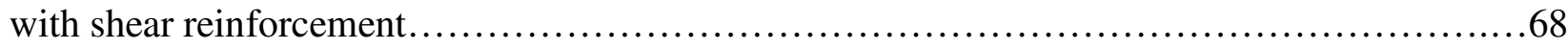

Figure 4.9-Load deflection curve for tested flexural beams............................. 70

Figure 4.10(a) - Crack pattern and failure mode of singly reinforced F1s flexural beam..........72

Figure 4.10(b) - Crack pattern and failure mode of singly reinforced F2s flexural beam..........73

Figure 4.10(c) - Crack pattern and failure mode of doubly reinforced F3s flexural beam..........73

Figure 4.11(a) - Load-strain responses for tested singly reinforced LWSCC flexural beam (F1s).74

Figure 4.11(b) - Load-strain responses for tested singly reinforced LWSCC flexural beam (F2s)75

Figure 4.11(c) -Load-strain responses for tested doubly reinforced LWSCC flexural beam (F3d)75

Figure 4.12-Experimental end rotations for tested flexural beams.........................77

Figure 5.1-Mean shear resistance factor for LWSCC/LWC beams with different types of aggregate

Figure.5.2- Mean normalized shear stress of LWSCC/LWC beams with different types of aggregates .88 


\section{LIST OF SYMBOLS AND ABBREVIATIONS}

SCC Self-consolidating concrete

LWSCC Lightweight self -consolidating concrete

LWC Lightweight concrete

LWA Lightweight aggregate

LWASCC Lightweight aggregate self -consolidating concrete

HPC High performance concrete

RC Reinforced concrete

VPC Volcanic pumice concrete

NC Normal concrete

FS $\quad$ Furnace slag

EC Expanded clay

ESH Expanded shale

SCM Supplementary cementing material

POCC Palm oil clinker concrete

PKSC Palm kernel shell concrete

PKS Palm kernel shell

CC Conventional concrete

OPS Oil palm shell

HRWRA High range water reducing admixtures

SF Silica fume

LVDT Linear variable displacement transducer

SRF Shear resistance factor

DF Ductility factor

DI Ductility index

Exp Experiment

P Phyllite

ITZ Interfacial transition zone

STF Failure after yielding of shear reinforcement

SCF Concrete crushing failure before yielding of shear reinforcement

a/d Shear span to depth ratio 


\begin{tabular}{|c|c|}
\hline $\mathrm{w} / \mathrm{b}$ & Water to binder ratio \\
\hline $\mathrm{V}$ & Shear force in a concrete section \\
\hline $\mathrm{V}_{\mathrm{c}}$ & Shear resistance of compression zone \\
\hline $\mathrm{V}_{\mathrm{a}}$ & Interlocking action of aggregates \\
\hline $\mathrm{V}_{\mathrm{d}}$ & Dowel action \\
\hline $\mathrm{V}_{\mathrm{n}}$ & Shear resistance of the beam \\
\hline $\mathrm{b}$ & Width of the cross-section \\
\hline $\mathrm{d}$ & Effective depth \\
\hline $\mathrm{V}_{\mathrm{u}}$ & Ultimate shear force \\
\hline $\mathrm{M}_{\mathrm{u}}$ & Ultimate moment capacity \\
\hline$f_{c}^{\prime}$ & Cylinder compressive strength of concrete \\
\hline$A_{v}$ & Area of shear reinforcement \\
\hline$f_{y t}$ & Characteristic yield strength of reinforcement \\
\hline $\mathrm{s}$ & Spacing of shear reinforcement \\
\hline$\varepsilon_{\mathrm{x}}$ & Longitudinal strain in the rebar \\
\hline $\mathrm{M}_{\mathrm{f}}$ & Factored moment \\
\hline $\mathrm{V}_{\mathrm{f}}$ & Factored shear force \\
\hline $\mathrm{E}_{\mathrm{s}}$ & Modulus of elasticity of non-prestressed reinforcement \\
\hline $\mathrm{S}_{\mathrm{Z}}$ & Crack spacing parameter \\
\hline $\mathrm{ag}$ & Maximum size of aggregate in the concrete \\
\hline$b_{v}$ & Width of the cross section, \\
\hline $\mathrm{f}_{\mathrm{cu}}$ & Cube compressive strength, \\
\hline $\mathrm{A}_{\mathrm{s}}$ & Tension reinforcement area \\
\hline $\mathrm{A}_{\mathrm{sv}}$ & Area of shear reinforcement \\
\hline$f_{y v}$ & Characteristic yield strength of shear reinforcement \\
\hline $\mathrm{S}_{\mathrm{v}}$ & Spacing of shear reinforcement \\
\hline h & Total beam height \\
\hline$\rho$ & Flexural reinforcement ratio \\
\hline $\mathrm{M}_{\mathrm{cr}}$ & Cracking moment \\
\hline
\end{tabular}




$\begin{array}{ll}\mathrm{I}_{\mathrm{g}} & \text { Second moment of inertia } \\ \mathrm{y}_{\mathrm{t}} & \text { Distance from the extreme tension fiber to the neutral axis } \\ \mathrm{M}_{\mathrm{u}} & \text { Moment capacity } \\ \varepsilon_{\mathrm{c}} & \text { Compressive strain } \\ \varepsilon_{\mathrm{cu}} & \text { Ultimate compressive strain of concrete } \\ \mathrm{f}_{\mathrm{y}}{ }^{\prime} & \text { Yield strength of compressive reinforcement } \\ \mathrm{d}^{\prime} & \text { Distance from extreme compression fibre to centroid of compression reinforcement } \\ \mathrm{c} & \text { Depth of neutral axis from the top fiber } \\ \mathrm{C}^{\prime} & \text { Total compression force } \\ \mathrm{C}_{\mathrm{s}} & \text { Force in the compression steel } \\ \mathrm{C}_{\mathrm{c}} & \text { Compression fore in concrete } \\ \mathrm{T} & \text { Tensile force in bottom steel. } \\ \mathrm{V}_{\mathrm{fl}} & \text { Shear at first flexural crack } \\ \mathrm{D}_{\mathrm{c}} & \text { Deflection at first diagonal crack } \\ \mathrm{D}_{\mathrm{u}} & \text { Deflection at peak shear load } \\ \mathrm{V}_{\mathrm{nu}} & \text { Normalized ultimate shear load } \\ \mathrm{V}_{\mathrm{nc}} & \text { Normalized inclined cracking shear load } \\ \mathrm{x} & \text { Distance } \\ \mathrm{D}_{\mathrm{y}} & \text { Deflection } \\ \chi & \text { Reduction factor } \\ \mathrm{V}_{\mathrm{ncz}} & \text { Normalized shear stress } \\ \phi & \text { Diameter } \\ & \end{array}$




\section{CHAPTER ONE}

\section{INTRODUCTION}

\subsection{General}

In the last few years, significant improvements have been achieved in the rheological and mechanical characteristics of concrete, particularly self-consolidating concrete (SCC). Since SCC was introduced, different types of SCCs have been developed to meet builders' requirements. One of the latest innovations in SCC technology is lightweight SCC (LWSCC) (Okamura and Ouchi 2003). For over 100 years, structural lightweight concrete (LWC) has been widely used as a building component (Hossain 2004a-b; Hossain 1997). The density of structural LWC typically ranges from 1400 to $2000 \mathrm{~kg} / \mathrm{m}^{3}$ (ACI 211.2 1981; Bamforth 1987). LWC may be produced by using either natural lightweight aggregates such as pumice, scoria, diatomite and palm oil clinker or with artificial lightweight aggregates such as expanded clay, shale, slate, perlite, vermiculite and blast-furnace slag (ACI 211.2 1981; Bamforth 1987; Topcu 1997; Bai et al. 2004; Hossain and Lachemi 2007a; Hossain et al. 2011; Hossain 2004a-b, 2009a-b; Curcio et al.1998).

Using lightweight aggregates in concrete has several advantages including lower thermal connectivity, maximized heat and sound insulation properties due to air voids. Furthermore, it is reported that reducing the dead load of a building by using lightweight concrete could lead to a considerable decrease in the cross-section of steel-reinforced columns, beams, plates and foundations, reducing the need for steel reinforcement and leading to increased cost savings (Hossain 2004a-b; Topcu 1997; Mor 1993).

Despite all advantages associated with the use of SCC in structures, its use is limited sometimes because of its high self-weight compared to other construction materials. In this regard, the development of new types of high performance concretes, such as Lightweight Self-Consolidating Concrete (LWSCC) responds to some of the urgent needs in the construction industry (Bentur et al. 2001; Kiliç et al. 2003; Aïtcin 1998). The development of SCC offers also limitless advantages in terms of reduction in the labor cost, better compaction and finish-ability in confined and restricted areas where compaction is difficult, and faster construction completion. 
LWSCC combines the favorable properties of LWC and SCC. These LWC advantages can be greatly utilized by incorporating lightweight aggregates in SCC mix design. Provided that the strength, mechanical and durability characteristics are comparable to normal weight SCC, LWSCC can be prompted as a new generation of high performance concrete in construction. Thus, it is believed that incorporating lightweight aggregate in self-consolidating concrete can enhance quality and produce high-strength lightweight concrete while preventing the segregation of lightweight aggregate (Hwang and Hung 2005; Shi 2005; Wang 2009).

Over the last decade numerous investigations on SCC and LWC (Hossain et al. 2009, 2011, Hossain 2015, 2004, 2006, 2012; Lotfy.et.al. 2014, 2015a-b; Hassan et al. 2008, 2010, 2012; Karahan et al. 2012, Mohammed et al. 2011, Hossain and Ahmed 2010, Hossain and Lachemi 2004, 2007a-b, 2009). Researches have also been conducted on the mix design, fresh and mechanical properties of LWSCC (Hwang et al. 2012; Bogas 2012; Topçu and Uygunoğlu 2010; Andiç-Çakır and Hızal 2012; Choi et al. 2006; Su and Miao 2003; Lo et al. 2007; Papanicolaou. and Kaffetzakis 2009; Topçu and Uygunoğlu 2007; Wu et al. 2009). LWSCC compressive strengths were within the $40-58 \mathrm{MPa}$ range, which are similar to the compressive capacity of a SCC with $2200 \mathrm{~kg} / \mathrm{m}^{3}$ density. LWSCC can attain a higher compressive strength than normal SCC at the same water/binder ratio with a $25 \%$ reduction in density. The elastic modulus of LWSCC and SCC increased with the increase of binder content. The elastic modulus of SCC were in values in the 29.5 - $31.5 \mathrm{GPa}$ range and within 22.7 - 27.2 GPa which corresponds to a reduction of $15 \%$ for LWSCC. Papanicolaou and Kaffetzakis (2009), presented the development of all-LWSCC mixtures using pumice focusing on the effect of coarse-to-fine aggregate ratio on the material's rheological and mechanical properties. In an extensive work Topcu and Uygunoglu (2007), studied the effect of different natural LWA types (pumice, volcanic tuff and diatomite) on the mechanical and physical properties of LWASCC. Wu et al. (2009) investigated workability of LWSCC and its mix proportion design using expanded shale aggregates at fixed fine and coarse aggregate contents using the volumetric method. Kim et al. (2010), studied the characteristics of SCC using two types of lightweight coarse aggregates with different densities, mostly semi-lightweight (2000 $\left.\mathrm{kg} / \mathrm{m}^{3}-2300 \mathrm{~kg} / \mathrm{m}^{3}\right)$.

Over the last few years, researches have been conducted at Ryerson University to develop LWSCC. Lachemi et al. (2009) developed different classes of LWSCC mixtures with two different 
types of lightweight aggregates (blast furnace slag and expanded shale aggregates). The influence of the type of concrete (LWSCC vs. normal weight SCC), and the type of lightweight aggregates on the steel-concrete bond strength and failure modes were also studied. Nine mixes were evaluated in terms of flowability, segregation resistance and filling capacity of fresh concrete. The mechanical properties of hardened LWSCC, such as compressive strength, splitting tensile strength, elastic modulus and density were assessed. Karahan et al. (2012), studied the influence of silica fume and metakaolin on mechanical and durability properties of LWSCC. The addition of silica fume or metakaolin was found to improve the strength and the freeze-thaw resistance of LWSCC mixtures.

More recently, Lotfy et al. (2014, 2015a-b) and Hossain (2015) developed LWSCC mixtures with furnace slag (FS), expanded clay (EC), expanded shale (ESH) aggregates and volcanic materials through comprehensive investigation on fresh state (slump flow diameter, V-funnel flow time, Jring flow diameter, J-ring height difference, L-box ratio, filling capacity, density and sieve segregation resistance), mechanical (compressive/flexural/split tensile/ bond strength) and durability (freeze-thaw, chloride permeability, drying shrinkage, water sorptivity, electrical resistivity, corrosion and acid resistance) properties. This specific studies have significantly contributed to the enhancement of LWSCC technology and proved very useful to the construction industry.

Researches have conducted on the flexure and shear resistance of LWC and normal weight SCC beams (Kim et al.; Lachemi et al. 2005; Mohammed et al. 2013). The test results confirmed that concrete shear strength is highly related to the amount of aggregate fracture at small crack widths when crack slip initiates. Aggregate type is a critical factor that influenced aggregate interlock. The volume of aggregate influences the contribution of aggregate interlock to the shear capacity for the SCC and normal concrete mixtures tested.

Lightweight concretes especially LWSCC have potential to be more widely used due to their benefits in structural elements/components. Detailed investigations on the LWSCC structural elements or components and development of design guidelines/specifications are very important. 


\subsection{Research significance}

Although researches have been conducted on the mix design and properties of LWSCC over the recent years, very limited number of studies were conducted on the structural performance of LWSCC (Ziehl et al. 2009). The proposed research on the shear and flexural performance of LWSCC beams is a timely initiative to make significant contributions to the LWSCC technology. The findings of this research will surely benefit engineers, builders and local authorities when designing and constructing civil infrastructures.

Lightweight concrete is being more and more widely used due to its better structural and durability performance. The lack of research studies specifically in Canada requires a detailed investigation of the structural performance of LWSCC mixtures in infrastructure to understand structural behavior and to compare existing design guidelines and specifications.

\subsection{Research objectives and scope}

The proposed research on the structural performance on LWSCC structural element made of blast furnace slag aggregate is an important step towards the design and construction of robust lightweight infrastructure systems for the 21 st century with enhanced workability, durability and economy. The objectives of this experimental and theoretical research are:

- Carry out experimental investigations on the shear behavior of LWSCC beams having variable parameters such as shear span to depth ratio (a/d), presence or absence of shear reinforcement, flexural reinforcement ratio and types of concrete LWSCC and normal weight SCC.

- Compare the shear behavior of LWSCC beams without shear reinforcement with their SCC counterparts based on concrete shear capacity, ultimate shear capacity, post-cracking shear transfer mechanism, post-cracking shear capacity, load-deflection response, ductility, energy absorbing capacity, strain development in concrete/and steel, failure modes, load/deflection at first flexure/inclined crack, number of cracks and influence of a/d.

- Analyze the shear behavior of LWSCC beams with shear reinforcement based on the influence of $\mathrm{a} / \mathrm{d}$ and reinforcement ratio on shear capacity, load-deflection response, strain development in concrete/and steel, failure modes, load/deflection at first flexure/inclined crack and number of cracks. 
- Carry out experimental tests on the flexure behavior of singly and doubly reinforced LWSCC beams having variable flexural reinforcement ratio under four point loading. Analyze the behavior of LWSCC beams based on load-deflection response, ductility, strain development in concrete/and steel, failure modes, load/deflection at first flexure/inclined crack and number of cracks.

- Compare the shear capacities of experimental LWSCC beams (with and without shear reinforcement) with those obtained from American, Canadian and British Codes. Analyze the shear strength prediction capability of these Codes.

- Compare the moment capacities of experimental singly and doubly reinforced LWSCC beams with those obtained from Canadian Code and analyze prediction capability of the Code.

- Compare the shear resistance of LWC concrete beams (with and without shear reinforcement) with various lightweight aggregates from previous research studies with special reference to LWSCC beams (made of slag aggregate) tested in this study. Assess the performance of various Codes in predicting the shear capacity of LWC beams (from previous research studies) and LWSCC beams.

- Make recommendations on the shear and flexure performance of LWSCC beams and suggests design guidelines based on existing Codes.

- Make recommendations for future research studies.

\subsection{Thesis outline}

Chapter One introduces LWSCC and a summary of advancement in LWSCC technology. It also describes the significance, objectives and scope of this research with a thesis outline.

Chapter Two presents the comprehensive literature review on lightweight aggregate, lightweight concrete, self-consolidating concrete, lightweight self-consolidating concrete, shear and flexural behavior of reinforced concrete beams and Code based analysis of shear and flexural capacities. Research conducted on the above topics are described and analyzed. 
Chapter 3 describes the experimental program including material properties, geometric dimensioning of flexural and shear beams, fabrication/casting/curing of beam specimens, test setup, instrumentation and testing procedures.

Chapter 4 presents the results of the experimental investigations on shear and flexural behavior of lightweight self-consolidating beams in addition to self-consolidating beams. The performance is described based on load-deflection response, strain development in rebar/concrete, moment end rotation behavior, energy absorption, ductility index, and crack formation/propagation and failure modes. Post -cracking shear transfer mechanism comparison between LWSCC and SCC beams is also described in this Chapter.

Chapter 5 compares the experimental shear and flexure capacities with those obtained from various Code based equations. Experimental shear resistances of LWSCC beams (made of slag aggregate) and other LWC beams (made of six different aggregate types from previous research studies) without shear reinforcement experimental shear capacity was compared with those predicted based on ACI, CSA and BS8110 Codes. Shear resistance capacity and shear transfer mechanism of beams with different types of lightweight aggregates are also analyzed. Moment capacities of LWSCC beams obtained from experiments and CSA code are also compared.

Chapter 6 summarizes the findings of the research and provides recommendation for future research study. 


\section{CHAPTER TWO}

\section{LITERATURE REVIEW}

\subsection{Introduction}

Lightweight self-consolidating concrete (LWSCC) is a relatively new development in the field of high performance concrete (HPC). LWSCC combines all of the best properties of the lightweight concrete (LWC) with the best properties of the SCC. This Chapter presents properties of lightweight aggregates, lightweight concrete, LWC and SCC as well as analysis and Code based procedures for flexure and shear strength of reinforced concrete (RC) beams based on comprehensive literature review on previous research studies.

\subsection{Lightweight aggregate}

Lightweight aggregates have a lower particle density due to cellular pore system as shown in Figure 2.1. This pore system is typically formed as a result of thermal processes. This process may be natural, such a volcanic action or artificially applied with the resulting aggregates classified as such, being of a volcanic origin. Natural lightweight aggregates like pumice and scoria are available in volcanic areas over the world. The cellular pore structure is formed when gas bubbles in the molten lava become trapped due to the rapid cooling of ejected lava (Hossain 2004a-b, 2015).

Two main types of thermal treatment are mainly used to develop synthetic lightweight aggregate such as agglomeration and expansion techniques. Agglomeration happens when some of the materials melt at temperatures above $1100^{\circ} \mathrm{C}$ and the particles that make up finished aggregate are bonded together by fusion. Alternatively, a cellular pore structure can also be developed by heating certain raw materials to incipient fusion. At this temperature, gasses are evolving within the pyroclastic mass, causing expansion, which bloats the aggregate whose internal structure is retained upon cooling (Lotfy 2012; CIP 36 2003). 

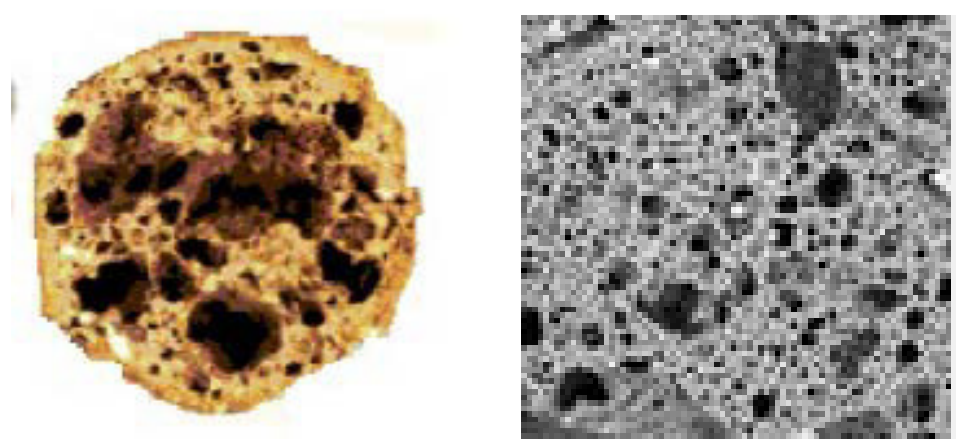

Figure 2.1- Internal pore structure of the lightweight aggregate (Lotfy 2012)

There are different types of lightweight aggregates available such as blast furnace slag, expanded shale, expanded clay etc (Lotfy 2012, Lotfy et al. 2014, and 2015a-b). Lightweight aggregates must comply with the requirement of ASTM C330 (2014). Due to the cellular nature of the lightweight aggregate particle absorption typically is in the range of 5-20\% of the weight of dry aggregate (CIP 36, 2003). Lightweight aggregate generally require a wetting prior to use to achieve a high degree of saturation (Lotfy 2012; Lotfy et al. 2014, 2015a-b; Hossain 2004a-b). Table 2.1 shows the allowable lightweight aggregate densities according to ASTM C330 specifications (2014).

Table 2.1- Allowable lightweight aggregate densities

\begin{tabular}{|l|c|}
\hline $\begin{array}{l}\text { Aggregate Size and Group } \\
\text { as per ASTM C330 (2014) }\end{array}$ & $\begin{array}{c}\text { Maximum Density } \\
\left(\mathrm{kg} / \mathrm{m}^{3}\right)\end{array}$ \\
\hline Fine aggregate & 1120 \\
\hline Coarse aggregate & 880 \\
\hline Combined fine and coarse aggregate & 1040 \\
\hline
\end{tabular}

\subsubsection{Slag lightweight aggregate}

Slag lightweight aggregates are generally manufactured from screened air-cooled blast furnace slag. Lafarge Canada produce slag lightweight aggregates having nominal sizes of $4.75 \mathrm{~mm}$ and $10 \mathrm{~mm}$ to be used as fine and coarse aggregates, respectively. According to Lafarge Canada Inc., the porosity of air-cooled blast furnace slag provides excellent mechanical bond with Portland 
cement paste resulting in up to $10 \%$ higher compressive strength with about $30 \%$ lighter concrete than normal weight concrete (Lotfy 2012; Lotfy et al. 2014, 2015a-b ).

\subsection{Lightweight concrete}

Structural lightweight aggregate concrete has been used in both reinforced and pre-stressed concretes. Structural lightweight concrete has a density less than $1840 \mathrm{kgm}^{3}$. For structural application concrete compressive strength should be greater than 17.2 $\mathrm{MPa}$ at 28 days according to ACI committee 318 requirements (ACI 318R 2005). The concrete mixture is produced with lightweight coarse aggregate. In some time portion of the entire fine aggregate may be a lightweight product (ACI 318R-05 2005).

The main use of the structural lightweight concrete is to reduce the dead load of the concrete structure. Lightweight aggregate concrete results in an overall saving of $10-20 \%$ of the total cost of the equivalent normal weight concrete. It allows for structural designer to reduce the size of the columns, footings and other load bearing elements. Increasing the space availability by a reduction in the sizes of structural elements. The high cost of the structural lightweight concrete is offset by size reduction of structural elements, less reinforcing steel and reduced volume of concrete resulting in less overall cost (Lotfy 2012; Ahmed 2011; Hossain 2004a-b; Gerritse 1980).

Structural lightweight concrete provides a higher fire rated concrete structures. The porosity of the lightweight aggregate provides a source of water for internal curing of the concrete that provide continued development of concrete strength and durability (Lotfy 2012; CIP-36 2003; Hossain and Lachemi 2007a; Hossain and Anwar 2015). Lightweight concrete considers as a high thermal insulation, and provide better heat and sound insulation than normal weight concrete (CIP 362003 ; Hossain and Anwar 2015; Hossain 2006). Structural lightweight concrete is well suitable for high earthquake region sincere reduced internal mass result in a lesser internal force.

The air content of the lightweight concrete is to be closely monitored and controlled to ensure that the density requirements are being achieved. Virtually all lightweight concrete is air entrained. Finishing the lightweight concrete require proper attention to detail. Excessive amount of water will cause the lightweight aggregate to segregate from the mortar. Due to the inherent higher total moisture content, it generally takes a longer time than normal weight concrete to dry to levels that 
might considered adequate for the application of floor covering material (CIP 36 2003; Hossain and Ahmed 2010).

Lightweight aggregate batched at a high degree of saturation may be substituted for normal weight aggregate to provide internal curing in concrete containing a high volume of cementitious materials. The benefits of internal curing are increasingly important when pozzolans such as silica fume, fly ash, volcanic ash, pumice, scoria metakaolin, calcined shales, clays and slates, as well as the fines of lightweight aggregate (LWA) are included in the mixture (Hossain 2009a-b; Hossain 2012, Hossain et al. 2011, 2015). It is well known that the pozzolanic reaction of finely divided alumina-silicates with calcium hydroxide liberated as cement hydrates is contingent upon the availability of moisture. Additionally, internal curing provided by absorbed water minimizes the plastic shrinkage due to rapid drying of concrete exposed to unfavorable drying conditions (Holm1980; Hossain 2009a-b).

\subsubsection{Properties of lightweight concrete}

The properties of lightweight aggregates have some bearing on the properties of the fresh and hardened concrete (Wesche 1968; Hossain 2004a-b; Hossain 2012, Hossain et al. 2011, 2015). However it was recognized that the properties of lightweight concrete are greatly influenced by the quality of the cementitious matrix, in common with those of normal weight concrete. Specific properties of aggregates that may affect the properties of the concrete are: particle shape and surface texture, relative density, bulk density, strength of lightweight aggregates, strength ceiling, total porosity, grading, moisture content and absorption, and modulus of elasticity of lightweight aggregate particles (ACI 213R-03 2003; IStructE 1987; Hossain 2012, 2015).

\subsubsection{Compressive strength of lightweight concrete}

Structural lightweight concrete mixture can be designed to achieve similar strength as normal weight concrete. There is no reliable correlation between aggregate strength and concrete strength indicating that strength is more dependent on the cementitious matrix (ACI 213R-03, 2003).

The strength ceiling is influenced predominantly by the coarse aggregate and may be quite high for certain lightweight aggregates, approaching that of some normal weight aggregates. This ceiling can be increased appreciably by reducing the maximum size of the coarse aggregate for 
most lightweight aggregates, especially the weaker and more friable ones. This reduction of particle size reduces the stress concentration around the aggregate and also allows for a more homogenous concrete matrix to be produced (ACI 213R-03 2003; Gerritse1981; Hossain 2012, Hossain 2006).

It is important to understand the transmission of force in the concrete. As indicated in Table 2.2 lightweight aggregate is softer than surrounding mortar therefore failure occurs right through the aggregate. However, the stiffer the aggregate the less is the stress in the mortar. Behavior of lightweight and normal weight concrete under compressive force is shown in Figures 2.2 and 2.3. Lightweight concrete has more brittle in nature than normal weight concrete (Gerritse1981).

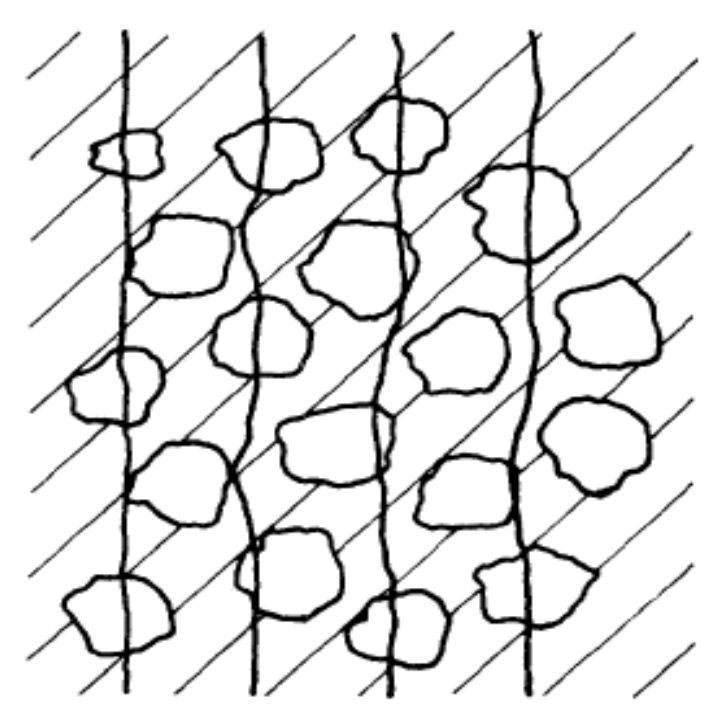

Figure 2.2-Lightweight concrete (Gerritse 1981)

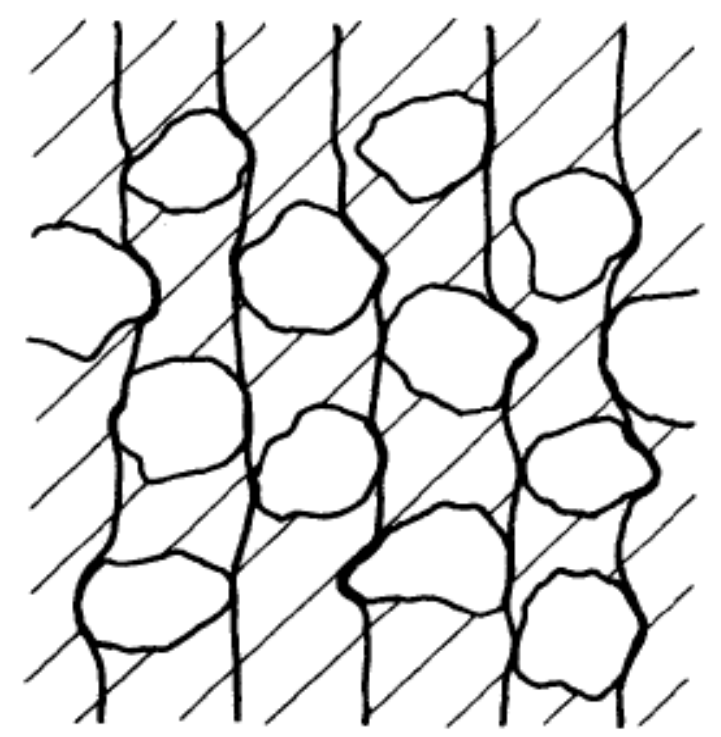

Figure 2.3-Normal weight concrete (Gerritse1981)

Table 2.2-Inductive values for compressive strength and modulus of elasticity (Gerritse1981)

\begin{tabular}{|l|l|l|}
\hline & $\begin{array}{l}\text { Compressive strength } \\
(\mathrm{MPa})\end{array}$ & $\begin{array}{l}\text { Modulus of elasticity } \\
\left(\mathrm{kN} / \mathrm{mm}^{2}\right)\end{array}$ \\
\hline Lightweight aggregate & $5-30$ & $5-30$ \\
\hline Cement mortar & $20-60$ & $20-30$ \\
\hline Normal aggregate & $60-100$ & $60-100$ \\
\hline
\end{tabular}




\subsubsection{Modulus of elasticity}

The modulus of elasticity depends on the relative amounts of paste and aggregate and the modulus of each constituent (LaRue1946; Pauw1960). Generally, the modulus of elasticity of lightweight concrete is considered to vary between $50 \%$ and $75 \%$ that of normal weight sand and gravel concrete of the same strength (Hossain 2004a-b; Hossain 2006; Hossain, 2012; Hossain 2015. Variations in lightweight aggregate grading usually have small effect on modulus of elasticity provided the relative volumes of cement paste and aggregate remain fairly constant (Hossain 2004a-b).

The stress-strain curve of lightweight concrete is affected by the lower modulus of elasticity and the relative strength of the aggregate and cement paste. If the aggregate is the weaker of the two, failure tends to occur suddenly in the aggregate, and the descending branch of the stress strain curve is very short or non- existent, as shown by upper solid line in Figure 2.4. The fracture surface of those lightweight concretes tends to be smoother than for normal weight concrete. On the other hand, if the aggregate does not fail the stress, strain curve will have a well-defined descending branch as shown by the curved lower solid line in Figure 2.4. As a result of lower modulus of elasticity of lightweight concrete, the strain at which the maximum compressive stress is reached is higher than normal weight concrete (Wight and Macgregor 1997; Hossain 1997; Hossain 2004ab).

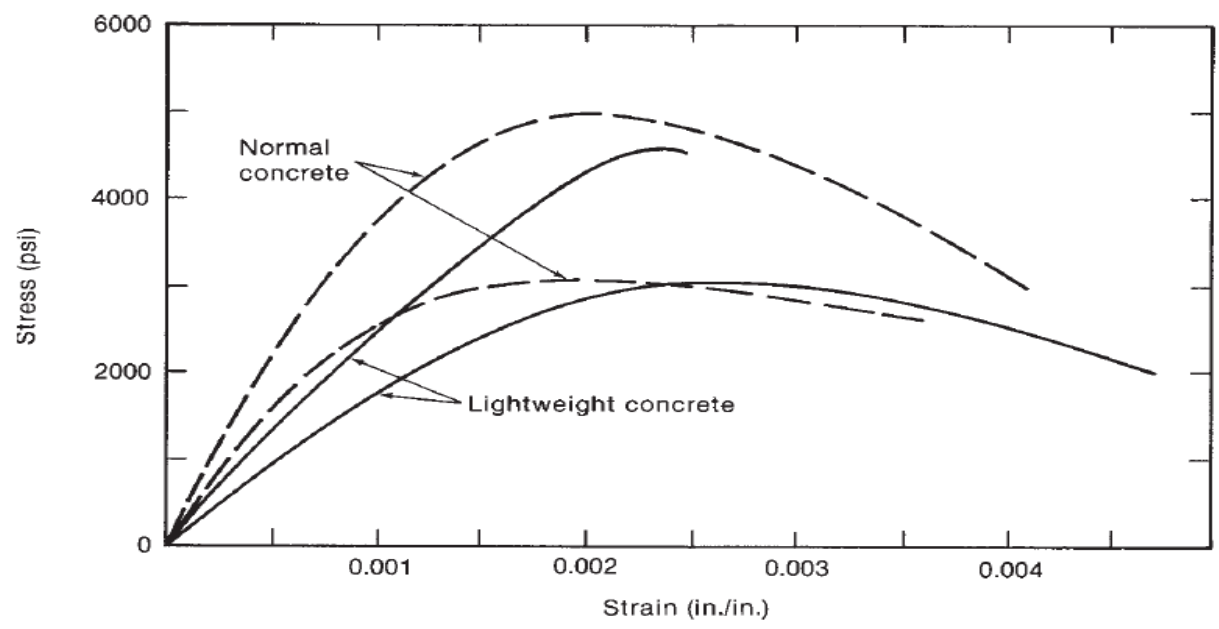

Figure 2.4 -Stress-strain curves for lightweight and normal weight concrete (Wight \& Macgregor 1997) 


\subsubsection{Tensile strength of lightweight concrete}

The tensile strength of concrete is only a fraction of its compressive strength and is dependent on the tensile strength of the coarse aggregate and mortar phases, and the degree to which the two phases are securely bonded. Traditionally, this value has been defined as a function of compressive strength. This should only be taken as a first approximation since it does not reflect the aggregate particle strength, surface characteristics of the aggregates or the concrete's moisture content and distribution (ACI 213R-03 2003). For a given lightweight aggregate, the tensile strength may also not increase in a manner comparable to the increase in compressive strength. Increases in tensile strength tend to occur at a lower rate relative to increases in compressive strength. This becomes more pronounced as compressive strength increases beyond $35 \mathrm{MPa}$ with tensile strengths being over-predicted. Replacing lightweight, fine aggregate with normal weight fine aggregate will also normally increase tensile strength (Juan 2011; Hossain 2004a-b; Hossain 1997).

Concrete tensile strengths can be measured through direct tensile tests or indirectly via splitting tensile tests or flexural tensile tests. Due to the weak and brittle nature of concrete under tension, indirect tensile tests are easier to perform and tensile splitting strengths and/or modulus of rupture values from flexural tensile tests are preferred. However, these values are influenced by moisture content and specimen storage conditions prior to the test as well as the different stress distributions within the specimen as the test is carried out (FIP 1983).

Splitting tensile strength of lightweight aggregate concrete has a larger scatter than that of normal weight concrete due to the influence of the aggregate and the influence of curing method The interfacial transition zone between the mortar and the aggregate also improved properties compared to normal weight aggregate (Neville1999). As the cement paste hydrates, the matrix is available to form inside the pores of the lightweight aggregate thus gripping the aggregate and producing good bond between the phases (Hossain 2004a-b).

\subsubsection{Examples of some research studies illustrating properties of lightweight concrete}

Hossain (2008) studied the characteristics of plain and deformed reinforcing bars in lightweight volcanic pumice concrete (VPC) and normal concrete (NC). VPC and NC are manufactured by incorporating crushed lightweight pumice and gravel aggregates, respectively. Bond tests are conducted on 112 pullout specimens to study the influence of type of concrete (NC or VPC), type 
of reinforcing bars (plain or deformed), length of embedment and age/strength of concrete on bond strength and failure modes. The load-slip responses, failure modes and bond strengths of VPC and $\mathrm{NC}$ are compared at various ages ranging from 1 to 28 days. The performance of Code based and other existing bond equations in predicting bond strength of plain and deformed bars is analyzed by taking into consideration of the influence of failure modes. Concrete types and embedded length. The bond strength of deformed bars in lightweight VPC was lower compared to those of NC. Normalized bond strength of NC specimens was found to be about 1.12 (ranges between 1.08 and 1.14) times higher compared to VPC. This can be considered as normal for a lightweight concrete. The existing CSA A 23.3-94 (2004) based bond equation reasonably predicts the bond strength of deformed bars for specimens showing pullout or splitting failure in both VPC and NC. However, CSA based equation over predicts bond strength of deformed bars where failures are characterized by yielding of steel

Hossain and Lachemi (2007) investigated the development of lightweight volcanic pumice concrete (VPC) using pumice as aggregate illustrating 21 concrete mixtures. Fresh, mechanical, and durability properties of VPC mixtures such as slump, air content, compressive strength, tensile strength, density, modulus of elasticity, drying shrinkage, and water permeability are described. The fire resistance of VPC subjected to elevated temperatures (maximum up to $800{ }^{\circ} \mathrm{C}$ ) for different durations (maximum up to 2 hours) is also analyzed. The performance is judged based on residual strength and physical changes of VPC compared with normal density concrete (NC). The investigation suggests the production of VPC for structural applications having satisfactory strength and durability characteristics. The strength of both VPC and NC is found to decrease with the increase of duration of fire and temperature. VPC shows better residual strength and strength retaining capacity compared with $\mathrm{NC}$ after exposure to elevated temperatures for different durations.

\subsection{Self-consolidating concrete}

Proper concrete compaction is very important to the structural integrity and overall quality in hardened concrete. Therefore, normal concrete requires internal and external vibration to properly compact the concrete and ensure that it completely fills all voids in the formwork eliminating unwanted entrapped air. Self-consolidating concrete (SCC) eliminates the need for vibration since it is able to consolidate under its own weight due to its increased workability (Hossain 2013). SCC 
was first introduced in Japan in the late 1980s by researchers at the University of Tokyo. The need for this new type of concrete was brought about by problems associated with poor compaction due to a decrease in skilled laborers in Japan (Okamura and Ouchi 2003). Figure 2.5 shows the casting of SCC at site with few labor utilization (EFNARC 2005).

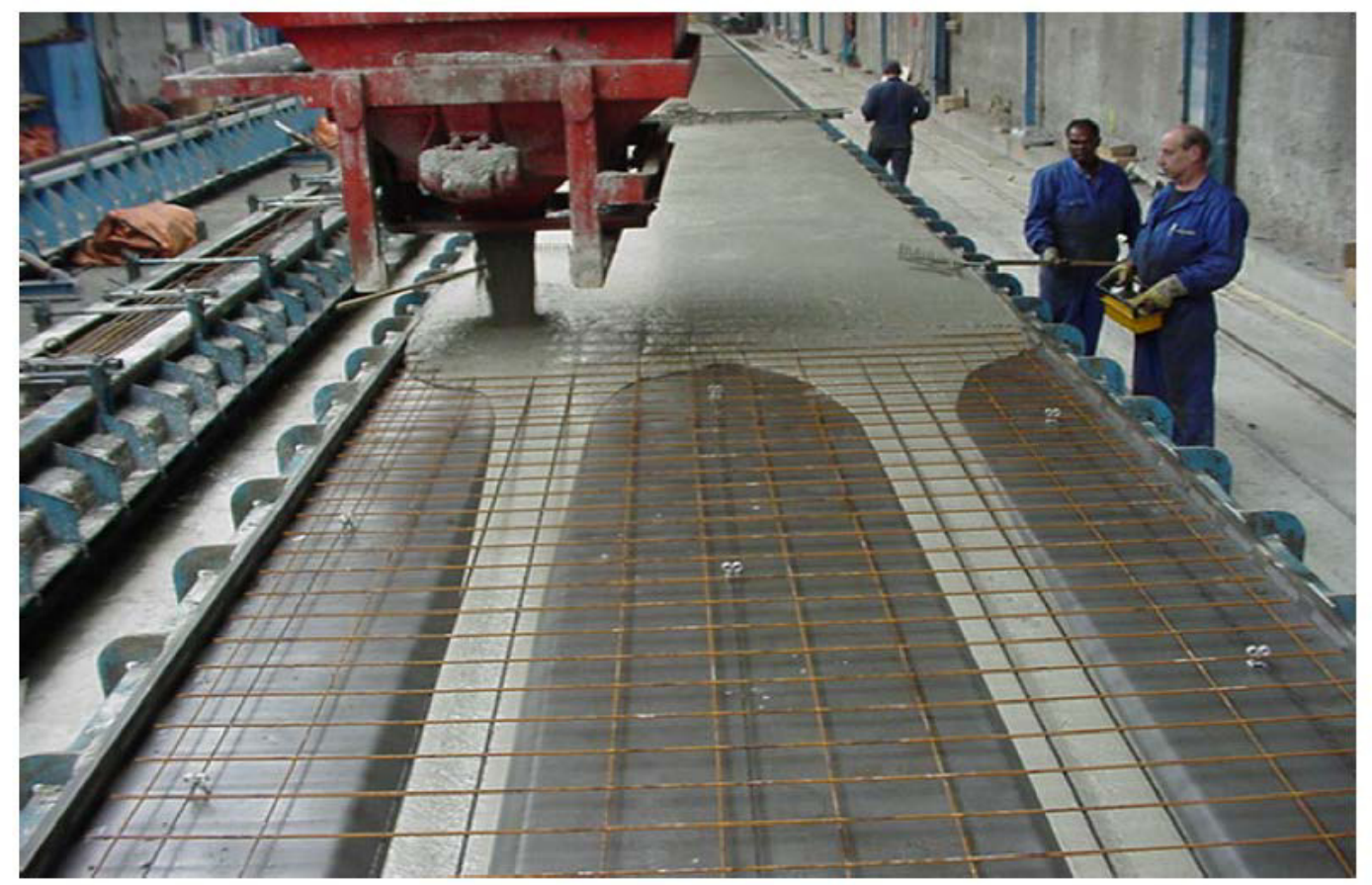

Figure 2.5 -Self consolidating concrete construction (EFNARC 2005)

Potentially, SCC could reduce the number of workers required to place the concrete while adding other benefits and improving material properties. By using chemical/mineral admixtures, primarily super-plasticizers, and by decreasing the coarse-to-fine aggregate ratios the concrete is able to flow much better while preventing segregation. Also, since the water demand is reduced due to the use of super-plasticizers, the strength and possibly the durability can be increased (EFNARC 2005; Yahia et al. 1999; Lachemi et al. 2003a-b; Hossain and Lachemi 2009; Hossain et al. 2010; Hassan et al. 2012).

Advantages of SCC are including: the number of workers required and the noise produced by mechanical vibration is reduced significantly; the surface finish of the concrete can be more smooth than that of conventional concrete; formwork damage from mechanical vibration is reduced, increasing the life of the forms; reinforcing bar configurations are not damaged; 
improved bond of concrete to pre-stressed strands could reduce strand end-slip and the top bar effect; and SCC is able to fill complicated shapes and congested reinforcement areas better than vibrated concrete ( Hwang and Hung 2005, Shi 2005, Yahia et al. 1999; Hossain and Lachemi 2007b, 2009).

\subsection{Lightweight self-consolidating concrete}

The lightweight self-compacting concrete (LWSCC) is a relatively new breakthrough (development) in the field of high performance concrete. It combines all of the best properties of the lightweight concrete with the best properties of the self-compacting concrete. The LWSCC is extremely convenient for the construction of buildings that do not require high compressive strengths of concrete, but need low weight (Hossain 2015). For example, these are prefabricated elements that need transportation and structures and elements where the concrete surface should be visible. It is especially suitable for restoration work in old structures (e.g., Replacement of wooden floors) that should not be additionally loaded (Topçu 2010; Choi et al. 2006)

The first application of LWSCC occurred in Japan in 1922 with the construction of a cable-stayed bridge's main girder. In the past few years, LWSCC has been used in a number of structural applications, such as precast stadium benches (Hubertova and Hela 2007) and pre-stressed beams with spans reaching up to $20 \mathrm{~m}$ (Dymond 2007).

When necessary, improvement of the lightweight concrete strength can be achieved by a combination of the coarse lightweight and the fine stone aggregates. The greatest strength is achieved by the concrete with aggregates of the expanded clay or slag and with the aggregate of the natural crushed stone. The advantage of the expanded clay aggregates is also in the grain shape (spherical shape), which improves the rheological properties of the mixtures and can also affect the increase in the compressive strength (Maghsoudi et al. 2011).

LWSCC also has a further impact on the construction cost by reducing the total dead load of the structural members and requiring less maintenance than a similar steel structure. This may represent considerable savings in large scale construction that could not otherwise be attained with the use of standard self-consolidating concrete (SCC). LWSCC can achieve better strength and durability while offering excellent workability (Hwang and Hung 2005, Shi and Wu 2005). 


\subsubsection{Examples of some studies on lightweight self-consolidating concrete with details}

Lofty (2012) and Lotfy et al. (2014, 2015a-b) carried out a response surface method based experimental study to model the influence of key parameters on properties of LWSCC mixtures developed with various types of lightweight aggregates namely, furnace slag (FS), expanded clay (EC), and expanded shale (ESH). Three key parameters were selected to derive mathematical models for evaluating fresh and hardened properties. Water/binder ratio of 0.30 to 0.40 , high range water reducing agent (HRWRA) of 0.3 to $1.2 \%$ (by total content of binder) and total binder content of 410 to $550 \mathrm{~kg} / \mathrm{m}^{3}$ were used for the design of LWSCC mixtures. Slump flow diameter, Vfunnel flow time, J-ring flow diameter, J-ring height difference, L-box ratio, filling capacity, bleeding, fresh air content, initial and final set times, sieve segregation, fresh/28-day air/oven dry unit weights and 7- and 28-day compressive strengths were evaluated. Utilizing the developed model, three optimum LWSCC mixes with high desirability were formulated and tested for mechanical, mass transport and durability characteristics. The optimized industrial LWSCC mixtures were produced in lab/industrial set-up with furnace slag, expanded clay, and expanded shale aggregates. The mixtures were evaluated by conducting compressive /flexural/split tensile strength, bond strength (pre/post corrosion), drying shrinkage, sorptivity, absorption , porosity, rapid chloride-ion permeability, hardened air void (\%), spacing factor, corrosion resistance, resistance to elevated temperature, salt scaling, freeze-thaw resistance, and sulphuric acid resistance tests. Following conclusion were made from this specific LWSCC study. Lightweight aggregates did not contribute significantly to the compressive strength of the LWSCC mixtures rather the paste quality, and bond between the paste and aggregate particles in the interfacial transition zone (ITZ) lead to the high compressive strength. Good correlation was not found between the 28-day compressive strength and dry unit weight of LWSCC. However, the data suggested that optimized LWSCCs with relatively low dry density $\left(1706 \mathrm{~kg} / \mathrm{m}^{3}\right)$ but with high aggregate packing density (less voids) and low coarse-to-total aggregates volume ratio, as is the case of expanded shale high strength-LWSCCs, will produce higher compressive strength (46.7 $\mathrm{MPa}$ ) than concrete mixtures with high dry density $1847 \mathrm{~kg} / \mathrm{m}^{3}$ ) such as FS-LWSCCs where the 28-day compressive strength was 42.6 MPa. Further, the water to binder ratio (w/b) and the segregation resistance of LWSCCs are main factors in establishing such relationship. LWSCC mixtures with high dry density, high w/b (0.4) and low segregation resistance $(>15)$ are susceptible to yield lower compressive strength even when compared to mixtures with lower dry densities. 
The highest flexural strength values were recorded for the optimized slag-LWSCCs and the lowest were recorded with expanded clay-LWSCCs. The quality, size and volume of coarse aggregate affected the flexural strength of LWSCC mixtures. Mixes made with slag aggregate showed high values because more coarse aggregate volume at (28.2\%) was used in these mixes compared to $24.5 \%$ in LWSCC mixes with expanded shale. The relative low quality of the coarse expanded clay aggregates resulted in low flexural strength values. Relatively strong correlation is established between the flexural/split tensile strength and the compressive strength of the optimized LWSCC mixtures. The flexural and split tensile strength of LWSCC mixtures were 8.5 to $10.5 \%$ and 5.5 to $6.6 \%$ of the 28-day compressive strength, respectively. On the other hand, the bond strength of LWSCC mixtures was 7.5 to $15 \%$ of the 28 -day compressive strength.

Hossain (2015) investigated the fresh, mechanical and durability properties of LWSCC mixtures produced from pumice aggregates and supplementary cementing materials derived from various combinations of volcanic ash, pumice powder and metakaolin. The fresh state properties are determined from slump flow, V-funnel flow time, bleeding, air content, and setting time and segregation tests. The mechanical properties and durability characteristics such as compressive strength, rapid chloride permeability, ultrasonic pulse velocity, and freeze-thaw/frost resistance, resistance to salt scaling and drying shrinkage are evaluated. The use of volcanic ash, pumice and metakaolin as SCMs has improved resistance to chloride penetration, freeze-thaw and salt scaling. Developed LWSCC mixtures have exhibited satisfactory durability and also satisfied the criteria for structural concrete.

\subsection{Analysis of reinforced concrete member in shear}

Extensive researches have been carried out on the shear behavior of reinforced concrete elements.

Despite this, there remain considerable areas of uncertainty and disagreement with respect to a rational theory to unify the approach towards shear design. Reinforced concrete shear is approached with classification into either members without transverse reinforcement or members where transverse reinforcement (Wight and Macgregor 1997; Gastebled and May 2001).

\subsubsection{Basic shear transfer mechanism in beams without shear reinforcement}

For slender beams, the shear force in a cracked section (V) is mainly resisted by the shear resistance of compression zone $\left(\mathrm{V}_{\mathrm{c}}\right)$, interlocking action of aggregates $\left(\mathrm{V}_{\mathrm{a}}\right)$, and dowel action $\left(\mathrm{V}_{\mathrm{d}}\right)$, as shown 
in Figure 2.6. For rectangular beams, after an incline crack has formed, the proportion of the shear force transferred by the various mechanisms is as follows, 20 to 40 percent by the un-cracked concrete of compression zone; 33 to 50 percent by interlocking action of aggregates; and 15 to 25 percent by dowel action $\left(\mathrm{V}_{\mathrm{d}}\right)$. Meanwhile, in a relatively short beam, the load is transferred directly from the loading points to the supports owing to arch action (Taylor 1970).

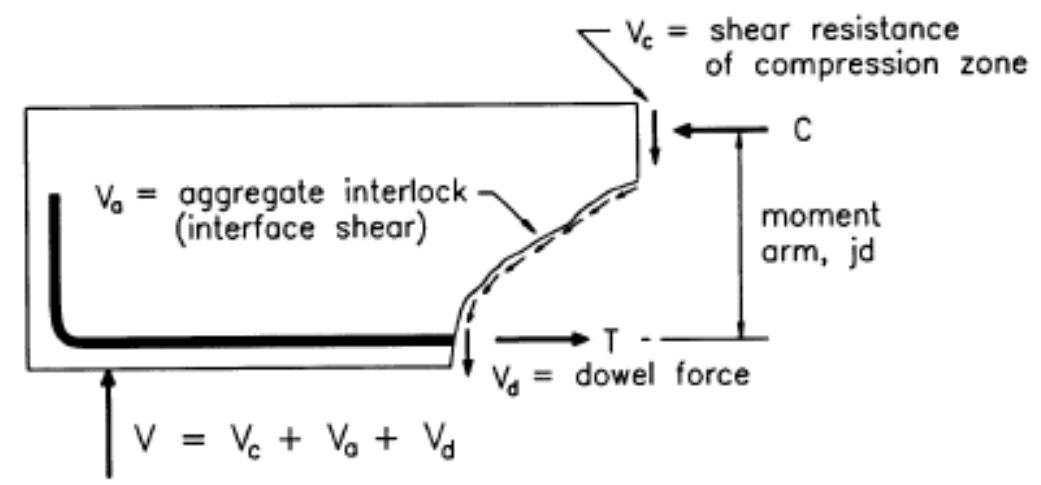

Figure 2.6 -Shear transfer mechanism of slender beams (Taylor 1970)

Interlocking action of aggregates: Previous experimental studies by Taylor (1970), has shown that a large portion of the total sheer force of the beam without web re-enforcement is carried across the cracks by aggregate interlocking. Among many variables, the width of the crack and the concrete strength are likely to be the most important factors. It is naturally expected that the interlocking force will be increased when the strength of concrete is high.

Dowel action: When shear displacement occurs along the cracks, a certain amount of shear force is transferred by means of the dowel action of the longitudinal bars. Although there is some contribution in dowel action by the number and arrangement of longitudinal bars, spacing of flexural cracks, and the amount of concrete cover, etc. The main factors influencing this action are the flexural rigidity of longitudinal bars and the strength of the surrounding concrete (Taylor 1970).

Arch action: In a relatively short beams, applied loads are transferred di-erectly to the supports by arch action. The main factors influencing this action are the span-to-height ratio of the analogous arch and the strength of the compression strut. The span-to-height ratio of the analogous arch is approximately equal to the shear span-to-depth ratio. The strength of the compression strut 
is closely related to the compressive strength of concrete and the area of tension reinforcement (Taylor 1970).

\subsubsection{Shear transfer mechanism beams with shear reinforcement}

Inclined crack causes the shear strength of beams to drop below the flexural capacity. The purpose of the shear reinforcement is to ensure the full flexural capacity can be developed. Prior to incline cracking, the strain in the stirrups is equal to the corresponding strain of the concrete beam, because concrete cracks at very small strain the stress in the stirrups prior to inclined cracking will not exceed 3 to $6 \mathrm{ksi}$. Thus, stirrups do not prevent inclined cracks from forming, they come into play only after the cracks have formed (Wight and Macgregor1997).

\subsubsection{Code based shear prediction}

An accepted rational physical method of shear resistance does not yet exist due to the complex nature of the shear failure mechanism in reinforced concrete beams therefore most design codes use empirical equations to calculate the shear capacity of the reinforced concrete beams. The formation of diagonal tension cracks is taken by design codes to be the ultimate shear capacity of the beams without shear reinforcement. For the beam with shear reinforcement, the shear resistance of the beam $\left(\mathrm{V}_{\mathrm{n}}\right)$ was calculated by adding the concrete shear resistance $\left(\mathrm{V}_{\mathrm{c}}\right)$ with transverse shear reinforcement contributions $\left(\mathrm{V}_{\mathrm{s}}\right)$. Previous studies demonstrated that beams with shear reinforcement have same diagonal cracking strength as beams without shear reinforcement (ACI 318-05 2005; CSA A23.3-04 2004; BS8110 1997).

$\mathrm{V}_{\mathrm{n}}=\mathrm{V}_{\mathrm{c}}+\mathrm{V}_{\mathrm{s}}$

ACI 318-05 (2005) presents the following basic equations (in SI units) for the shear resistance of concrete and shear reinforcement:

$\mathrm{V}_{\mathrm{c}}=\left(\sqrt{\mathrm{f}_{\mathrm{c}}^{\prime}}+120 \mathrm{p}_{\mathrm{w}} \frac{\mathrm{V}_{\mathrm{u}} \mathrm{d}}{\mathrm{M}_{\mathrm{u}}}\right) \frac{\mathrm{b}_{\mathrm{w}} \mathrm{d}}{7} \leq 0.3 \sqrt{\mathrm{f}_{\mathrm{c}}^{\prime}} \mathrm{b}_{\mathrm{w}} \mathrm{d}$

$V_{s}=\frac{A_{v} f_{y t} d}{s}$ 
where $b$ is the width of the cross-section, $d$ is the effective depth, Vu and $M_{u}$ are the ultimate shear force and moment capacity of the section, respectively, $f_{c}^{\prime}$ is the cylinder compressive strength of concrete, $A_{v}$ is the area of shear reinforcement, $f_{y t}$ is the characteristic yield strength of reinforcement, $s$ is the spacing of shear reinforcement.

According to Canadian Code (CSA A23.3-04, 2004) based on modified compression field theory, $\mathrm{V}_{\mathrm{c}}$ and $\mathrm{V}_{\mathrm{s}}$ can be obtained from the following equations:

$V_{\mathbf{C}}=\beta \sqrt{f_{c}^{\prime}} b_{w} d_{v}$

The value of $\beta$ shall be determined from:

$\beta=\frac{520}{\left[\left(1+1500 \varepsilon_{\mathrm{x}}\right)\left(1000+\mathrm{S}_{\mathrm{ze}}\right)\right]}$

$\mathrm{S}_{\mathrm{ze}}=\frac{35 \mathrm{~s}_{\mathrm{z}}}{15}+\mathrm{a}_{\mathrm{g}} \leq 0.85 \mathrm{~S}_{\mathrm{z}}$

$\varepsilon_{X}=\frac{\frac{M_{f}}{d_{V}}+V_{f}}{2 A_{s} E_{S}}$

$V_{s}=\frac{A_{v} f_{y} d_{v}}{s}$

where $b$ is the width of the cross section, $d$ is the effective shear depth which can be taken as the greater of 0.9 of the beam depth or 0.72 of the beam height, $f_{c}^{\prime}$ is the cylinder compressive strength, $A_{y}$ is the area of shear reinforcement, $f_{y}$ is the characteristic yield strength of reinforcement and $s$ is the spacing of shear reinforcement. $\sqrt{\mathrm{f}_{\mathrm{c}}^{\prime}}$ Should be less than $8 \mathrm{MPa}$. According to clause 11.3.4, $\varepsilon \mathrm{x}$ is the longitudinal strain at mid-depth of the member due to factored loads, $\mathrm{M}_{\mathrm{f}}$ is the factored moment at section, $\mathrm{V}_{\mathrm{f}}$ is the factored shear force at section, $\mathrm{E}_{\mathrm{s}}$ is the modulus of elasticity of nonprestressed reinforcement, $S z$ and $d_{v}$ represent crack spacing parameter dependent on crack control characteristics of longitudinal reinforcement and $\mathrm{ag}_{\mathrm{g}}$ is maximum size of aggregate in the concrete. For high-strength concrete with $\mathrm{f}_{\mathrm{c}}^{\prime}$ greater than $70 \mathrm{MPa}$, $\mathrm{ag}_{\mathrm{g}}$ shall be taken as zero.

According to British standards (BS8110-part1, 1997), $\mathrm{V}_{\mathrm{c}}$ and $\mathrm{V}_{\mathrm{s}}$ can be calculated from:

$\mathrm{V}_{\mathrm{C}}=0.79\left(\frac{100 \mathrm{~A}_{\mathrm{s}}}{\mathrm{bd}}\right)^{\frac{1}{3}}\left(\frac{400}{\mathrm{~d}}\right)^{\frac{1}{4}}\left(\frac{\mathrm{f}_{\mathrm{cu}}}{25}\right)^{\frac{1}{3}}$

$\mathrm{V}_{\mathrm{S}}=\frac{\mathrm{A}_{\mathrm{sv}}}{\mathrm{S}_{\mathrm{v}}} 0.95 \mathrm{f}_{\mathrm{yv}} \mathrm{d}$ 
This Code limits the maximum allowable concrete compressive strength to $40 \mathrm{MPa}$ with an alternative table used for values of compressive strength below $25 \mathrm{MPa}$ depending only on the amount of longitudinal steel provided. In BS8110, $b_{v}$ is the width of the cross section, $d$ is the effective depth, $\mathrm{f}_{\mathrm{cu}}$ is the cube compressive strength, $\mathrm{A}_{\mathrm{s}}$ is the tension reinforcement area in $\mathrm{mm}^{2}$. $A_{s v}$ is the area of shear reinforcement, $f_{y v}$ is the characteristic yield strength of shear reinforcement and $s_{v}$ is the spacing of shear reinforcement. $f_{c u}$ should be less than or equal to $40 \mathrm{MPa}$ for calculation purpose only.

ACI 318-05 and CSA A23.3-04 shear strength equation use the cylinder's compressive strength, but BS8110 shear strength equation adopt cube's compressive strength in the shear strength calculation.

\subsubsection{Shear strength of reinforced lightweight concrete members}

The availability and proven performance of lightweight aggregates have led to the improved functionality and economical design of buildings, bridges and marine structures for more than 80 years. During much of this period, designs were based on properties of normal weight concrete, properly adjusted by engineers, but without adequate guidance on recommended practices specifically pertaining to lightweight concrete (Juan 2011). Today, all major international codes of practice accept lightweight aggregate concrete as a structural medium with general guidelines for engineers (ACI 318-05 2005; CSA A23.3-04 2004; \& BS8110 1997).

Lightweight concrete members have been shown by test and performance to behave in fundamentally the same manner as its normal weight counterpart with differences in properties and failure modes (Gerritse 1981; Taylor 1963). From a shear and diagonal tension perspective, these properties are sufficiently different to require design modifications. Codes of practice generally approach this issue by introducing reduction factors to normal weight concrete shear equations. This is because although lightweight concrete has higher material tensile strength, under air drying, which is the case in practice, it will generally have a lower tensile strength that normal weight concrete of equal compressive strength (Hanson 1968). 
The ACI 318-05 (2005) code uses a reduction factor equal reduction factor equal to 0.75 for alllightweight concrete, 0.85 for sand lightweight concrete and 1.0 for normal weight concrete. CSA A23.3-04 (2004) code uses reduction factor equal to 0.75 for low density concrete (with an air

dry density less than $1850 \mathrm{~kg} / \mathrm{m}^{3}$ ), 0.85 for semi lightweight concrete (with an air dry density between 1850 and $2150 \mathrm{~kg} / \mathrm{m}^{3}$ ) and 1.0 for normal weight concrete (with air dry density between 2150 and $2500 \mathrm{~kg} / \mathrm{m}^{3}$ ) BS8110 (1997) code adopts a reduction factor equal to 0.8 for lightweight concretes and 1.0 for normal weight concrete.

\subsubsection{Previous studies on shear behavior of reinforced concrete beams}

Adom and Africa (2013) studied the shear behavior of concrete beams made from phyllite lightweight aggregate subjected to monotonic and cyclic loading. Details of the experimental LWC beams are presented in Table 2.3 and Figure 2.6(a).Sixteen beams were casted and tested in the laboratory. Ten of these beams were without shear reinforcement whilst remaining had shear reinforcement. Five different beam dimensions with different cross sectional areas (140 mm x 310 $\mathrm{mm}, 140 \mathrm{~mm} \times 265 \mathrm{~mm}, 110 \mathrm{~mm} \times 225 \mathrm{~mm}, 110 \mathrm{~mm} \times 184 \mathrm{~mm}$, and $90 \mathrm{~mm} \times 150 \mathrm{~mm}$ ) and respective length $(2400 \mathrm{~mm}, 2000 \mathrm{~mm}, 1700 \mathrm{~mm}, 1500 \mathrm{~mm}$, and $1000 \mathrm{~mm})$ were considered for the beams without shear reinforcement (P1-P10). Each type of beam dimension was reinforced with $1 \%$ and $2 \%$ amount longitudinal steel reinforcement. The six beams with shear reinforcement (P11-P16) had dimensions $145 \mathrm{~mm}$ x $265 \mathrm{~mm}$ x $2000 \mathrm{~mm}$. The beams with stirrups reinforcement was made of 3 stirrup spacing types; R6@250 mm (P11 and P12), R6 @150 mm (P13 and P14) and R6@100 mm (P15 and P16). The shear span to depth ratio was kept between 2.35 and 2.5 to ensure that shear rather than bending failure occurred in all beams during testing. The beams were tested by four point bend test. Results showed that the ACI 318, BS8110 and European (EC) codes are conservative in the prediction of phyllite concrete beams without shear reinforcement but they all overestimate the shear strength of phyllite concrete beams with shear reinforcement. It is recommended that the predicted shear capacity of phyllite beams reinforced with steel stirrups be modified by a reduction factor of 0.7 in order to specify a high enough safety factor on their ultimate strength. 
Table 2.3-Details of lightweight concrete beams tested by Adom and Afrifa (2013)

\begin{tabular}{|c|c|c|c|c|c|c|c|c|c|c|}
\hline Beam & $\begin{array}{c}\mathrm{f}_{\mathrm{cu}} \\
\mathrm{MPa}\end{array}$ & $\begin{array}{c}\mathrm{f}_{\mathrm{y}} \\
\mathrm{MPa}\end{array}$ & $\begin{array}{c}\mathrm{b} \\
\mathrm{mm}\end{array}$ & $\begin{array}{c}\mathrm{d} \\
\mathrm{mm}\end{array}$ & $\begin{array}{c}\mathrm{h} \\
\mathrm{mm}\end{array}$ & $\mathrm{a} / \mathrm{d}$ & $\rho \%$ & \multicolumn{2}{|c|}{ Stirrups } & \begin{tabular}{c}
$\mathrm{V}$ \\
\cline { 9 - 10 }
\end{tabular} \\
& & & & & & & & Detail & $\begin{array}{c}\mathrm{f}_{\mathrm{y}} \\
\mathrm{kN}\end{array}$ & \\
\hline P1 & 23.5 & 375 & 140 & 282 & 310 & 2.45 & 1 & - & - & 40.0 \\
\hline P2 & 23.5 & 375 & 140 & 282 & 310 & 2.45 & 2 & - & - & 60.0 \\
\hline P3 & 23.5 & 375 & 140 & 237 & 265 & 2.45 & 1 & - & - & 44.0 \\
\hline P4 & 23.5 & 375 & 140 & 237 & 265 & 2.45 & 2 & - & - & 66.0 \\
\hline P5 & 23 & 375 & 110 & 197 & 225 & 2.45 & 1 & - & - & 28.0 \\
\hline P6 & 23 & 375 & 110 & 197 & 225 & 2.45 & 2 & - & - & 46.0 \\
\hline P7 & 23 & 375 & 110 & 156 & 184 & 2.45 & 1 & - & - & 24.0 \\
\hline P8 & 23 & 375 & 110 & 156 & 184 & 2.45 & 2 & - & - & 28.0 \\
\hline P9 & 23 & 375 & 90 & 122 & 150 & 2.35 & 1 & - & - & 18.0 \\
\hline P10 & 23 & 375 & 90 & 122 & 150 & 2.35 & 2 & - & - & 24.0 \\
\hline P11 & 23.5 & 375 & 145 & 230 & 265 & 2.45 & 2 & $6 @ 250 \mathrm{~mm}$ & 250 & 106.0 \\
\hline P12 & 23.5 & 375 & 145 & 230 & 265 & 2.45 & 2 & $6 @ 250 \mathrm{~mm}$ & 250 & 86.0 \\
\hline P13 & 23.5 & 375 & 145 & 230 & 265 & 2.45 & 2 & $6 @ 150 \mathrm{~mm}$ & 250 & 96.0 \\
\hline P14 & 23.5 & 375 & 145 & 230 & 265 & 2.45 & 2 & $6 @ 150 \mathrm{~mm}$ & 250 & 114.0 \\
\hline P15 & 23.5 & 375 & 145 & 230 & 265 & 2.45 & 2 & $6 @ 100 \mathrm{~mm}$ & 250 & 128.0 \\
\hline P16 & 23.5 & 375 & 145 & 230 & 265 & 2.45 & 2 & $6 @ 100 \mathrm{~mm}$ & 250 & 118.0 \\
\hline
\end{tabular}

d: Effective depth; h: Total height/depth; a/d: shear span (a) to depth (d) ratio; $\rho$ (=100As/bd: flexural reinforcement ratio, V: shear resistance of beam. fcu: concrete compressive strength, fy: steel yield strength
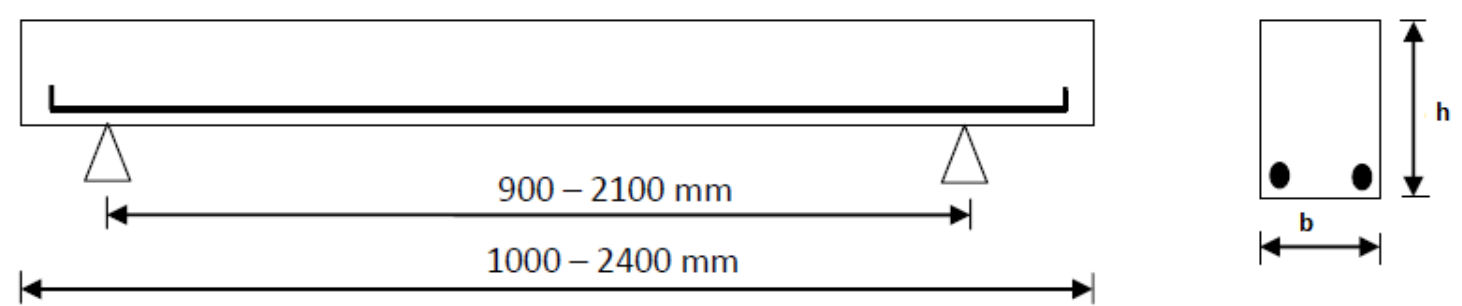

Beam without shear reinforcement (P1-P10)

Link spacing varies (R6@250,R6@150,R6@100)
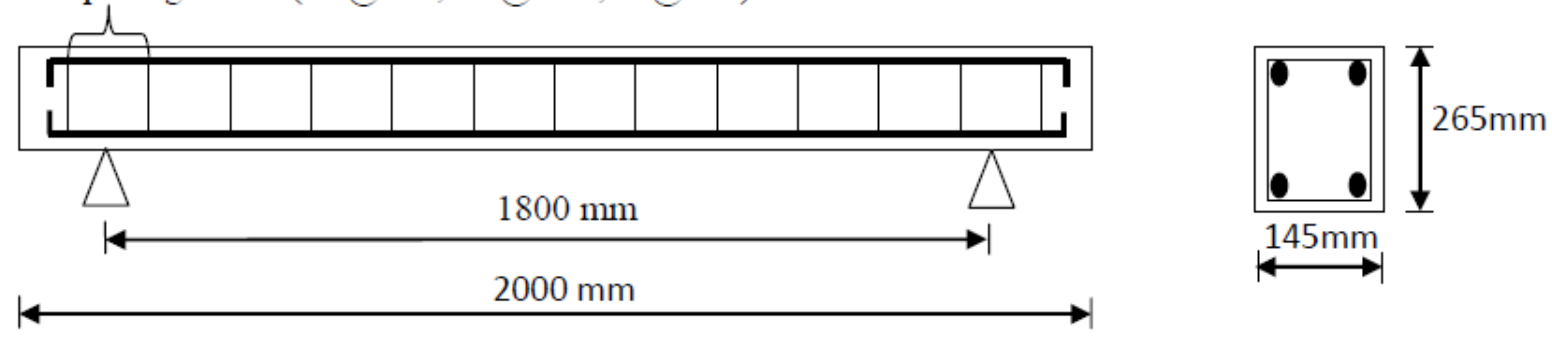

Beam with shear reinforcement (P11-P16)

Figure 2.6(a) -Beam details of lightweight concrete beams tested by Adom and Afrifa (2013) 
Mohammed et al. (2013) investigated the shear behavior of reinforced concrete beams made of palm oil clinker (POCC) lightweight aggregate. Details of the experimental LWC beams are presented in Table 2.4. All beams had rectangular cross section of $150 \times 300 \mathrm{~mm}$, with a total length of $2400 \mathrm{~mm}$. The beam dimension were also sufficiently large to simulate a real structural element. The yield strength of the tension steel bar was $590 \mathrm{MPa}$. For the purpose of this study, three parameters selected the shear behaviour of the reinforced beams are, tension reinforcement ratio ( $\rho)$, shear span to effective depth ratio (a/d) and compressive strength of the concrete. Details of the experimental set up is shown in Figure 2.6(b). The results show that the failure mode of the reinforced POCC beam is similar to that of conventional reinforced concrete beam. In addition, the shear equation of the Canadian Standard Association (CSA A23.3 2004) can be used in designing reinforced POCC beam with flexural reinforcement percentage greater than one. However, a 0.5 safety factor should be included in the formula for flexural reinforcement percentage less than one.

Table 2.4 - Details of lightweight concrete beams tested by Mohammed et al. (2013)

\begin{tabular}{|c|c|c|c|c|c|c|c|c|}
\hline Beam & $\begin{array}{c}\mathrm{f}_{\mathrm{cu}} \\
\mathrm{MPa}\end{array}$ & $\begin{array}{c}\mathrm{f}_{\mathrm{y}} \\
\mathrm{MPa}\end{array}$ & $\begin{array}{c}\mathrm{b} \\
\mathrm{mm}\end{array}$ & $\begin{array}{c}\mathrm{d} \\
\mathrm{mm}\end{array}$ & $\begin{array}{c}\mathrm{h} \\
\mathrm{mm}\end{array}$ & $\mathrm{a} / \mathrm{d}$ & $\rho \%$ & $\begin{array}{c}\mathrm{V} \\
\mathrm{kN}\end{array}$ \\
\hline AD-3 & 31.5 & 590 & 150 & 262 & 300 & 3 & 1.0 & 27.5 \\
\hline AD-1 & 31.5 & 590 & 150 & 262 & 300 & 1 & 1.0 & 19.5 \\
\hline WC-1 & 20.3 & 590 & 150 & 262 & 300 & 2 & 1.0 & 21.5 \\
\hline WC-3 & 39.8 & 590 & 150 & 262 & 300 & 2 & 1.0 & 25.0 \\
\hline SR-1 & 31.5 & 590 & 150 & 250 & 300 & 2 & 3.4 & 30.5 \\
\hline SR-3 & 31.5 & 590 & 150 & 266 & 300 & 2 & 0.3 & 12.5 \\
\hline
\end{tabular}

d: Effective depth; h: Total height/depth; a/d: shear span (a) to depth (d) ratio; $\rho$ (=100As/bd: flexural reinforcement ratio, V: shear resistance of beam. fcu: concrete compressive strength, fy: steel yield strength

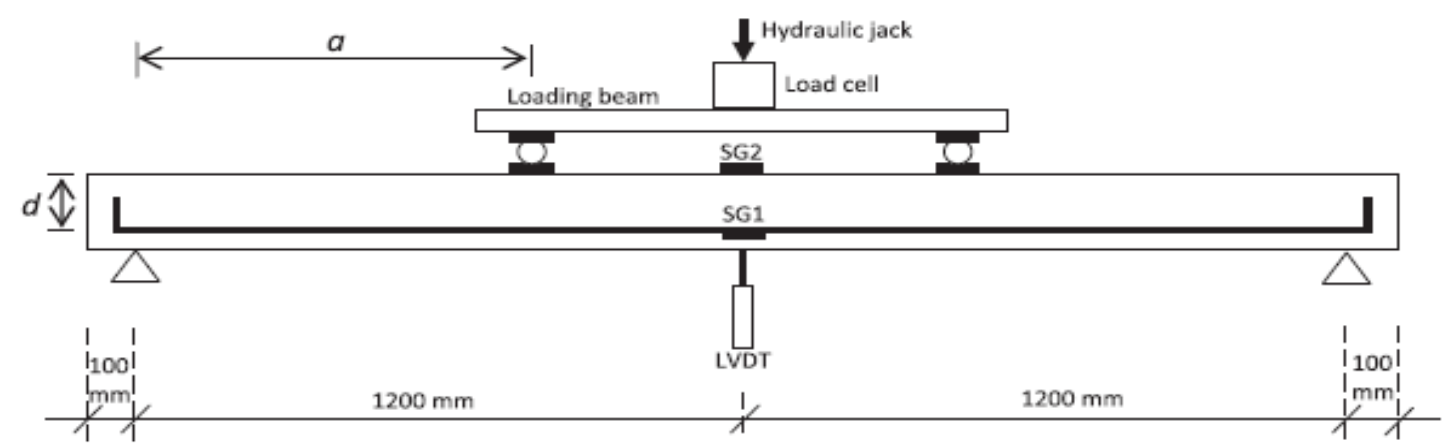

Figure 2.6(b) -The experimental set-up for the beams tested by Mohammed et al. (2013) 
Alengaram et al. (2011) studied the shear behavior of palm kernel shell concrete (PKSC) beams prepared using palm kernel shell (PKS) as a lightweight aggregate. Details of the experimental LWC beams are presented in Table 2.5 and Figure 2.6(c). A total of four lightweight concrete beam specimens of $150 \mathrm{~mm}$ wide, $250 \mathrm{~mm}$ overall depth and $2600 \mathrm{~mm}$ long were prepared. The shear span to effective depth ratios of 1.44 and 2.15 were used for beams with and without shear reinforcement, respectively. Good aggregate interlock in PKSC was identified. Further, PKSC was able to produce twice as many flexural and shear cracks compared to normal weight concrete control beams.

Table 2.5- Details of lightweight concrete beams tested by Alengaram et al. (2011)

\begin{tabular}{|c|c|c|c|c|c|c|c|c|c|c|}
\hline Beam & $\begin{array}{c}\mathrm{f}_{\mathrm{cu}} \\
\mathrm{MPa}\end{array}$ & $\begin{array}{c}\mathrm{f}_{\mathrm{y}} \\
\mathrm{MPa}\end{array}$ & $\begin{array}{c}\mathrm{b} \\
\mathrm{mm}\end{array}$ & $\begin{array}{c}\mathrm{d} \\
\mathrm{mm}\end{array}$ & $\begin{array}{c}\mathrm{h} \\
\mathrm{mm}\end{array}$ & $\mathrm{a} / \mathrm{d}$ & $\rho \%$ & \multicolumn{2}{|c|}{ Stirrups } & \begin{tabular}{c}
$\mathrm{V}$ \\
\cline { 7 - 10 }
\end{tabular} \\
& & & & & & & & Detail & $\begin{array}{c}\mathrm{f}_{\mathrm{y}} \\
\mathrm{MPa}\end{array}$ & \\
\hline PKSC-P1 & 37.9 & 505 & 150 & 214 & 250 & 1.44 & 3.48 & - & - & 67.1 \\
\hline PKSC-P2 & 33.6 & 505 & 150 & 214 & 250 & 1.44 & 3.70 & - & - & 58.9 \\
\hline PKSC-L1 & 32.6 & 505 & 150 & 208 & 250 & 2.15 & 1.6 & $6 @ 150 \mathrm{~mm}$ & 350 & 57.5 \\
\hline PKSC-L2 & 33.7 & 505 & 150 & 208 & 250 & 2.15 & 0.72 & $6 @ 150 \mathrm{~mm}$ & 350 & 110 \\
\hline
\end{tabular}

d: Effective depth; h: Total height/depth; a/d: shear span (a) to depth (d) ratio; $\rho$ (=100As/bd: flexural reinforcement ratio, V: shear resistance of beam. fcu: concrete compressive strength, fy: steel yield strength

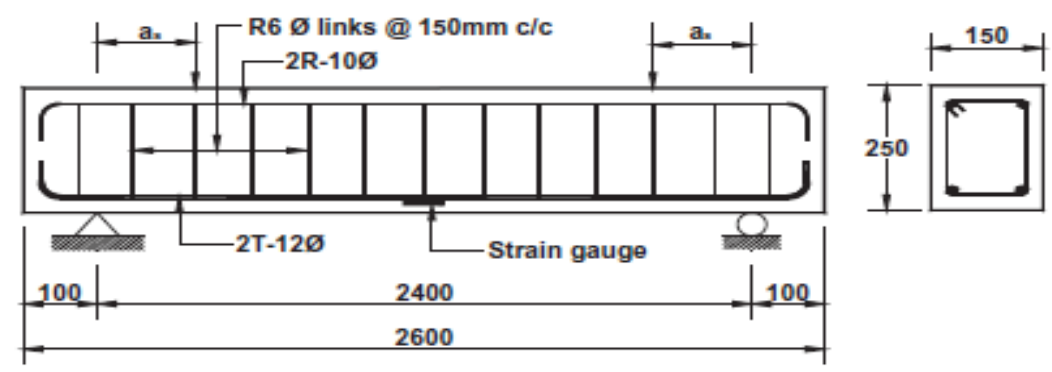

Beam with shear reinforcement
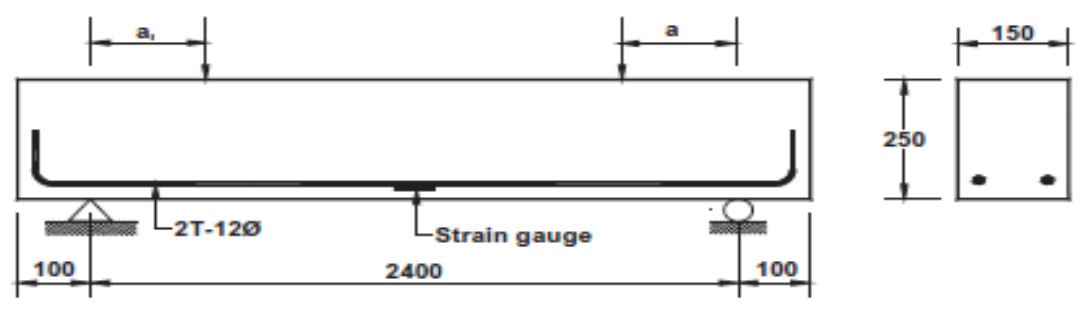

Beam without shear reinforcement

Figure 2.6(c) -Reinforcement details of the beams tested by Alengaram et al. (2011) (All dimension are in $\mathrm{mm}$ ) 
Gunasekara et al. (2013) conducted tests and analyzed the shear behavior of reinforced concrete beams made with crushed coconut shell as coarse aggregate. Details of the experimental LWC beams are presented in Table 2.6.and Figure2.6 (d). A total of four beams were fabricated and tested with coconut shell aggregate concrete. Two beams were designed without shear reinforcement and two beams were designed with shear reinforcement. In each set two number of $10 \mathrm{~mm}$ diameters and two number of $12 \mathrm{~mm}$ diameters were used as a reinforcement respectively. The width (b), effective depth (d) and length (l) of the beams were maintained at $150 \mathrm{~mm}, 200 \mathrm{~mm}$ and $2600 \mathrm{~mm}$, respectively for all the beams. The beam size and length were chosen to ensure that the beams would fail in shear. The minimum shear reinforcement criteria is also considered such that a diagonal crack would be intercept by at least one web reinforcement. It was observed that the shear behavior of coconut shell concrete is comparable to that of other lightweight concrete. The results of concrete compression strain and steel tension strain showed that coconut shell is able to archive its full strain capacity under shear loadings. However, the failure zones of coconut shell concrete were larger than for control concrete beams.

Table 2.6 - Details of lightweight concrete beams tested by Gunasekara et al. (2013)

\begin{tabular}{|c|c|c|c|c|c|c|c|c|c|c|}
\hline \multirow[t]{2}{*}{ Beam } & \multirow{2}{*}{$\begin{array}{c}\mathrm{f}_{\mathrm{cu}} \\
\mathrm{MPa}\end{array}$} & \multirow{2}{*}{$\begin{array}{c}\mathrm{f}_{\mathrm{y}} \\
\mathrm{MPa}\end{array}$} & \multirow{2}{*}{$\underset{\mathrm{mm}}{\mathrm{b}}$} & \multirow{2}{*}{$\underset{\mathrm{mm}}{\mathrm{d}}$} & \multirow{2}{*}{$\begin{array}{c}\mathrm{h} \\
\mathrm{mm}\end{array}$} & \multirow[t]{2}{*}{$\mathrm{a} / \mathrm{d}$} & \multirow[t]{2}{*}{$\rho \%$} & \multicolumn{2}{|c|}{ Stirrups } & \multirow{2}{*}{$\begin{array}{c}\mathrm{V} \\
\mathrm{kN}\end{array}$} \\
\hline & & & & & & & & Detail & $\begin{array}{c}f_{y} \\
\mathrm{MPa} \\
\end{array}$ & \\
\hline WOS1-CSAC & 26.7 & 450 & 150 & 200 & 230 & 4 & 0.52 & - & - & 22.5 \\
\hline WOS2-CSAC & 26.7 & 450 & 150 & 200 & 230 & 4 & 0.75 & - & - & 23.3 \\
\hline WS1-CSAC & 26.7 & 450 & 150 & 200 & 230 & 4 & 0.52 & $6 @ 150 \mathrm{~mm}$ & 250 & 51.2 \\
\hline WS2-CSAC & 26.7 & 450 & 150 & 200 & 230 & 4 & 0.75 & $6 @ 150 \mathrm{~mm}$ & 250 & 27.2 \\
\hline
\end{tabular}

(6@150mm denotes 6mm diameter bar at 150mm c/c spacing): d: Effective depth; h: Total height/depth; a/d: shear span (a) to depth (d) ratio; $\rho(=100 \mathrm{As} / \mathrm{bd}$ : flexural reinforcement ratio, V: shear resistance of beam. fcu: concrete compressive strength, fy: steel yield strength 

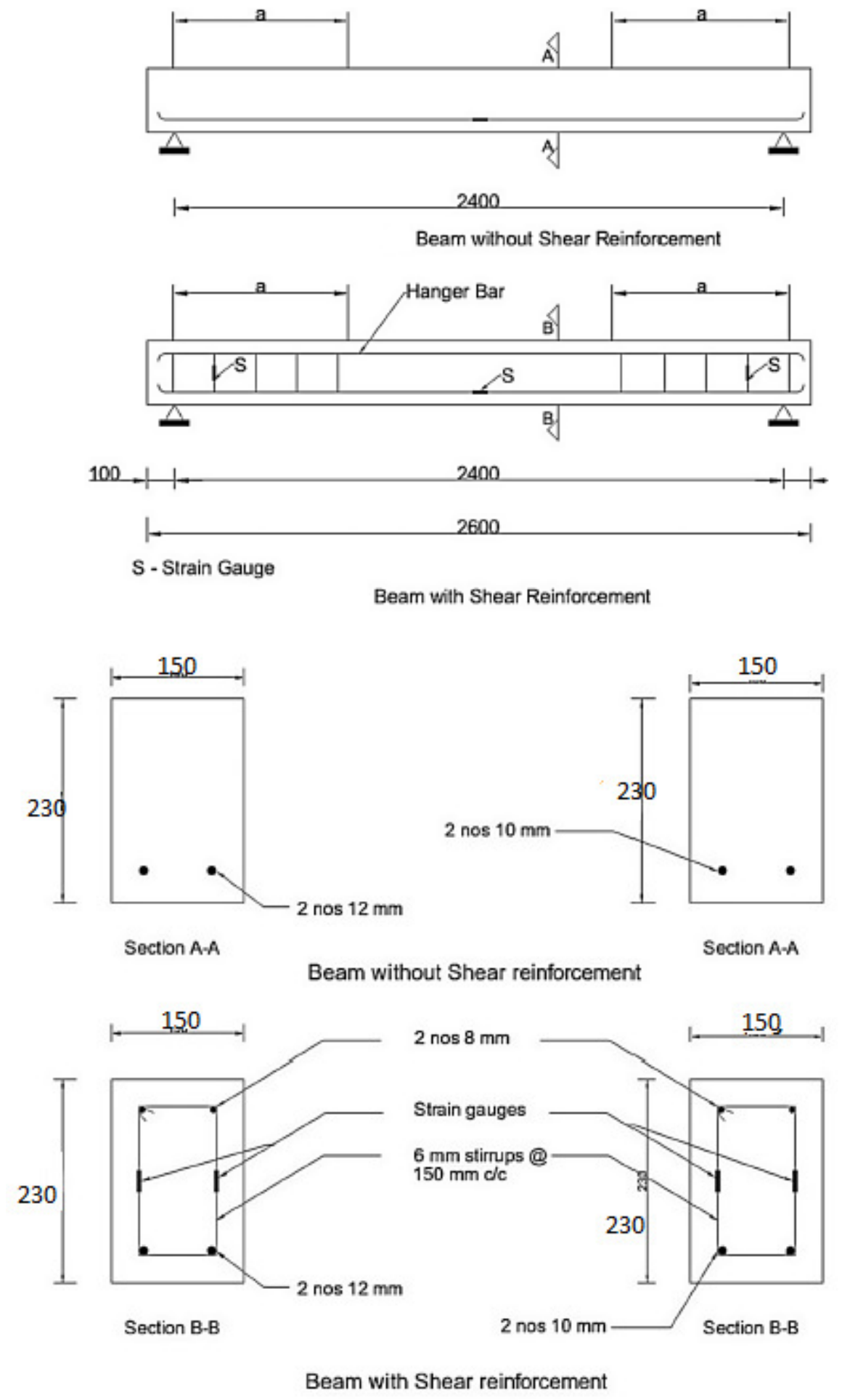

Figure 2.6(d) -Reinforcement details of the beams tested by Gunasekara et al. (2013) (All dimension are in $\mathrm{mm}$ ) 
Juan (2011), studied the shear behavior of lightweight concrete beams made of expanded clay lightweight aggregate. Details of the experimental LWC beams are presented in Table 2.7 and Figure 2.6(e). All beams without shear reinforcement had a rectangular cross section, $300 \mathrm{~mm}$ wide by $125 \mathrm{~mm}$ deep with an overall length of $1350 \mathrm{~mm}$. The beams are designed to behave similar manner to one way spanning slabs. Flexural tension reinforcement was provided longitudinal reinforcement ratio of $0.63 \%$. Span lengths for each beam was maintained and kept constant for each beam geometry. The shear span to depth ratios were then varied by adjusting the distance of the loading point from the support. By doing this, the shear span to depth ratios between 1.5and 3.5 in the experimental program was obtained. Results found that beams without shear reinforcement behaved in a similar manner to the reference normal weight concrete beams until the onset of diagonal cracking. Thereafter, while normal weight concrete beams were able to continue resisting shear until a flexural mode of physical failure occurred, lightweight aggregate concrete was unable to develop sufficient resistance and physically failed in a brittle shear mode. Comparison of the performance of these lightweight high-strength concrete beams with and without transverse reinforcement against design equations of the American Concrete Institute and the British Standards Institute show that the design equations can be used with confidence.

Table 2.7 - Details of lightweight concrete beams tested by Juan. (2011)

\begin{tabular}{|c|c|c|c|c|c|c|c|c|}
\hline Beam & $\begin{array}{c}\mathrm{f}_{\mathrm{cu}} \\
\mathrm{MPa}\end{array}$ & $\begin{array}{c}\mathrm{f}_{\mathrm{y}} \\
\mathrm{MPa}\end{array}$ & $\begin{array}{c}\mathrm{b} \\
\mathrm{mm}\end{array}$ & $\begin{array}{c}\mathrm{d} \\
\mathrm{mm}\end{array}$ & $\begin{array}{c}\mathrm{h} \\
\mathrm{mm}\end{array}$ & $\mathrm{a} / \mathrm{d}$ & $\rho \%$ & $\begin{array}{c}\mathrm{V} \\
\mathrm{kN}\end{array}$ \\
\hline S.B 1.5 & 42.6 & 590 & 300 & 100 & 125 & 1.5 & 0.63 & 37.5 \\
\hline S.B 2 & 42.6 & 590 & 300 & 100 & 125 & 2.0 & 0.63 & 33.5 \\
\hline S.B 3 & 42.6 & 590 & 300 & 100 & 125 & 3.0 & 0.63 & 34.3 \\
\hline S.B 3.5 & 42.6 & 590 & 300 & 100 & 125 & 3.5 & 0.63 & 27.5 \\
\hline SB C50 1.5 & 43.8 & 590 & 300 & 100 & 125 & 1.5 & 0.63 & 65.0 \\
\hline SB C50 2.0 & 43.8 & 590 & 300 & 100 & 125 & 2.0 & 0.63 & 37.0 \\
\hline SB C50 3.0 & 43.8 & 590 & 300 & 100 & 125 & 3.0 & 0.63 & 30.0 \\
\hline SB C50 3.5 & 43.8 & 590 & 300 & 100 & 125 & 3.5 & 0.63 & 31.5 \\
\hline SB C50 P0.78 3.0 & 46.9 & 590 & 300 & 100 & 125 & 3.0 & 0.78 & 30.0 \\
\hline SA C50 3.0 & 49.6 & 590 & 300 & 100 & 125 & 3.0 & 0.63 & 32.5 \\
\hline SG C50 3.0 & 53.0 & 590 & 300 & 100 & 125 & 3.0 & 0.63 & 35.0 \\
\hline SB C70 1.5 & 64.9 & 590 & 300 & 100 & 125 & 1.5 & 0.63 & 67.5 \\
\hline SB C70 2.0 & 64.9 & 590 & 300 & 100 & 125 & 3.0 & 0.63 & 40.0 \\
\hline SB C70 3.0 & 69.8 & 590 & 300 & 100 & 125 & 3.0 & 0.63 & 33.0 \\
\hline SB C70 3.5 & 69.8 & 590 & 300 & 100 & 125 & 3.5 & 0.63 & 31.3 \\
\hline
\end{tabular}

d: Effective depth; h: Total height/depth; a/d: shear span (a) to depth (d) ratio; $\rho$ (=100As/bd: flexural reinforcement ratio, V: shear resistance of beam. fcu: concrete compressive strength, fy: steel yield strength 


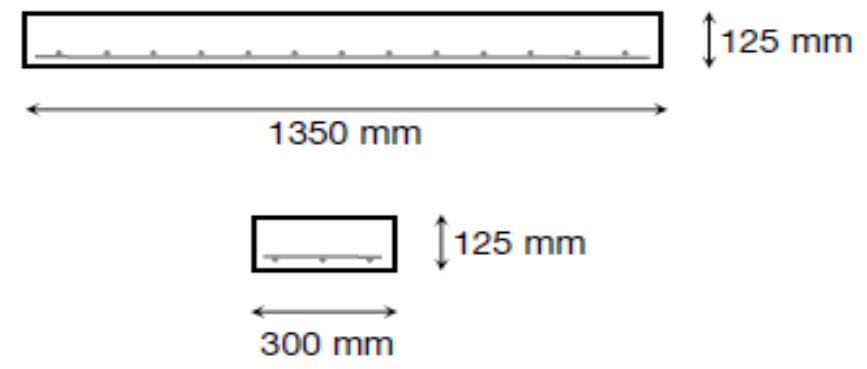

Figure 2.6(e) -Geometry details of the beams tested by Gunasekara et al. (2013)

Ahmed (2011) investigated shear and flexural behavior of lightweight concrete beams made of expanded shale lightweight aggregate. Details of the experimental LWC beams are presented in Table 2.8. The main parameters considered in the shear experimental program were the different concrete compressive strength, different tensile steel reinforcement, different stirrups spacing and different shear span to depth ratio. The length of all specimen was $3600 \mathrm{~mm}$. All the shear beams were tested in four point with different distance between the two loading points. The distance between the loading points for the shear beams was vary including four distance as the following $2515 \mathrm{~mm}, 2261 \mathrm{~mm},, 1753 \mathrm{~mm}$ and $1219 \mathrm{~mm}$ for using shear span to depth ratio (a/d) equal to 1.5 , 2, 3 and 4 respectively. Figure 2.6(f) shows the experimental set-up of the beams. ACI Code specifications are found to underestimate the maximum shear capacity of reinforced LWC beams with an average difference of $7 \%$. The cracking moment capacity of LWC beams is well predicted by the ACI code. However, the ACI specifications are found to underestimate the maximum deflection and capacity of reinforced LWC beams with an average difference of $11 \%$.

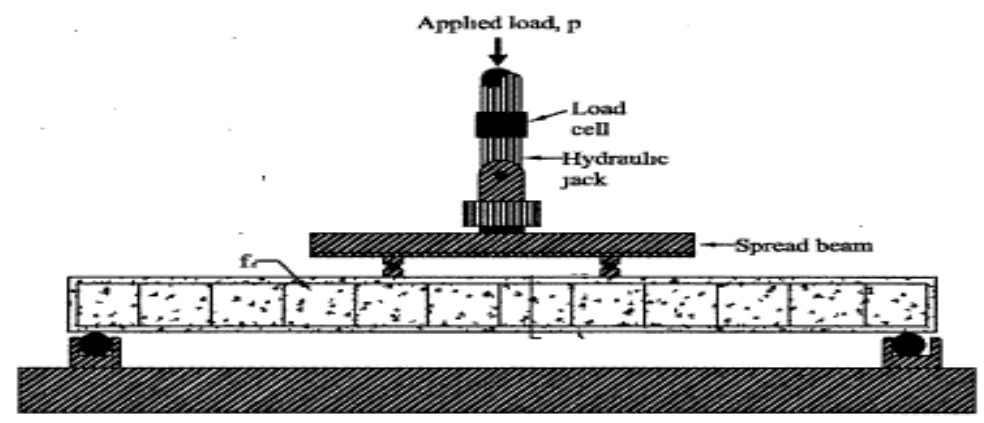

Figure 2.6(f) - Experimental set-up of the beams tested by Gunasekara et al. (2013) 
Table 2.8- Details of lightweight concrete beams tested by Ahmed (2011)

\begin{tabular}{|c|c|c|c|c|c|c|c|c|c|c|}
\hline Beam & $\begin{array}{c}\mathrm{f}_{\mathrm{cu}} \\
\mathrm{MPa}\end{array}$ & $\begin{array}{c}\mathrm{f}_{\mathrm{y}} \\
\mathrm{MPa}\end{array}$ & $\begin{array}{c}\mathrm{b} \\
\mathrm{mm}\end{array}$ & $\begin{array}{c}\mathrm{d} \\
\mathrm{mm}\end{array}$ & $\begin{array}{c}\mathrm{h} \\
\mathrm{mm}\end{array}$ & $\mathrm{a} / \mathrm{d}$ & $\rho \%$ & \multicolumn{2}{|c|}{ Stirrups } & $\mathrm{V}$ \\
\cline { 6 - 10 } & & & & & & & & Detail & $\begin{array}{c}\mathrm{f}_{\mathrm{y}} \\
\mathrm{MPa}\end{array}$ & \\
\hline B4C7.40S0 & 63.6 & 460 & 200 & 150 & 175 & 4 & 1.12 & - & - & 35.0 \\
\hline B3C7.40S0 & 63.6 & 460 & 200 & 300 & 340 & 3 & 1.12 & - & - & 43.0 \\
\hline B2C7.40S0 & 63.6 & 460 & 200 & 600 & 650 & 2 & 1.12 & - & - & 52.0 \\
\hline B2.C7.40S0-2 & 63.6 & 460 & 200 & 600 & 650 & 2 & 1.12 & - & - & 58.0 \\
\hline B4C9.96S12 & 68.5 & 460 & 200 & 265 & 300 & 4 & 2.21 & $8 @ 300 \mathrm{~mm}$ & 410 & 148.0 \\
\hline B4C8.48S12 & 58.0 & 460 & 200 & 265 & 300 & 4 & 2.21 & $8 @ 300 \mathrm{~mm}$ & 410 & 146.6 \\
\hline B4C7.40S12 & 50.9 & 460 & 200 & 265 & 300 & 4 & 2.21 & $8 @ 300 \mathrm{~mm}$ & 410 & 132.0 \\
\hline B1.5C5.7S10 & 39.5 & 460 & 200 & 265 & 300 & 1.5 & 1.12 & $8 @ 254 \mathrm{~mm}$ & 410 & 170.9 \\
\hline B1.5C5.7S9 & 39.5 & 460 & 200 & 265 & 300 & 1.5 & 1.12 & $8 @ 229 \mathrm{~mm}$ & 410 & 160.5 \\
\hline B1.5C5.7S8 & 39.5 & 460 & 200 & 265 & 300 & 1.5 & 1.12 & $8 @ 203 \mathrm{~mm}$ & 410 & 157.1 \\
\hline B1.5C5.7S7 & 39.5 & 460 & 200 & 265 & 300 & 1.5 & 1.12 & $8 @ 178 \mathrm{~mm}$ & 410 & 161.8 \\
\hline B1.5C6.12S5 & 42.1 & 460 & 200 & 265 & 300 & 1.5 & 1.12 & $8 @ 127 \mathrm{~mm}$ & 410 & 233.6 \\
\hline B1.5C6.12S3.5 & 42.1 & 460 & 200 & 265 & 300 & 1.5 & 1.12 & $8 @ 89 \mathrm{~mm}$ & 410 & 197.9 \\
\hline B1.5C6.12S2.5 & 42.1 & 460 & 200 & 265 & 300 & 1.5 & 1.12 & $8 @ 64 \mathrm{~mm}$ & 410 & 200.1 \\
\hline
\end{tabular}

(8@300mm denotes $8 \mathrm{~mm}$ diameter bar at 300mm c/c spacing); d: Effective depth; h: Total height/depth; a/d: shear span (a) to depth (d) ratio; $\rho$ (=100As/bd: flexural reinforcement ratio, V: shear resistance of beam. fcu: concrete compressive strength, $\mathrm{f}_{\mathrm{y}}$ : steel yield strength

Oliver et al (2001) investigated a fracture mechanics model for the flexural-shear failure of reinforced concrete beams without stirrups. Assuming that the ultimate shear load is reached when the splitting crack starts to propagate, a predictive model is developed. The critical load is obtained considering the energy balance of the system during splitting crack propagation. The position of the critical diagonal crack is obtained using Kim and White's semi-empirical formula. By making a number of simplifying assumptions and using the empirical formula for the assessment of the fracture energy proposed by the CEB-FIP Model Code (1983), an analytical formula is obtained. The model is benchmarked against an empirical formula proposed by the CEB-FIP Model Code. The two formulas are shown to have the same form and the predictions are shown to be in agreement.

Lee and Watanabe (2000) investigated shear design method considering failure modes is proposed for reinforced concrete $(\mathrm{RC})$ beams with shear reinforcement. The proposed equation is capable of predicting the shear strength of RC beams based on two shear failure modes. These failure modes are shear failure after yielding of shear reinforcement (STF) and concrete crushing failure before yielding of shear reinforcement (SCF), which can be determined as a function of material 
properties of RC beams. In calculating the shear strength of the beams failing in STF mode, the strain hardening effect of steel is considered. For the beams failing in SCF mode, the real yield stress of steel, commonly used in calculating the shear strength provided by transverse steel in the cur-rent shear design procedures, is replaced by the stress of the shear reinforcement at shear strength. Calculated shear strength by the proposed equation is compared with experimental results and is shown to be in good agreement. The shear strengths predicted by the proposed equation were compared to test results of 133 beams. Failure modes STF and SCF, when compared, showed good agreement with test results. On the other hand, the ACI code (2005) shear design procedure is very conservative when compared to test results.

Dymond et al. (2007) studied the shear strength of a lightweight self-consolidating concrete bridge girder. LWSCC is advantageous in the bridge industry because members made with this material have a significantly lower self-weight, and in its fresh state, LWSCC has a low viscosity which eliminates the need for vibration during fabrication. A composite section was fabricated with a single precast bulb-tee LWSCC beam and a lightweight concrete cast-in-place deck. A simply supported test configuration was constructed with two point loads to quantify the web-shear strength of the girder. The experimental shear strength is compared to four analytical models from different AASHTO specifications. Based on the results of this limited study, the theoretical predictions for the web-shear strength of this girder were all conservative when compared to the experimentally measured failure strength.

Kim et al. (2010) studied shear characteristics and design for high-strength self-consolidating concrete. This research performed 48 push-off tests to investigate the influence of SCC aggregate and paste volumes on the shear capacity and these results were compared with those obtained from similar conventional concrete (CC) samples. The variables included coarse aggregate type (river gravel and limestone), three coarse aggregate volumes for the SCC mixtures. The aggregate type, aggregate volume, and concrete strength were found to have significant effects on the aggregate interlock. Test results were used to propose new aggregate interlock models based on the modified compression field theory adopted in the AASHTO Load and Resistance Factor Design Specifications. More appropriate expressions have been developed to determine the limiting value of concrete shear strength for CC and SCC precast, prestressed concrete girders with similar mixture proportions, and a 28-day compressive strength greater than $70 \mathrm{MPa}$. Lower strength 
concrete specimens tended to have less coarse aggregate fractures resulting in more aggregate interlock, leading to a larger amount of energy absorption. The test results confirmed that concrete shear strength is highly related to the amount of aggregate fracture at small crack widths when crack slip initiates. Aggregate type is a critical factor that influenced aggregate interlock. For both the SCC and CC specimens, concrete mixtures containing river gravel exhibited more aggregate interlock compared to those containing limestone aggregate. Statistically, the effect of aggregate type was clearly identified over the range of crack slip values. The volume of aggregate influences the contribution of aggregate interlock to the shear capacity for the SCC and CC mixtures tested.

Hassan et al, (2008, 2010a-b) investigated strength, cracking and deflection performance of large scale self-consolidating concrete beams subjected to shear failure. Twenty concrete beams without shear reinforcement were tested to shear failure under simply supported three-point loading conditions. The variables were concrete type, coarse aggregate content, beam depth (150-750 mm) and longitudinal reinforcing steel ratio of $1 \%$ and $2 \%$.The performance was evaluated based on crack pattern, crack width, load at first flexure/diagonal (shear) crack, ultimate shear resistance, post-cracking shear resistance/ductility, load deflection response and failure mode. The results showed that the ultimate shear strength of SCC beams was slightly lower than that of their normal concrete counterparts. The results also validated the performance of various Code-based equations in predicting the crack width and first flexural cracking moment/load.

\subsection{Analysis of reinforced concrete member in flexure}

The theory of flexure for reinforced concrete is based on a three basic assumptions which are sufficient to allow one to calculate the moment resistance of a beam. Three basic assumptions are: plane section before bending remain plane after bending, the strain in the reinforcement is equal to the strain in the concrete at the same level and the stresses in the concrete and reinforcement can be computed from the strain by using stress-strain curves for concrete and steel. Plane section remains plane assumption made in the development of flexural theory for beams is valid for beams constructed with any material. The second assumptions is necessary because concrete and reinforcement must act together to carry load (Wight and Macgregor 1997). 
Flexural tension cracks will occur in the section when the stress in the extreme section fiber equal to modulus of rupture. Up to this point moment-curvature relationship is linear and it is defined as an un-cracked elastic range behavior.

The theoretical cracking moment $\left(\mathrm{M}_{\mathrm{cr}}\right)$ of the beam at the onset of first flexural crack can be determined by using the Eq.2.11 recommended by ACI 318 (2005) and CSA A23.3 (2004) codes.

$\mathbf{M}_{\mathbf{c r}}=\frac{\mathbf{f}_{\mathbf{r}} \mathbf{I}_{\mathbf{g}}}{y_{t}}$

Where, $I_{g}$ is the second moment of inertia of gross concrete section about neutral axis (neglecting reinforcement) and $\mathrm{y}_{\mathrm{t}}$ is the distance from the extreme tension fiber to the neutral axis.

\subsubsection{Theoretical ultimate moment of the LWSCC flexural beams}

In engineering practice, it is often required to evaluate the ultimate flexural capacity of a beam. At ultimate stage, concrete reaches its maximum compressive strain which is equal to 0.0035 according to CSA A23.3-04 (2004) code of practice. At ultimate state, the tensile steel reinforcement could be either in elastic or plastic state. If the section is over reinforced, failure will be governed by crushing of concrete and the nature of failure is brittle and therefore, undesirable. If the section is under reinforced, steel controlled failure by elongation and yielding of the tensile reinforcement and the nature of the failure is ductile therefore favored by designers. The section provided with tension and compression reinforcement is called doubly reinforced beams. This type of section is preferred when an earthquake loading occurs, control of long term deformation, ductility improvement and architectural constraints.

Singly reinforced beam ultimate moment capacity: Figure 2.7 shows the singly reinforced beam stress-strain behavior at ultimate stage. Two distinct zones can be observed compression zone and tension zone separated by a neutral axis. Concrete can resist tensile forces until it cracked. Thereafter these forces are transferred to the reinforcing bars which are located in the tension zone, through bending between concrete and steel. With further load increase, applied moment gradually increases and properly design beams undergo three type of changes before failure such as elastic un-cracked behavior, elastic cracked behavior and inelastic behavior (yielding stage). At ultimate stage, tensile steel reinforcement is designed to be in the plastic range and the beam is called underreinforced where concrete crushing occurs after yielding of tensile steel reinforcement. In the case 
where concrete and steel reach the yielding and crushing stage together is called balance condition (Chaallal and Lachemi 2010).

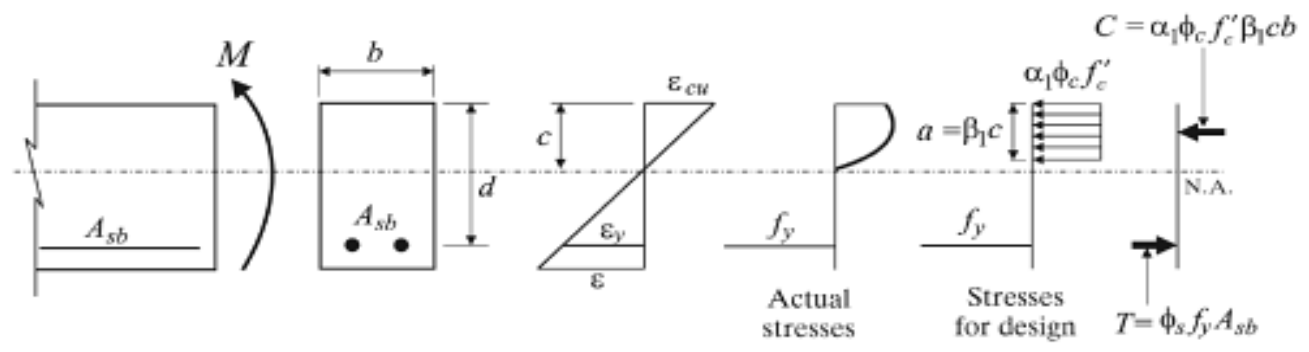

Figure 2.7- Singly reinforced beam at ultimate stage (Chaallal and Lachemi 2010)

The use of an actual parabolic stress strain curve is impractical, therefore CSA.A23.04 (2004) allows to use an equivalent rectangular stress block denoted by factor $\alpha_{1}$ and $\beta_{1}$ instead of parabolic function of the actual stress-strain curve. As per CSA A23.3 (2004), the ultimate moment capacity $\left(\mathrm{M}_{\mathrm{u}}\right)$ for singly reinforced beam can be obtained by using Eqs. 2.12 and 2.13:

$\mathrm{M}_{\mathrm{u}}=\mathrm{f}_{\mathrm{y}} \mathrm{A}_{\mathrm{s}}\left(\mathrm{d}-\frac{\mathrm{a}}{2}\right)$

$\mathrm{a}=\frac{\mathrm{f}_{\mathrm{y}} \mathrm{A}_{\mathrm{s}}}{\alpha_{1} \mathrm{f}_{\mathrm{c}}^{\prime} \mathrm{b}}$

Doubly reinforced beam ultimate moment capacity: Figure 2.8 shows the stress-strain behavior of doubly reinforced beam at ultimate stage. At the ultimate limit state maximum compressive strain in the concrete $\varepsilon_{\mathrm{c}}$ is eaual to $\varepsilon_{\mathrm{cu}}$ (ultimate compressive strain of concrete). However there is no way of knowing wheatear the steel reinforcement (compression and tension rebar) has reached the yield point. For calculation purpose it can be assumed that steel is yielded. This assumptions need to be validated before doing the calculation

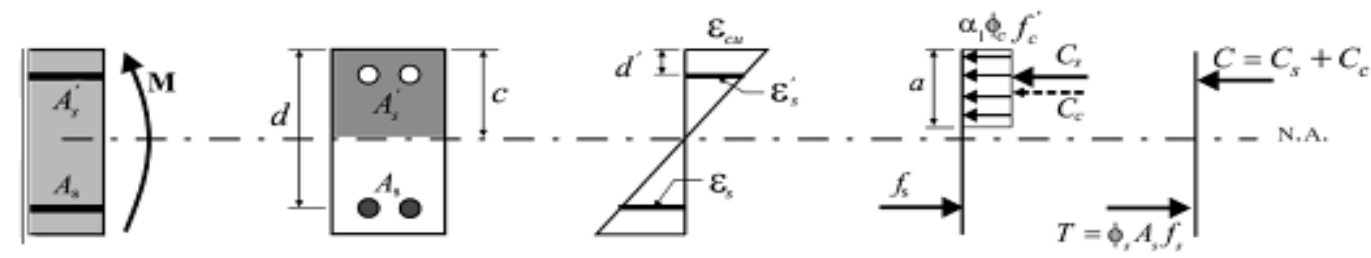

Figure 2.8 -Doubly reinforced beam at ultimate stage (Chaallal and Lachemi 2010) 
Also as per CSA A23.3 (2004), the ultimate moment capacity $\left(\mathrm{M}_{\mathrm{u}}\right)$ for doubly reinforced beam can be obtained by using Eqs. 2.14 and 2.15:

$M_{u}=\left(f_{y} A_{s}-f_{y}^{\prime} A_{s}^{\prime}\right)\left(d-\frac{a}{2}\right)+f_{y}^{\prime} A_{s}^{\prime}\left(d-d^{\prime}\right)$

$\mathrm{a}=\frac{\mathrm{f}_{\mathrm{y}} \mathrm{A}_{\mathrm{s}}-\mathrm{f}_{\mathrm{y}}^{\prime} A_{\mathrm{s}}^{\prime}}{\alpha_{1} f_{\mathrm{c}}^{\prime} \mathrm{b}}$

' $a$ ' is the depth of equivalent rectangular stress block, $f_{y}$ is the yield strength of tensile reinforcement, $\mathrm{f}_{\mathrm{y}}{ }^{\prime}$ is the yield strength of compressive reinforcement, $\mathrm{f}_{\mathrm{c}}{ }^{\prime}$ is the compressive strength of concrete, $b$ is the width of the member, $\alpha_{1}$ is the equivalent rectangular stress block factor $\left(\alpha_{1}=0.85-0.0015 \mathrm{f}^{\prime} \mathrm{c} \geq 0.67\right), \mathrm{A}_{\mathrm{s}}$ or $\mathrm{A}_{\mathrm{sb}}$ is the area of tension reinforcement, $\mathrm{A}_{\mathrm{s}}{ }^{\prime}$ is the area of compression reinforcement, $d$ is the effective depth of cross section (distance from extreme compression fiber to centroid of tension reinforcement, $\mathrm{d}^{\prime}$ is the distance from extreme compression fibre to centroid of compression reinforcement, $\mathrm{c}$ is the depth of neutral axis from the top fiber, $\mathrm{C}$ is the total compression force $\mathrm{C}_{\mathrm{s}}$ is the force in the compression steel, $\mathrm{C}_{\mathrm{c}}$ is the compression fore in concrete and $\mathrm{T}$ is the tensile force in bottom steel.

\subsubsection{Some previous studies of flexural behavior of lightweight concrete beams}

Teo et al. (2006) investigated flexural behavior of reinforced concrete beams produced from oil palm shell aggregates (OPS). Utilizing OPS in concrete production not only solves problem of disposing this solid waste but also help conserve natural resources. A total of 6 under -reinforced beams with varying reinforcement ratios $(0.52-3.9 \%)$ were fabricated and tested. The investigation revealed that the flexural behavior of reinforced OPS concrete beams was comparable to that of other lightweight concretes and experimental results compare reasonably well with the current code of practice. It was observed that beams with low reinforcement ratios satisfied all the serviceability requirements as per BS8110 (1997).

Lim et al. (2006) studied the flexural response of reinforced lightweight aggregate concrete beams (LWAC). Twenty one beams were tested in this study, including three normal weight concrete (NWC) beams for reference may exist with regard to other vital issues. The research covered a wide range of key parameters to address major design issues. The results indicated that LWAC beams closely resemble normal weight concrete beams in terms of ultimate strength. The structural 
design provisions contained in the major codes of practice were scrutinized in light of these results, and suitable recommendations are made for the confident flexural design of LWAC beams.

Adom and Afrifa (2011) investigated the flexural behaviour of 12 reinforced concrete (RC) beams made of phyllite coarse aggregates produced as by-product of underground gold mining activity. The beams were tested to failure under four point test. Collapse of the beams which were adequately designed against shear failure occurred mostly through either flexural-shear failure and/or diagonal tension failure. The exper-imental failure loads averaged approximately $115 \%$ of the theoretical failure loads. It was observed that the beams developed early shear cracks and higher flexural crack widths than allowable at service loads. Deflections compared reasonably well with the design code requirement but displacement ductility was low. It is recommended that prescribed British Standard (BS 8110 1997) concrete shear stress values be multiplied by 0.8 to assure that the predicted shear capacity of phyllite concrete would be low and reasonable as compared to flexural capacity. In that case, BS 8110 can be used to provide adequate load factor against flexural failure for under-reinforced RC beams made of phyllite coarse aggregates.

\subsection{Summary}

Research has been conducted on the material properties of LWC, SCC and LWSCC for tailoring enhanced mechanical and durability properties. LWSCC has been used in many structural applications over the last decades. Literature review confirmed that very few research studies have been conducted to study flexural and shear behavior of LWSCC beams to date. This warrants investigations on the evaluation of the structural performance of LWSCC based structural elements and to evaluate existing design guidelines for practical design. Current study on the shear and flexure performance of LWSCC beams made of slag aggregate will contribute to the existing technology. 


\section{CHAPTER THREE}

\section{EXPERIMENTAL PROGRAM}

\subsection{Introduction}

An experimental research had been conducted to study the shear and flexural behavior of lightweight self-consolidating concrete (LWSCC) beams made with slag aggregate. Nine shear beams (six without shear reinforcement and three with shear reinforcement) and three flexural beams (two singly reinforced and one doubly reinforced) were tested under four point static loading to failure. Two types of concrete were used to cast the six shear beams without shear reinforcement (three with normal weight self-consolidating concrete 'SCC' and three with LWSCC). SCC beams were tested as a control specimens to compare the structural performance compared with their LWSCC counterparts.

\subsection{Beam geometry and reinforcement configuration}

\subsubsection{Shear beams}

The experimental program was designed to evaluate shear behavior of LWSCC beams and estimate concrete contribution to overall shear resistance $\left(\mathrm{V}_{\mathrm{c}}\right)$. Total of nine shear beams with and without shear reinforcement were cast and tested. First three LWSCC beams were designed only for adequate flexural reinforcements without shear reinforcement as shown in Figures 3.1 and 3.2. Second three LWSCC beams were designed with the same amount of flexural reinforcement as in the first set of beams in addition to the stirrups provided at $133 \mathrm{~mm}$ spacing (center to center) as indicated in Figures 3.3 and 3.4. Third set of three SCC beams were similar to the first set of LWSCC beams and served as control specimens.

First Three LWSCC beams had different height (H) of 150, 200, and $300 \mathrm{~mm}$ while the width (b) was kept constant at $100 \mathrm{~mm}$. Second three beams had a height of 156, 206 and $306 \mathrm{~mm}$ and the width of the beam was same as the first three beams. Geometric dimensions and reinforcement details of the experimental beams are summarized in Table 3.1. The total length of all the beams was at $1100 \mathrm{~mm}$ with an effective span of $800 \mathrm{~mm}$. The shear span (a) to effective depth (d) ratio was kept between 1.05 and 2.14 to ensure the shear failure. Beams with the shear reinforcements 
were provided with 2, \#6 $\mathrm{mm}$ diameter hanger bars at the top to support $6 \mathrm{~mm}$ dia stirrups (plain steel bar) provided at $133 \mathrm{~mm} \mathrm{c} / \mathrm{c}$ as shown Figure 3.4. Flexural reinforcements were provided with $10 \mathrm{~mm}$ dia deformed steel bars. Flexural reinforcement ratio varied from $1.15 \%$ to $1.6 \%$.

Table 3.1-Shear beams geometry and reinforcement configuration

\begin{tabular}{|c|c|c|c|c|c|}
\hline Beam code & $\begin{array}{l}\text { Effective } \\
\text { depth } \\
\text { (d) } \mathrm{mm}\end{array}$ & $\begin{array}{c}\text { Total } \\
\text { height/depth } \\
\text { (H) } \mathrm{mm}\end{array}$ & $\begin{array}{l}\text { Shear span } \\
\text { (a) to } \\
\text { depth (d) } \\
\text { ratio } \\
\text { a/d }\end{array}$ & $\begin{array}{c}\text { Flexural } \\
\text { reinforcement } \\
\text { ratio, } \rho \\
\left(=100 \mathrm{~A}_{\mathrm{s}} / \mathrm{bd}\right)^{*} \\
\%\end{array}$ & $\begin{array}{c}\text { Shear } \\
\text { reinforcement } \\
\text { spacing } \\
\text { mm }\end{array}$ \\
\hline \multicolumn{6}{|c|}{ width $(b)=100 \mathrm{~mm}$, effective span $(S)=800 \mathrm{~mm}$ and length $=1100 \mathrm{~mm}$} \\
\hline \multicolumn{6}{|c|}{ Beams without shear reinforcement } \\
\hline LWSCC-150 & 124 & 150 & 2.14 & 1.6 & - \\
\hline LWSCC-200 & 174 & 200 & 1.53 & 1.15 & - \\
\hline LWSCC-300 & 253 & 300 & 1.05 & 1.57 & - \\
\hline SCC-150 & 124 & 150 & 2.14 & 1.6 & - \\
\hline SCC-200 & 174 & 200 & 1.53 & 1.15 & - \\
\hline SCC-300 & 253 & 300 & 1.05 & 1.57 & - \\
\hline \multicolumn{6}{|c|}{ Beams with shear reinforcement } \\
\hline LWSCC-156S & 124 & 156 & 2.14 & 1.6 & 133 \\
\hline LWSCC-206S & 174 & 206 & 1.53 & 1.57 & 133 \\
\hline LWSCC-306S & 253 & 306 & 1.05 & 1.6 & 133 \\
\hline
\end{tabular}

The beam code was denoted by concrete type, total beam depth/height and addition of letter of "S" at the end to indicate the shear reinforcement presence. For example, LWSCC beam having a total depth/height of $156 \mathrm{~mm}$ with shear reinforcement is coded as: LWSCC-156s 


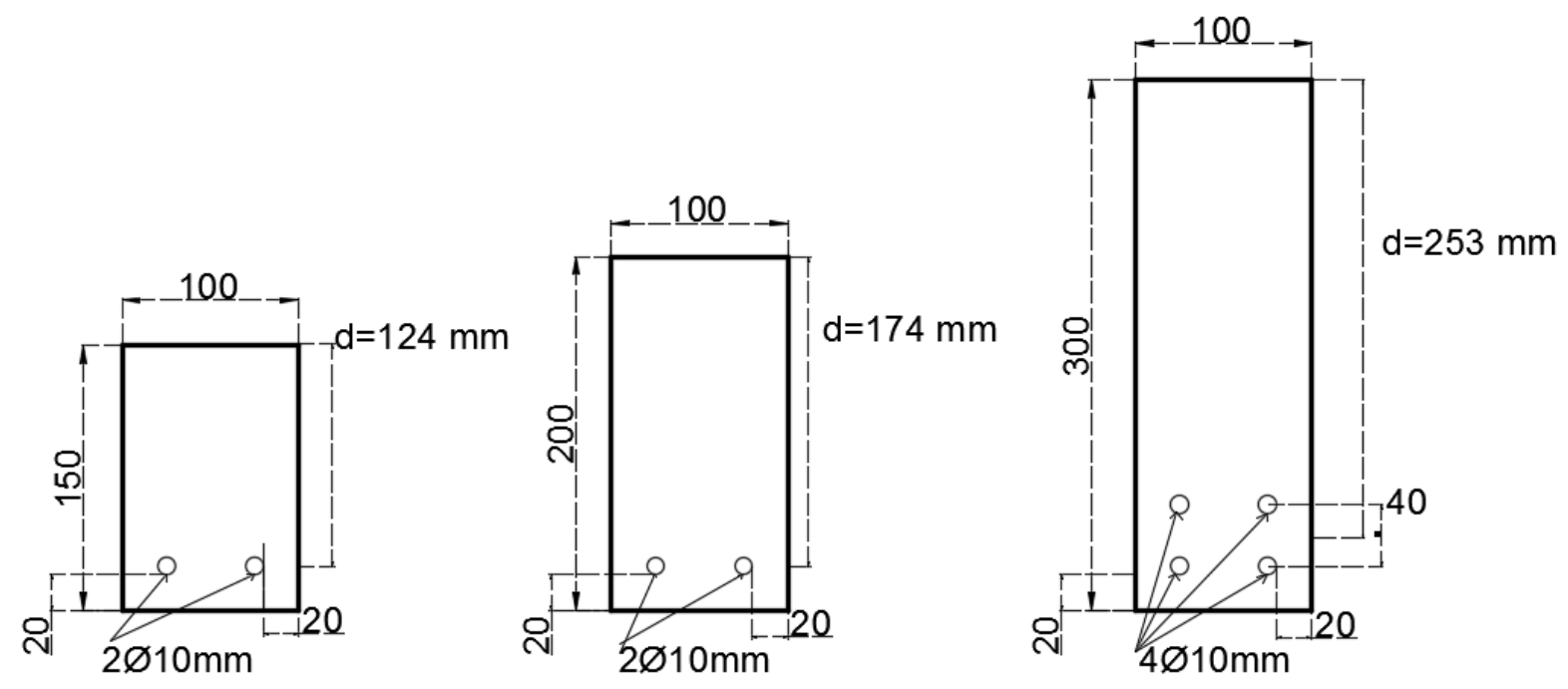

Figure 3.1- Shear beam cross-sections without shear reinforcement (dimensions in mm)

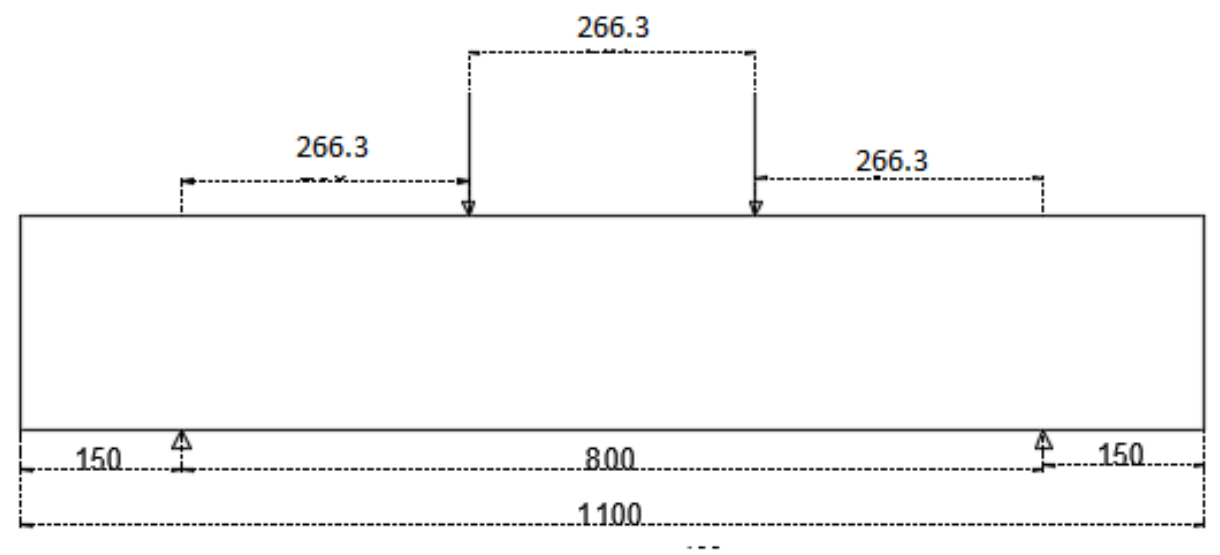

Figure 3.2-Shear beams without shear reinforcement showing four point loading (dimensions in $\mathrm{mm}$ ) 

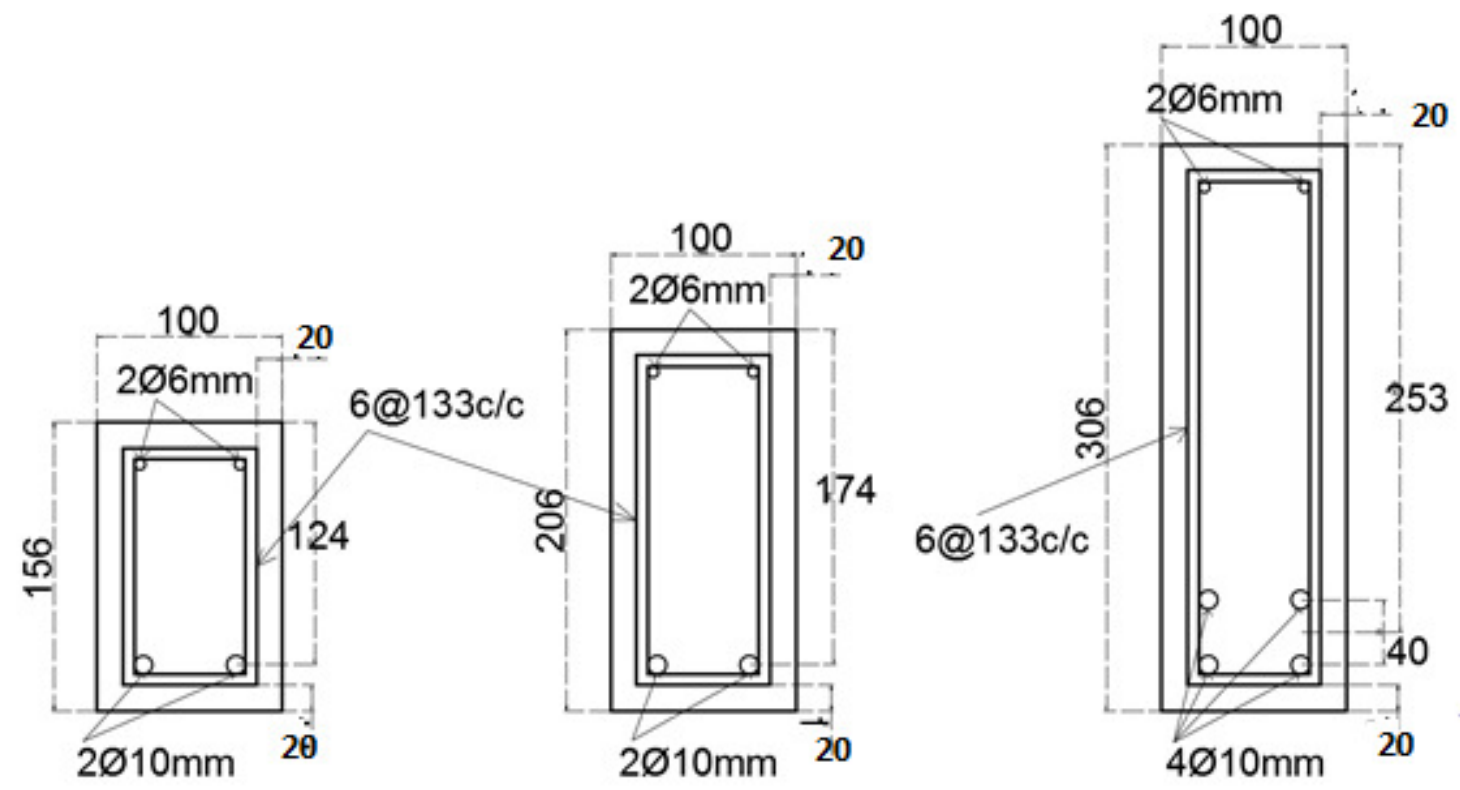

Figure 3.3- Shear beams cross section with shear reinforcement (dimensions in $\mathrm{mm}$ )

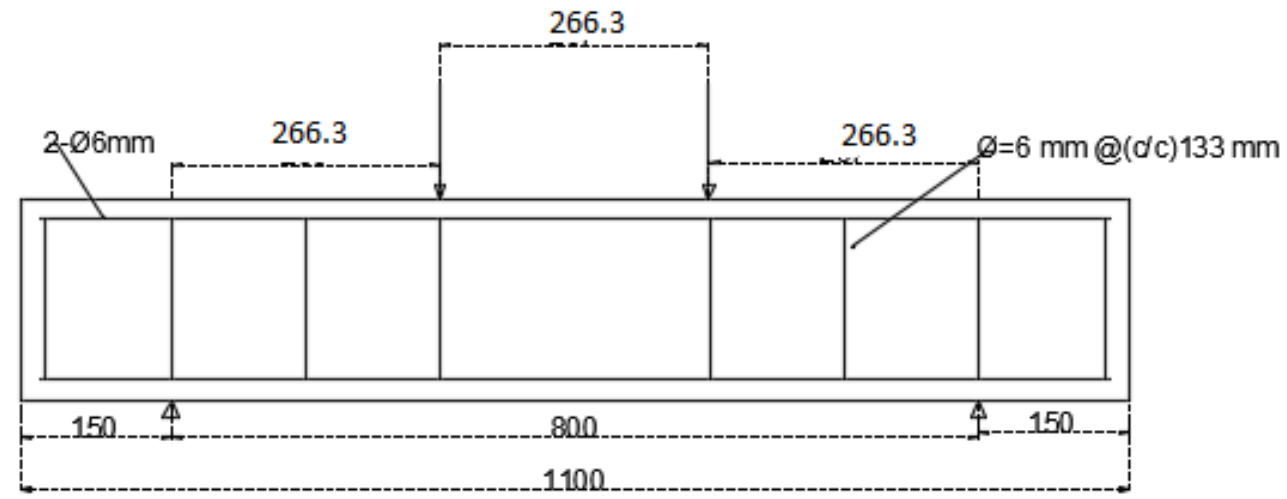

Figure 3.4-Shear beams with shear reinforcement showing four point loading (dimensions in $\mathrm{mm})$

\subsubsection{Flexural beams}

The experimental program was designed to evaluate flexural behavior of LWSCC beams and estimate ultimate flexural capacity. A total of 3 flexural beams with adequate shear reinforcement were casted and tested. All beams were designed as under-reinforced and first two flexural beams were singly reinforced beams and third beam was doubly reinforced and they were denoted as F1s, F2s and F3d, respectively. 'F', 's' and 'd' in beam code represent flexure beam, singly reinforced and double reinforced, respectively. The width and effective depth of the beams were maintained at $150 \mathrm{~mm}$ and $200 \mathrm{~mm}$ for all beams while shear span to effective depth ratio was kept at 5.75 to 
make the beams fail in flexure. Three flexural reinforcement configurations were used, $0.66 \%$, $1.0 \%$ and $1.7 \%$. All beams had a clear cover of $20 \mathrm{~mm} .6 \mathrm{~mm}$ plain steel bars @ $60 \mathrm{~mm}$ c/c were as shear reinforcement. Flexural beam cross-sections and reinforcement configurations are shown in Figures 3.5 and 3.6 and Table 3.2.

Table 3.2 - Flexural beams geometry and reinforcement configuration

\begin{tabular}{|c|c|c|c|c|c|c|}
\hline $\begin{array}{l}\text { Beam } \\
\text { code }\end{array}$ & $\begin{array}{l}\text { Beam } \\
\text { type }\end{array}$ & $\begin{array}{c}\text { Beam } \\
\text { depth } \\
\mathrm{mm}\end{array}$ & $\begin{array}{c}\text { Effective } \\
\text { depth } \\
\text { mm }\end{array}$ & $\begin{array}{c}\text { Bottom } \\
\text { flexural } \\
\text { reinforcement }\end{array}$ & $\begin{array}{l}\text { Compression flexural } \\
\text { reinforcement }\end{array}$ & $\begin{array}{c}\text { Flexural } \\
\text { reinforcement } \\
\text { ratio } \%\end{array}$ \\
\hline \multicolumn{7}{|c|}{ Width:150mm, Length: 3300mm, Span: $3000 \mathrm{~mm}$} \\
\hline F1s & Singly & 231 & 200 & 2, \# 10mm & $2, \# 6 \mathrm{~mm}$ & 0.66 \\
\hline F2s & Singly & 231 & 200 & 3, \# 10mm & $2, \# 6 \mathrm{~mm}$ & 1.00 \\
\hline F3d & Doubly & 233 & 200 & $3, \# 15 \mathrm{~mm}$ & $2, \# 10 \mathrm{~mm}$ & 1.70 \\
\hline
\end{tabular}
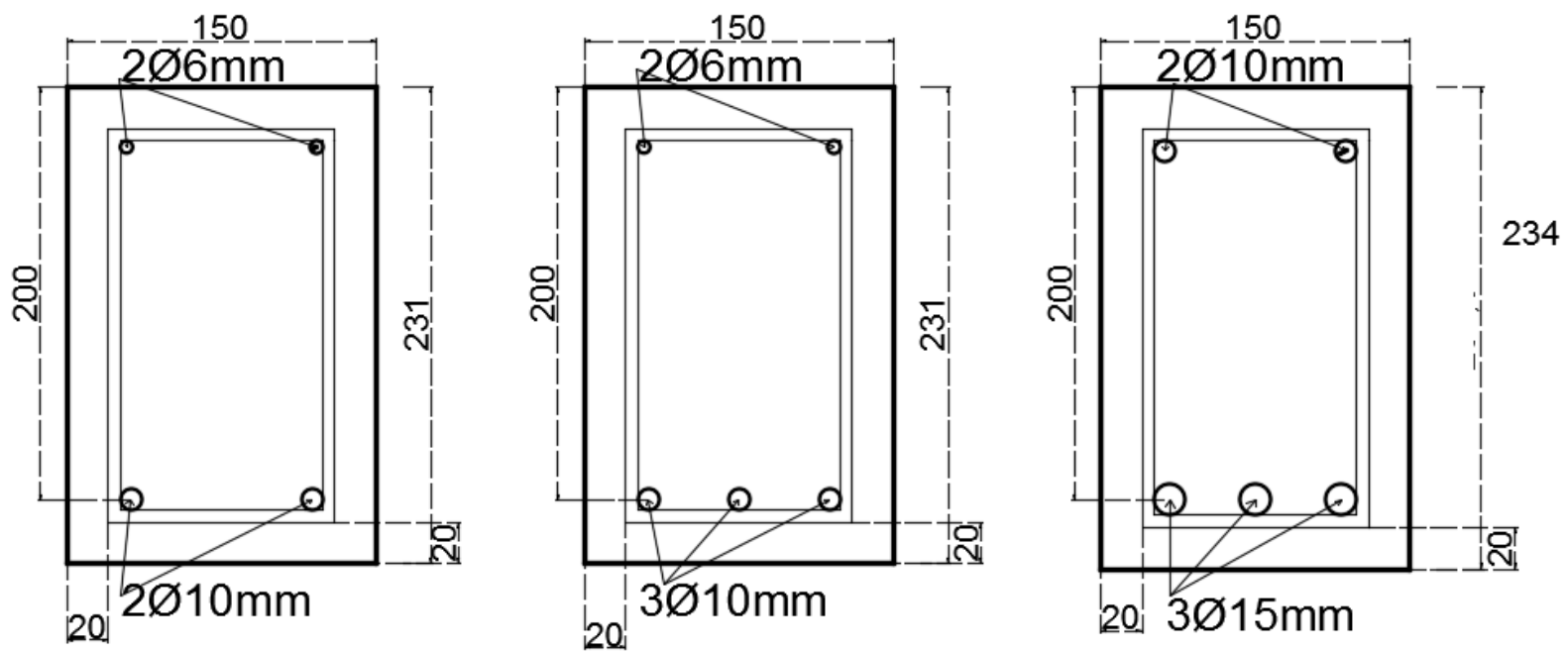

Figure 3.5- Flexural beam cross sections (dimensions in $\mathrm{mm}$ ) 


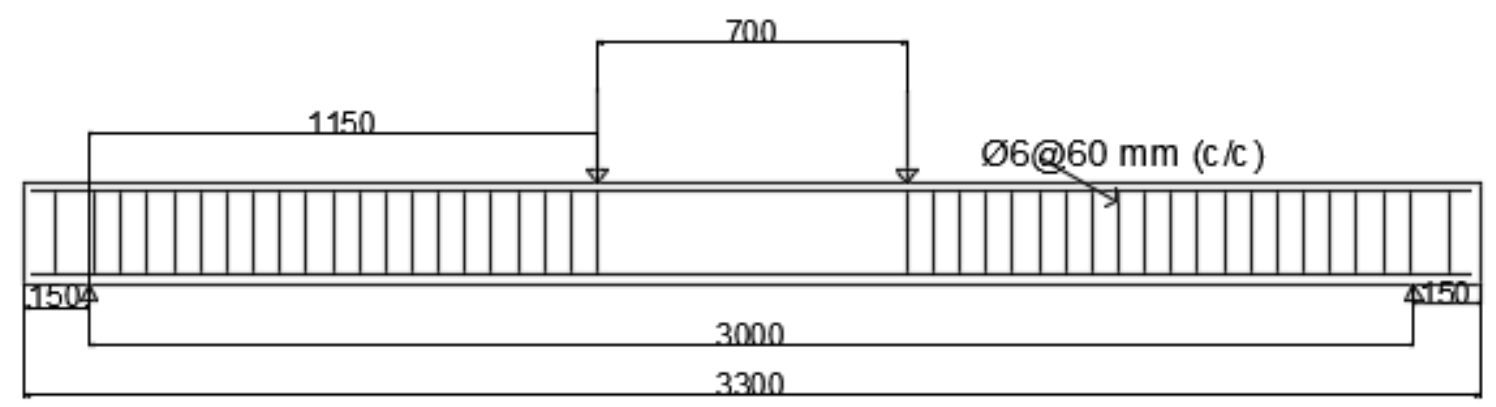

Figure 3.6 - Flexural beams showing four point loading (dimensions in mm)

\subsection{Materials}

\subsubsection{Concrete materials and properties}

Two types of concretes such as LWSCC and SCC were used in this study. Mix designs of LWSCC and SCC are presented in Table 3.3. CSA Type 10 or the ASTM Type 1 normal Portland cement with specific gravity of 3.17 was used. Class F fly ash according to CSA classification with a calcium oxide $(\mathrm{CaO})$ content of less than $8 \%$, a typical bulk density value of $540 \sim 860 \mathrm{~kg} / \mathrm{m}^{3}$ and specific gravity of 2.6 was used. A dry-densified silica fume (SF) powder was used to develop a sticky but flowable mixture to enhance segregation resistance. Table 3.4 indicates the physical, chemical properties of the cement, fly ash and silica fume used in this research.

Table 3.3 - Mixture proportions

\begin{tabular}{|l|l|l|l|}
\hline Material & LWSCC & Material & SCC \\
\hline Type 10 Cement $\left(\mathrm{kg} / \mathrm{m}^{3}\right)$ & 424 & Type 10 Cement $\left(\mathrm{kg} / \mathrm{m}^{3}\right)$ & 455 \\
\hline Fly ash $\left(\mathrm{kg} / \mathrm{m}^{3}\right)$ & 66.25 & Crushed gravels -Coarse aggregate $\left(\mathrm{kg} / \mathrm{m}^{3}\right)$ & 722 \\
\hline Silica fume $\left(\mathrm{kg} / \mathrm{m}^{3}\right)$ & 39.75 & Sand - Fine aggregate $\left(\mathrm{kg} / \mathrm{m}^{3}\right)$ & 1052 \\
\hline HRWRA $\left(1 / \mathrm{m}^{3}\right)$ & 4.75 & Water & 185.1 \\
\hline Water $\left(1 / \mathrm{m}^{3}\right)$ & 185.5 & HRWRA & $0.63 \%$ \\
\cline { 1 - 2 } Slag coarse aggregate $\left(\mathrm{kg} / \mathrm{m}^{3}\right)$ & 500 & & \\
\cline { 1 - 2 } Slag fine aggregate $\left(\mathrm{kg} / \mathrm{m}^{3}\right)$ & 707 & \multicolumn{2}{|l}{} \\
\cline { 1 - 3 } & \multicolumn{2}{|l}{} & \multicolumn{2}{|l}{}
\end{tabular}


Table 3.4- Chemical and physical properties of cementing material

\begin{tabular}{|c|c|c|c|}
\hline Chemical composition & Cement & Fly Ash & Silica Fume \\
\hline $\mathrm{SiO}_{2}(\%)$ & 19.6 & 46.7 & 95.21 \\
\hline $\mathrm{Al}_{2} \mathrm{O}_{3}(\%)$ & 4.9 & 22.8 & 0.21 \\
\hline $\mathrm{Fe}_{2} \mathrm{O}_{3}(\%)$ & 3.1 & 15.5 & 0.13 \\
\hline $\mathrm{CaO}(\%)$ & 61.4 & 5.8 & 0.23 \\
\hline $\mathrm{MgO}(\%)$ & 3.0 & - & - \\
\hline $\mathrm{SO}_{3}(\%)$ & 3.6 & 0.5 & 0.33 \\
\hline Alkalis as $\mathrm{Na}_{2} \mathrm{O}(\%)$ & 0.7 & 0.7 & 0.85 \\
\hline
\end{tabular}

Lightweight blast furnace slag aggregates were used to develop the LWSCC mixtures. The slag aggregates having nominal size of $10 \mathrm{~mm}$ and $4.75 \mathrm{~mm}$ were used as coarse and fine aggregates as shown in Figure 3.7. Table 3.5 indicates specifications for coarse and fine lightweight aggregates gradations according to ASTM C330 (2009). It also indicates the gradation and physical properties of fine and coarse lightweight furnace slag aggregate. Normal weight crushed gravel with a nominal size of $10 \mathrm{~mm}$ and sand were used as coarse and fine aggregate, respectively for SCC.

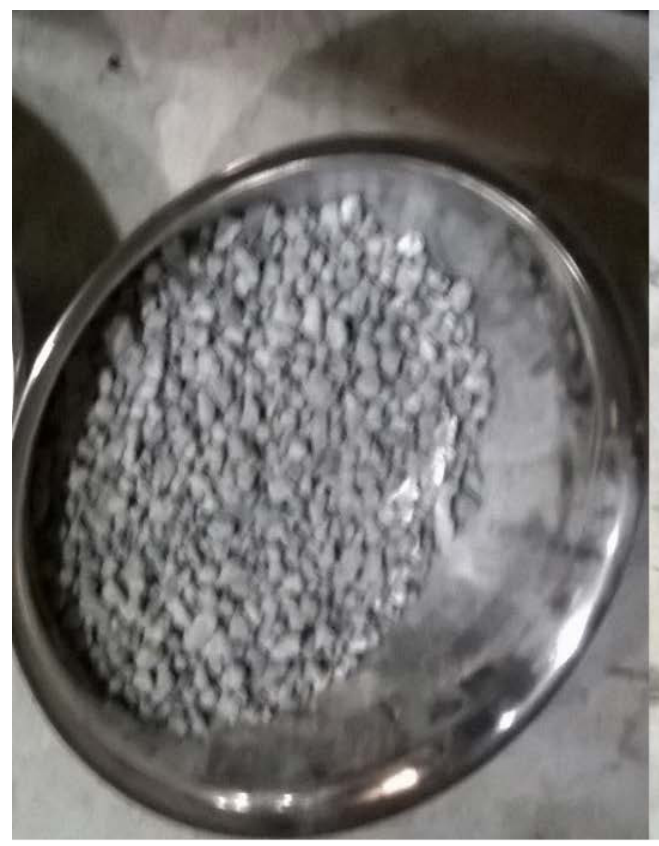

Coarse aggregate

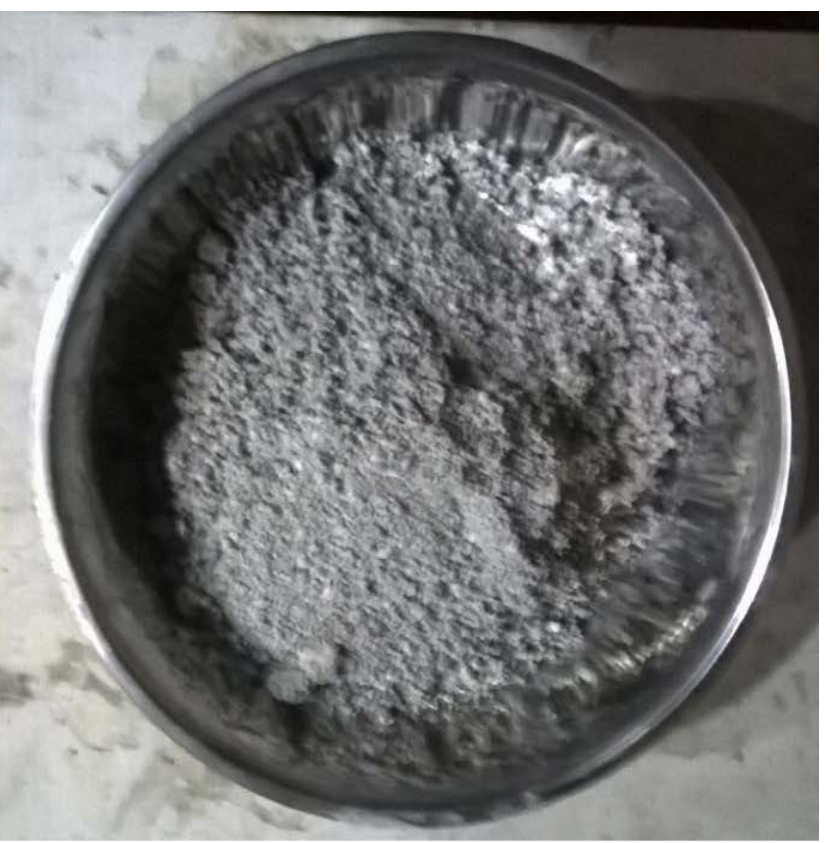

Fine aggregate

Figure 3.7- Blast furnace slag aggregate 
Table 3.5- Lightweight slag aggregate gradation

\begin{tabular}{|l|c|c|c|c|}
\hline \multirow{2}{*}{$\begin{array}{l}\text { Sieve Size } \\
(\mathrm{mm})\end{array}$} & \multicolumn{4}{|c|}{ Passing (\%) } \\
\cline { 2 - 5 } & ASTM- C330 Specifications & \multicolumn{2}{c|}{ Slag aggregate } \\
\cline { 2 - 5 } & Fine & Coarse & Fine & Coarse \\
\hline 13.2 & 100 & 100 & 100 & 100 \\
\hline 9.5 & $80-100$ & 100 & 100 & 90.3 \\
\hline 4.75 & $5-40$ & $85-100$ & 100 & 23.2 \\
\hline 2.36 & $0-20$ & - & 81.2 & 10.2 \\
\hline 1.18 & $0-10$ & $40-80$ & 49 & - \\
\hline 0.6 & - & - & 26.5 & - \\
\hline 0.3 & - & $10-35$ & 15.3 & - \\
\hline 0.15 & - & $5-25$ & 9.5 & - \\
\hline Bulk Specific gravity (dry) & - & - & 2.17 & 1.61 \\
\hline Bulk Specific gravity (SSD) & - & - & 2.2 & 1.75 \\
\hline $\begin{array}{l}\text { Dry loose bulk density } \\
\left(\text { kg/m }{ }^{3}\right)\end{array}$ & $1120(\max )$ & $880(\max )$ & 1356 & 950 \\
\hline Absorptions (\%) & & & & \\
\hline
\end{tabular}

During the preparation of LWSCC, coarse and fine slag aggregates were pre-soaked for a minimum of 72 hours as indicated in the Figure 3.8 due to higher water absorption. Excess water in the aggregate was drained out without losing the fine particles as shown in Figure 3.9. Saturated surface dry aggregate was used for the mixing and proper water adjustment was made according to the water absorption of the aggregate and the moisture content of the aggregate at the time of mixing.

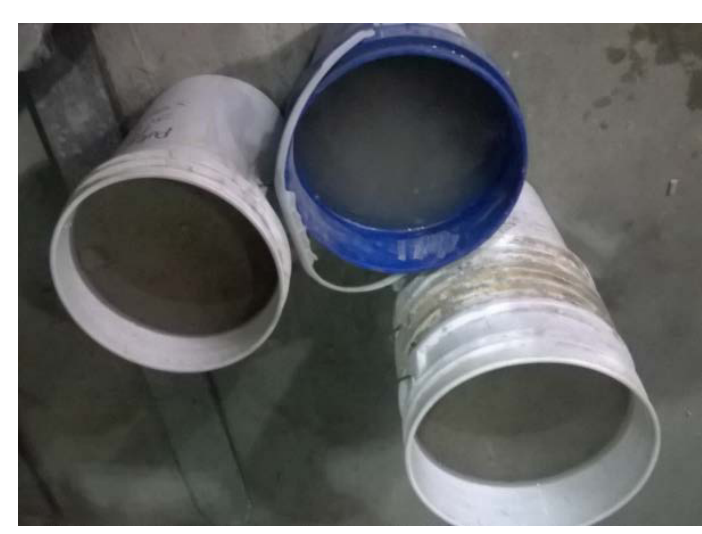

Figure 3.8-Slag aggregates -72 hours pre-soaking
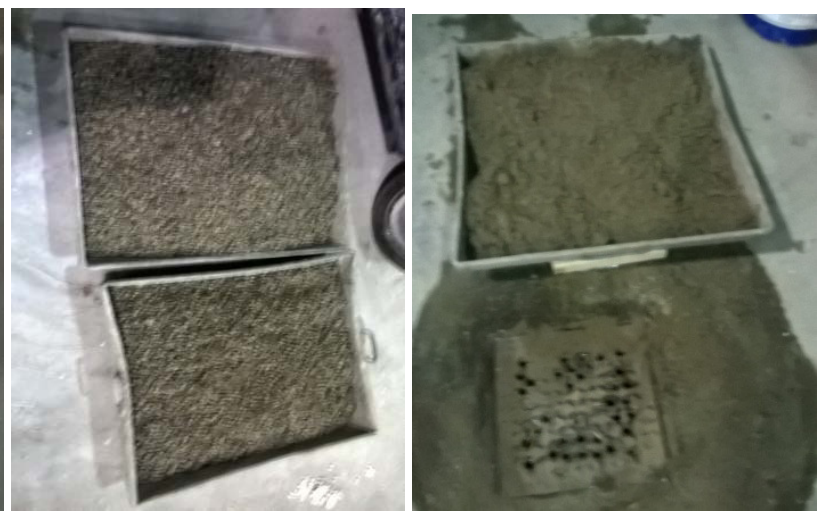

Figure 3.9- Slag aggregate drain-off 
A polycarboxylate based high range water reducing admixtures (HRWRA) satisfying ASTM C494 provisional compliance requirements for Type A water reducing and Type $\mathrm{F}$ high range water reducing admixtures was used in the LWSCC and SCC mixtures.

\subsubsection{Reinforcement properties}

Coupon tension tests were performed to determine the yield strength of the rebar used in the beam specimens. Stress-strain responses of the rebars are presented in Figure 3.10. Yield strength and strain of the rebars are summarized in Table 3.6
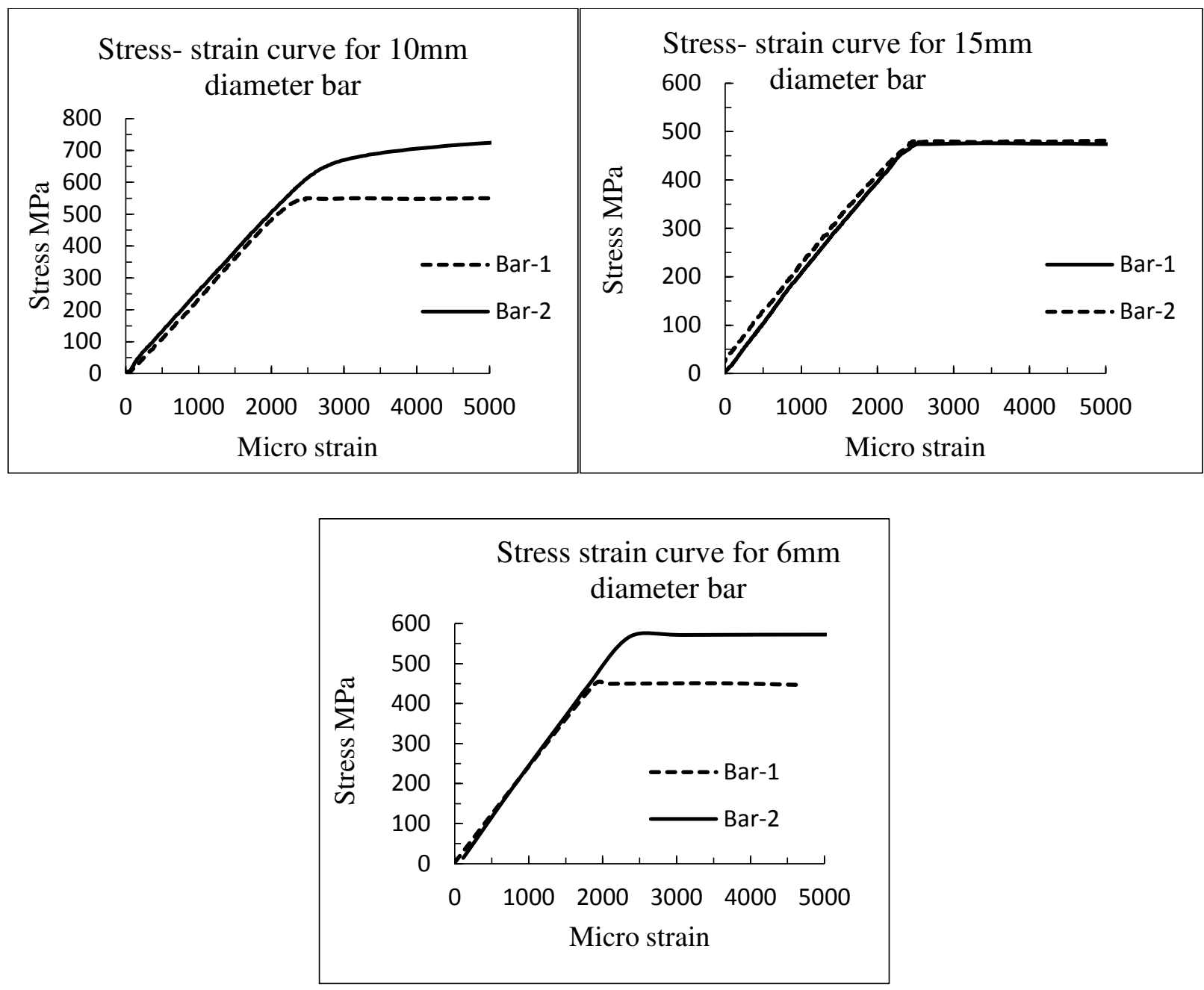

Figure 3.10 - Stress-strain response of reinforcement bars 
Table 3.6 -Rebar stress-strain response table

\begin{tabular}{|l|l|l|l|l|l|l|}
\hline \multirow{2}{*}{$\begin{array}{l}\text { Rebar } \\
\text { diameter }\end{array}$} & \multicolumn{3}{|l|}{ Yield stress (MPa) } & \multicolumn{3}{c|}{ Yield micro-strain } \\
\cline { 2 - 7 } & Bar-1 & Bar-2 & Average & Bar-1 & Bar-2 & Average \\
\hline $6 \mathrm{~mm}$ & 450 & 448 & 449 & 1895 & 1892 & 1893 \\
\hline $10 \mathrm{~mm}$ & 532 & 628 & 567 & 2330 & 2380 & 2355 \\
\hline $15 \mathrm{~mm}$ & 472 & 480 & 476 & 2270 & 2270 & 2270 \\
\hline
\end{tabular}

\subsection{Beam fabrication, casting and curing}

Three wooden moulds were prepared to accommodate three shear beams of all different height as indicated in the Figure 3.11(a). Specimens with a height of $300 \mathrm{~mm}$ and $306 \mathrm{~mm}$ required more than one layer of steel bar in such case; a spacing of $30 \mathrm{~mm}$ was kept between the layers. For specimens with shear reinforcement, rebars were ground smooth to facilitate the fixing of strain gauges at left and right side of the stirrups near the support as well as at the mid-span of the flexural reinforcing bar (tension rebar).

Immediately after the LWSCC/SCC mixing, beam specimens were cast in wooden molds without any vibration and segregation. Total volume of 100 liter of concrete (one batch) was necessary to cast the three shear beams. Total of two batches of LWSCC and one batch of SCC were required to cast the shear beams without and with shear reinforcement. Visual observation LWSCC properly filled the forms with ease of movement and same was the case for normal weight SCC.

One wooden mould was prepared to cast the flexural beams. Flexural beam reinforcements (both shear and flexural) were ground smooth to facilitate the fixing of strain gauges. Total volume of 160 liters (one batch) of concrete was enough to cast the one flexural beam. Therefore, 3 batches of LWSCC were prepared to cast the 3 flexural beams. Figures 3.11(b-c) shows beam moulds with reinforcement casing, casting of beams showing concrete pouring and the cast beams in the mould. Beam moulds were removed after 24 hours of casting and the beams were moisture cured for five days as shown in Figure 3.12 and then air cured until 28 days of testing as shown in Figure 3.13.

Control specimens in the form cylinders and beams were also cast to determine strength of concrete and cured under similar conditions as beam specimens until testing. The compressive strength of LWSCC and SCC were determined from 100 x $200 \mathrm{~mm}$ control cylinders for each batch according to ASTM C39 (2003). Flexural strength of the LWSCC at 28 days was determined from beam four 
point bending test as per ASTM C78 (2010). Total length, height and width of the flexural beam specimens were $304.8,76.0$, and $50.0 \mathrm{~mm}$, respectively. Table 3.7 shows the density, compressive strength and flexural strength of the concretes at the age of testing (28 days) - mean value of at least three specimens are reported.

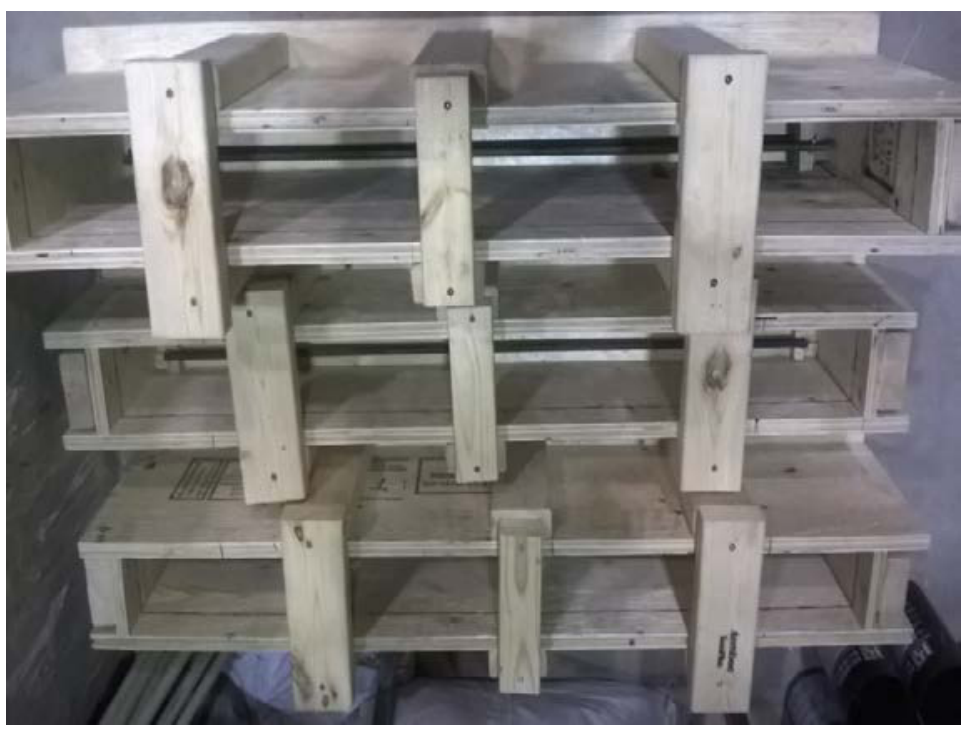

Figure 3.11(a) - Mould or formwork showing reinforcement casing

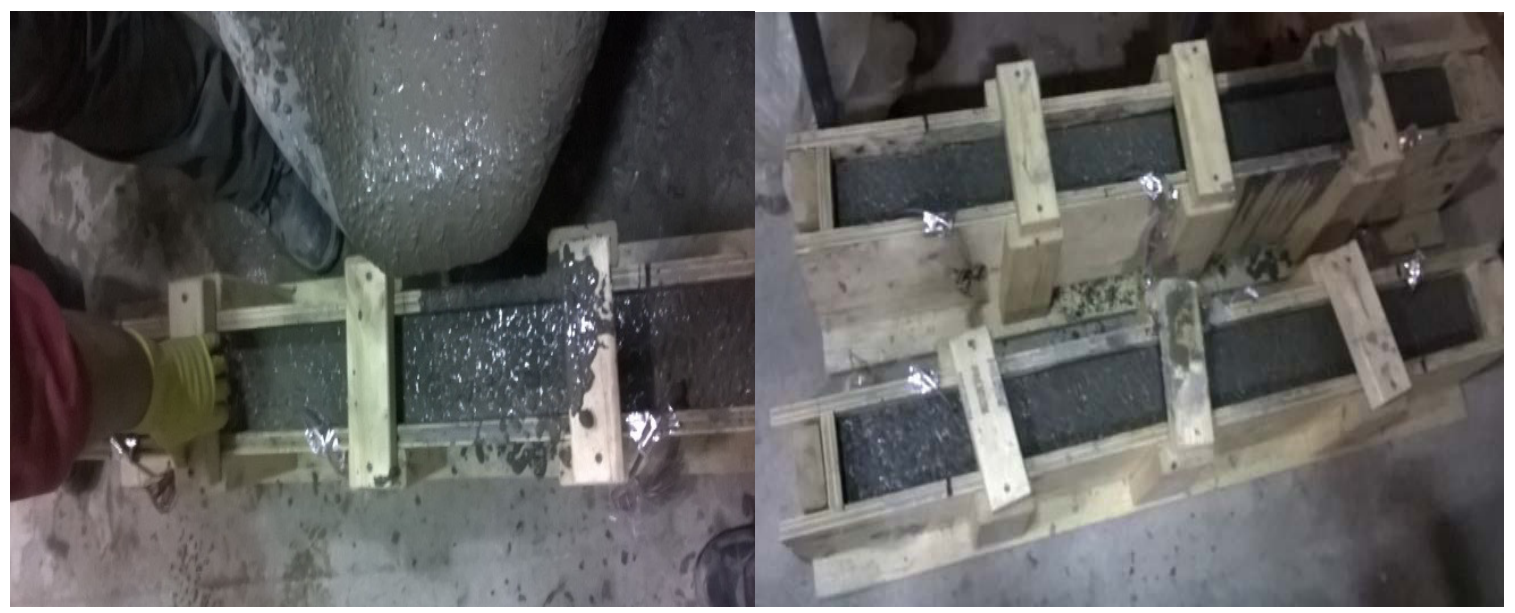

Figure 3.11(b) - Beam casting showing concrete pouring and casted beams 

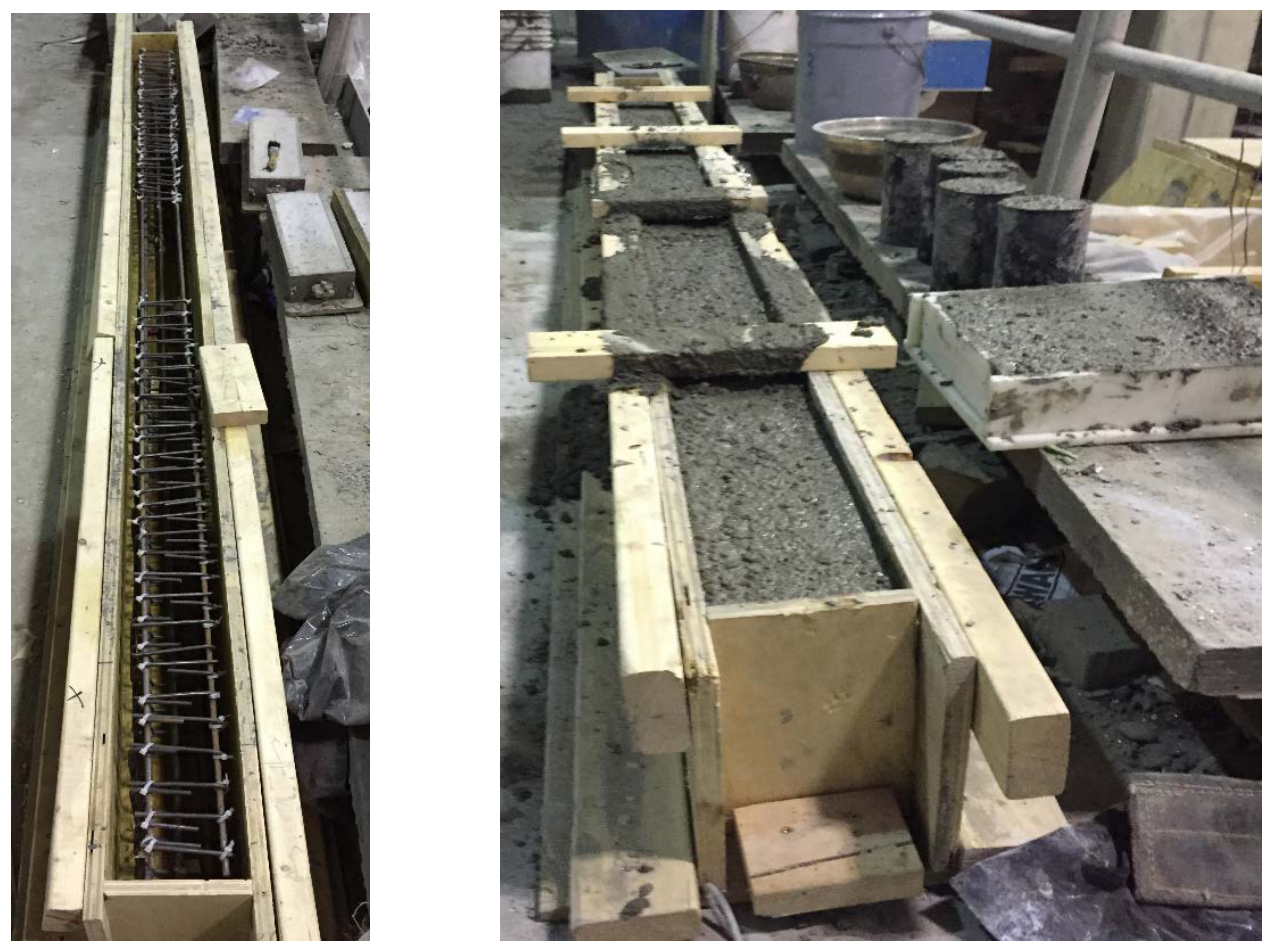

Figure 3.11 (c) - Beam formwork and casted beam

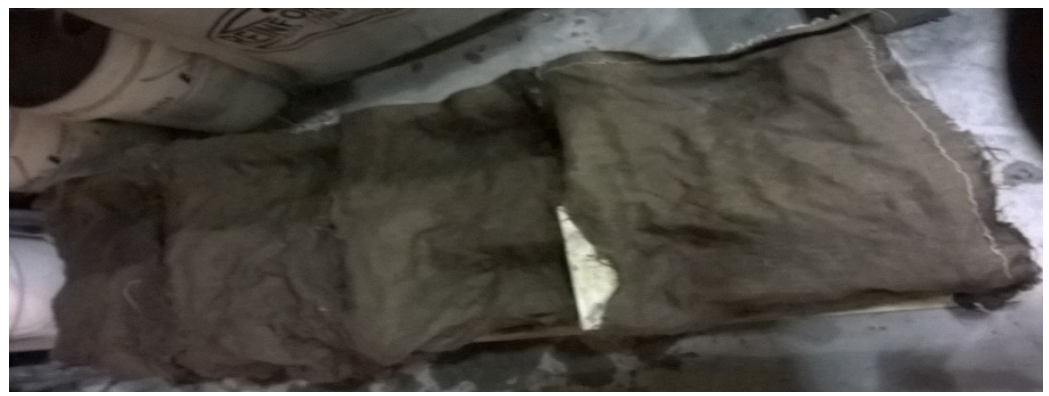

Figure 3.12- Moist curing of beams and control specimens
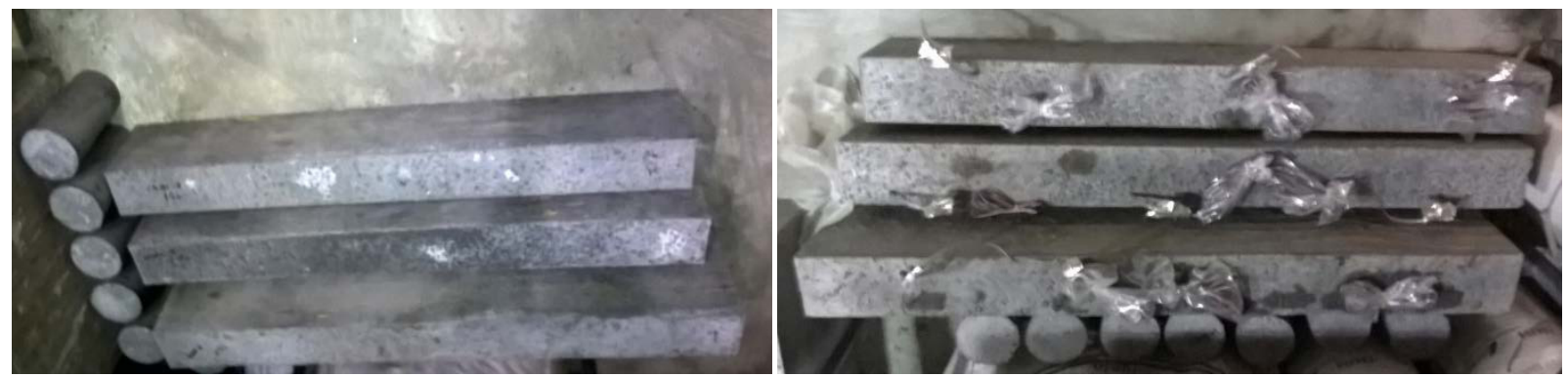

Figure 3.13- Air curing of beams and control specimens 
Table 3.7- Concrete compressive strength, flexural strength and density at 28 days.

\begin{tabular}{|c|c|c|c|}
\hline Concrete batch & $\begin{array}{c}\text { Mean } \\
\text { compressive } \\
\text { strength } \\
(\mathrm{MPa})\end{array}$ & $\begin{array}{c}\text { Mean } \\
\text { flexural } \\
\text { strength } \\
(\mathrm{MPa})\end{array}$ & $\begin{array}{c}\text { Mean air dry } \\
\text { density } \\
\left(\mathrm{kg} / \mathrm{m}^{3}\right)\end{array}$ \\
\hline LWSCC Shear beams without stirrups & 33.5 & 3.1 & 1790 \\
\hline SCC beams without stirrups & 53.0 & 3.8 & 2350 \\
\hline LWSCC shear beams with stirrups & 36.0 & 3.2 & 1810 \\
\hline LWSCC-flexural beam F1s & 40.5 & 3.3 & 1806 \\
\hline LWSCC-flexural beam F2s & 41.0 & 3.6 & 1815 \\
\hline LWSCC-flexural beam F3d & 42.5 & 3.8 & 1818 \\
\hline
\end{tabular}

\subsection{Experimental set up and instrumentation}

All specimens were tested as simply supported beam under four-point loading condition. Experimental set-up for shear beam beams without and with shear reinforcement is shown in Figure 3.14. LVDT (Linear variable displacement transducer) was fixed at mid span to measure the central deflection. Figure 3.15 shows the location of steel strain gauges that were attached to measure strain in the flexural and shear reinforcement.

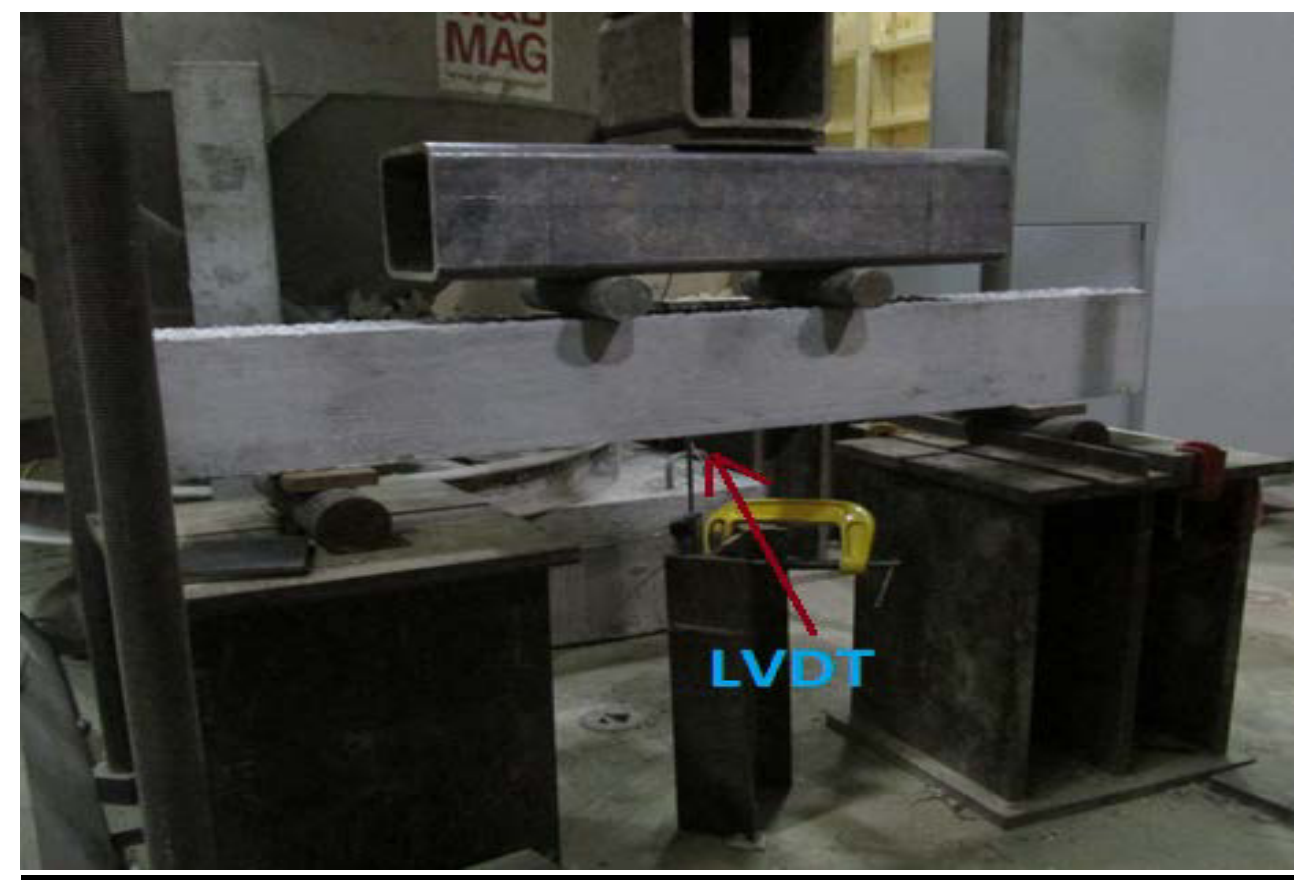

Figure 3.14 -Shear beam experimental set-up and instrumentation 


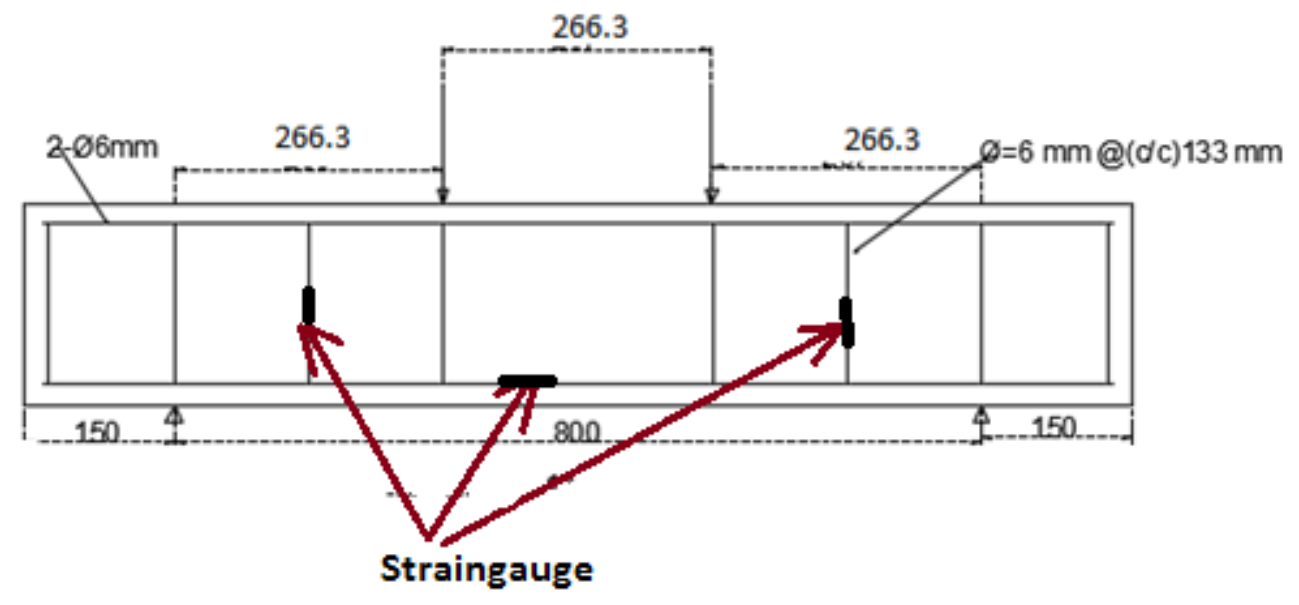

Figure 3.15- Strain gauge locations for shear beams

Flexural specimen Experimental set-up for flexural beams tested under four point loading is shown in Figure 3.16. Three LVDTs (Linear variable displacement transducer) were fixed at mid span and $750 \mathrm{~mm}$ from the left and right support to measure the deflection. An inclinometer was fixed near the support to measure the rotation angle. A strain gauge was installed at mid span on concrete top surface to measure the concrete compressive strain as shown in Figure 3.16. Strain gauges were also installed on the shear and flexural reinforcement at strategic location as shown in Figure 3.17 to monitor strain development.

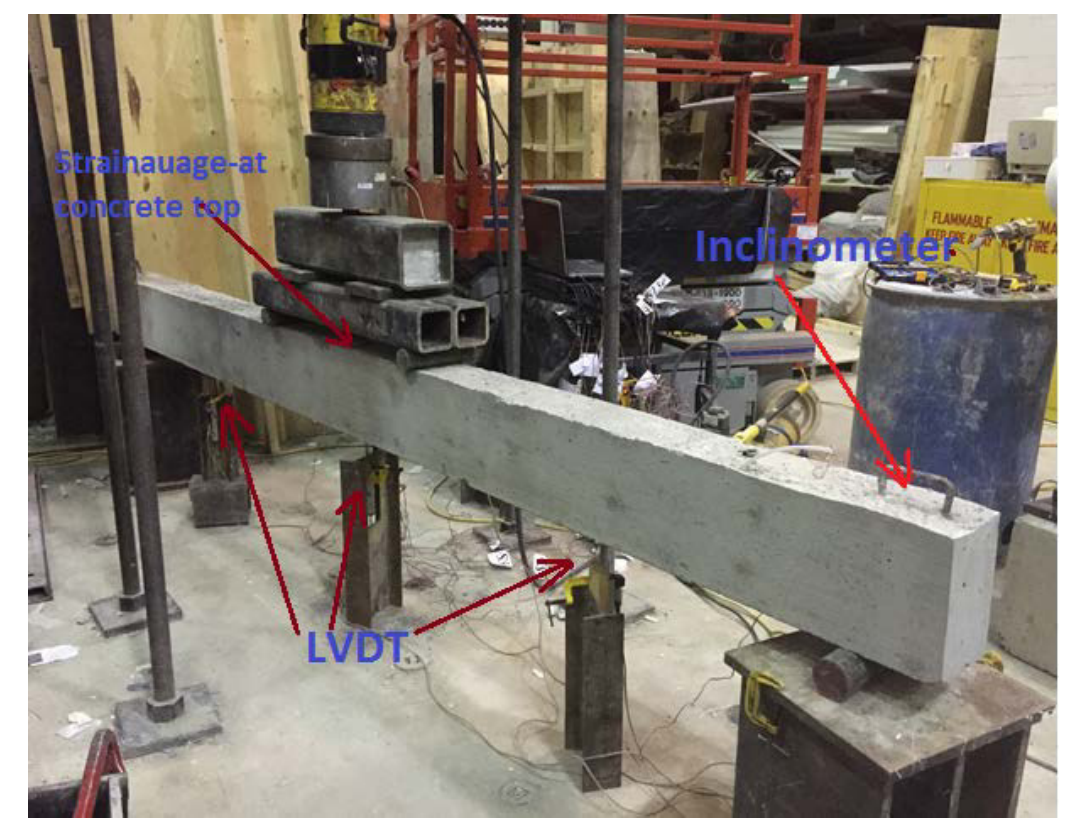

Figure 3.16 - Experimental set-up and instrumentation for flexural beams 


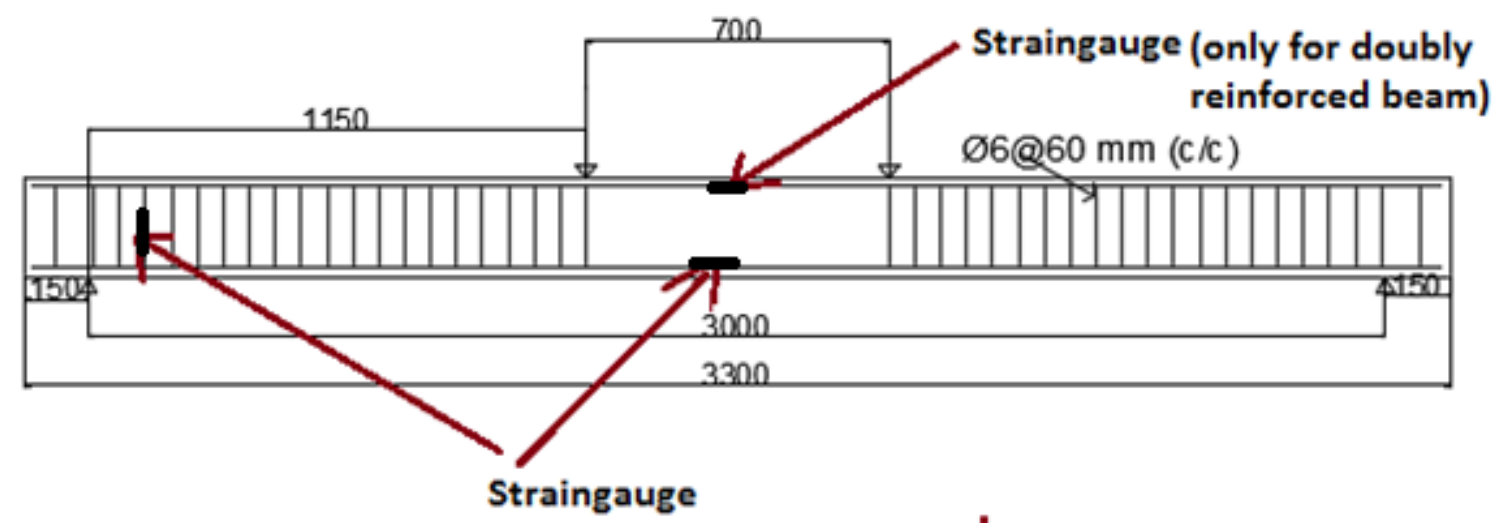

Figure 3.17- Strain gauge locations in flexural beams

A hydraulic jack was used to apply the load incrementally with $5 \mathrm{kN}$ for each increment and the load was kept constant for some minutes after each increment to observe the crack pattern. All strain gauges, load and LVDT were connected to a computer control data acquisition systems. The initiation and development of shear and flexural cracks and cracking loads at various stages were recorded during the test. During testing to failure, load-deformation response and strain development in steel/concrete were recorded. Test also provided information on the overall behavior of the beam including development of crack, crack patterns, load transfer mechanism and failure modes.

\subsection{Summary}

Experimental research program is descried by illustrating beam specimen preparation (fabrication and casting), material properties, specimen instrumentation and test procedure. A total of 9 shear beams and 3 flexural beams were tested to failure. The test results will be presented and described in Chapter Four. 


\section{CHAPTER FOUR}

\section{EXPERIMENTAL RESULTS AND DISCUSSION}

\subsection{Introduction}

This Chapter presents the results of the experimental investigation on shear and flexural behavior of lightweight self-consolidating concrete (SCC) beams. The performance is described based on load-deflection response, first diagonal crack load, strain development, moment-end rotation response, energy absorption, ductility index, crack formation and propagation and failure modes. Comparison between LWSCC beams and normal weight self-consolidating concrete (SCC) beams with especial reference to post--cracking shear transfer mechanism is also presented.

\subsection{LWSCC and SCC shear beams without shear reinforcement}

Experimental tests had been carried out to study the shear behavior of the LWSCC and SCC beams. Six shear beams without shear reinforcement were tested under four point loading to failure. LWSCC and SCC were used to cast six beams with three different cross-sections. Shear span to effective depth ratios (a/d) were 1.05, 1.53 and 2.14 for beams with the height/total depth $(\mathrm{H})$ of 150, 200,300 mm, respectively. Adequate flexural reinforcement was provided with the reinforcement ratio of $1.6 \%, 1.15 \%$ and $1.57 \%$. However, no shear reinforcement was provided in these beams.

\subsubsection{Load deflection behavior}

Experimental load deflection curves for the tested SCC/LWSCC shear beams without shear reinforcement are shown in Figure 4.1(a-b). The slope changes of the curve indicates a reduction in the stiffness of the beam. The initial straight line segment of the curve shows that prior to flexural cracking, stiffness of the beam remained constant. Crack development during loading is indicated by abrupt changes (formation of kinks) in the load-deflection curves. After formation of inclined/diagonal crack, stiffness of the beams suddenly decreased in both LWSCC and SCC beams. When the load reached the ultimate shear capacity, a sudden brittle shear failure was 
occurred. Immediately after the shear failure, a significant reduction in the load carrying capacity was observed.

The ultimate load/shear capacity for SCC beams were higher than corresponding LWSCC beams as per Figure 4.1(a-b). On the other hand, LWSCC beams showed higher deflection evolution compared with their SCC counterparts.

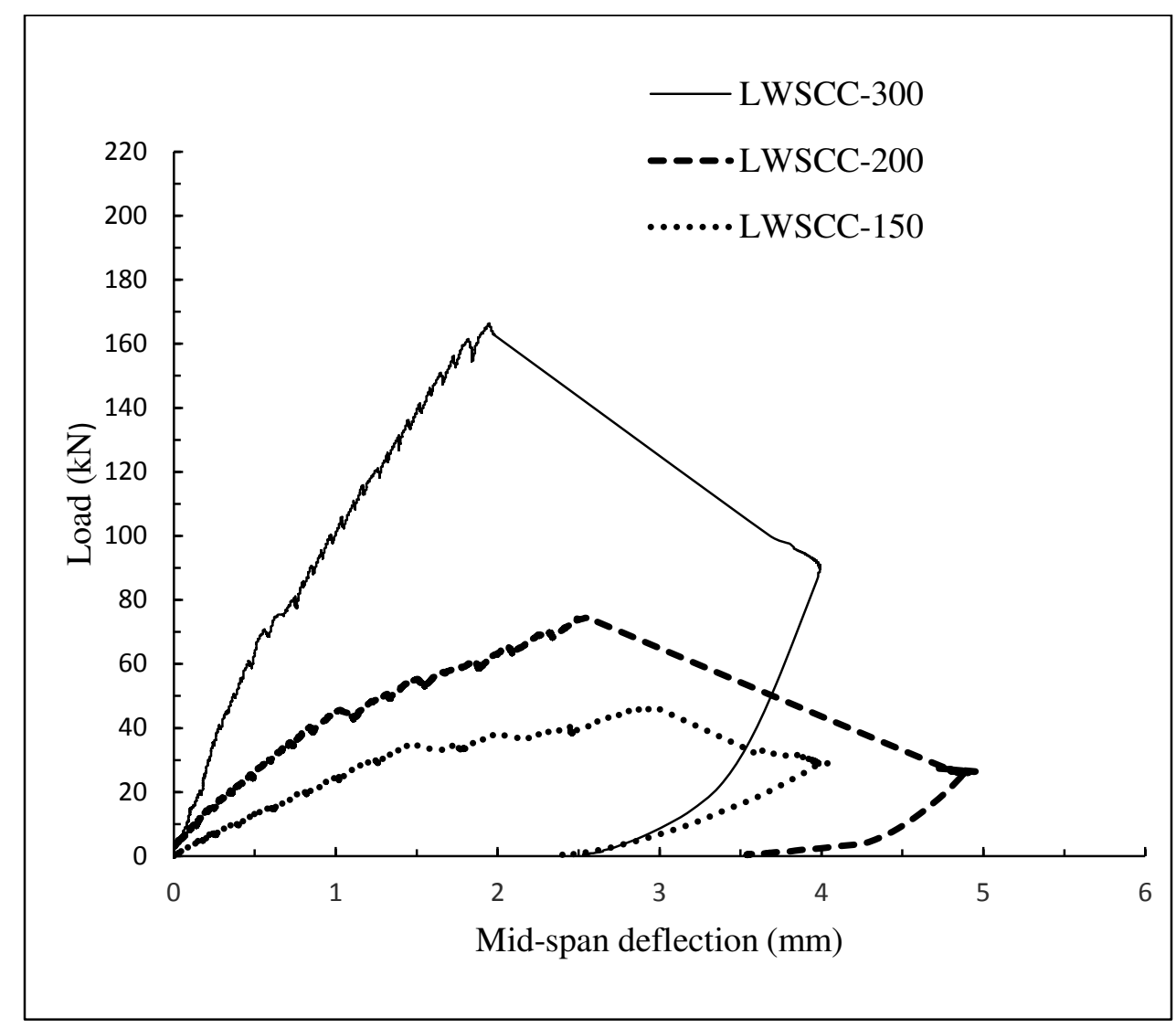

Figure 4.1 (a) - Load-deflection response for LWSCC shear beams without shear reinforcement 


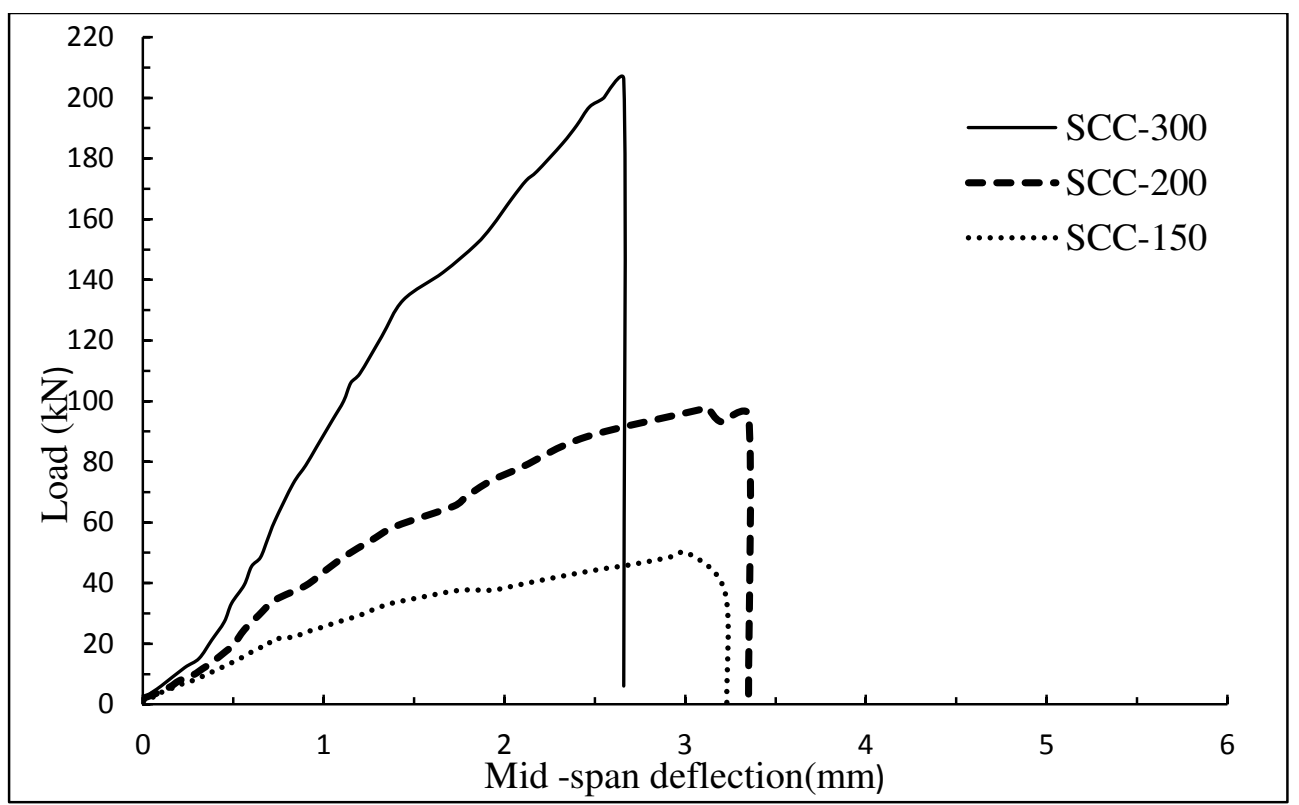

Figure 4.1 (b) -Load-deflection response for SCC shear beams without shear reinforcement

\subsubsection{Failure mode and cracking behavior}

During loading, fine vertical flexural cracks were formed within the mid span of all beams (zero shear region). With increase of load, new flexural cracks were formed within the zero shear regions and in the shear span prior to the formation of first shear cracks. The inclined shear crack initially formed near the support, as expected. With further increase in load, diagonal shear cracks propagated towards the loading point of the beam with the formation of additional shear and flexural cracks along the beam. Finally sudden shear failure was occurred immediately after dominant diagonal shear cracks formed within one or two side of the shear span as shown in Figures 4.2(a-b). The volume of sound at shear failure was identifiably louder in high depth beams than the small depth ones. Table 4.1 indicates the experimental summary for shear beams without shear reinforcement showing concrete compressive strength, failure modes, shear loads at first flexure/diagonal crack, deflection at first diagonal crack, peak shear load, peak load deflection and angle of diagonal crack.

Formation of the first flexural crack was observed at lower loads in LWSCC beams when compared to the SCC beams. This observation is an indication of lower bending/flexural strength of LWSCC. The angle of dominant diagonal crack was approximately within the range of 50-65 degree for LWSCC beams and 40-60 degree for SCC beams. Angle of diagonal shear crack tends 
to increase with the increasing of height of the LWSCC and SCC beams. Diagonal shear crack loads varied from 48.1 to $68 \%$ of ultimate loads for LWSCC beams and 51.8 to $69.5 \%$ of ultimate loads for SCC beams. LWSCC beams had about 14 to 17 cracks at failure and SCC beams had around 6 to 9 cracks. So LWSCC beams developed more crack than SCC beams at failure.

For SCC/LWSCC-300 beams, inclined shear crack occurred along the diagonal between the point of load application and the support since this beam had an effective span to depth ratio closer to 1 (Figure 4.2 a). This type of shear failure is called arch action mechanism. Normally arch action failure occurs in a deep beam where effective span to depth ratio is less than or equal to one.

Table 4.1- Experimental summary for shear beams without shear reinforcement

\begin{tabular}{|l|c|c|c|c|c|c|c|c|c|}
\hline $\begin{array}{l}\text { Beam } \\
\text { code }\end{array}$ & $\mathrm{a} / \mathrm{d}$ & $\begin{array}{c}\text { Concrete } \\
\text { Strength } \\
(\mathrm{MPa})\end{array}$ & $\begin{array}{l}\text { Failure } \\
\text { pattern }\end{array}$ & $\begin{array}{c}\text { Shear } \\
\text { at first } \\
\text { flexure } \\
\mathrm{V}_{\mathrm{fl}} \\
(\mathrm{kN})\end{array}$ & $\begin{array}{c}\text { Deflection } \\
\text { at first } \\
\text { diagonal } \\
\text { crack } \\
\mathrm{D}_{\mathrm{c}}(\mathrm{mm})\end{array}$ & $\begin{array}{c}\text { Shear at } \\
\text { first } \\
\text { diagonal } \\
\text { crack } \\
\mathrm{V}_{\mathrm{c}}(\mathrm{kN})\end{array}$ & $\begin{array}{c}\text { Peak/ } \\
\text { failure } \\
\text { shear } \\
\mathrm{V}_{\mathrm{u}} \\
(\mathrm{kN})\end{array}$ & $\begin{array}{c}\text { Deflect } \\
\text {-ion at } \\
\text { peak } \\
\text { shear } \\
\text { load } \\
\mathrm{D}_{\mathrm{u}} \\
\mathrm{mm})\end{array}$ & $\begin{array}{c}\text { Diago- } \\
\text { nal } \\
\text { crack } \\
\text { angle } \\
(\mathrm{Degree})\end{array}$ \\
\hline $\begin{array}{l}\text { LWSCC- } \\
150\end{array}$ & 2.14 & 33.5 & Shear & 3.0 & 0.7 & 16.0 & 23.5 & 2.8 & 50 \\
\hline $\begin{array}{l}\text { LWSCC- } \\
200\end{array}$ & 1.53 & 33.5 & Shear & 5.0 & 0.9 & 22.5 & 37.5 & 2.5 & 55 \\
\hline $\begin{array}{l}\text { LWSCC- } \\
300\end{array}$ & 1.05 & 33.5 & Shear & 10.0 & 0.7 & 40.0 & 83.0 & 1.9 & 65 \\
\hline SCC-150 & 2.14 & 53.0 & Shear & 8.8 & 0.6 & 16.5 & 25.0 & 2.9 & 40 \\
\hline SCC-200 & 1.53 & 53.0 & Shear & 17.0 & 0.6 & 27.5 & 53.0 & 3.1 & 46 \\
\hline SCC-300 & 1.05 & 53.0 & Shear & 22.0 & 1.1 & 48.0 & 103.0 & 2.5 & 60 \\
\hline
\end{tabular}

In all beams except SCC/LWSCC-300, cracks were formed along the longitudinal tension steel at the bottom of the compression strut and the resulting failure mechanism is called shear-tension failure since all these beams had effective span to depth ratio ranging between 1 and 2.5. LWSCC beams had partially fractured coarse aggregate along the failure surface. Overall, failure modes of SCC and LWSCC beams were found similar. 

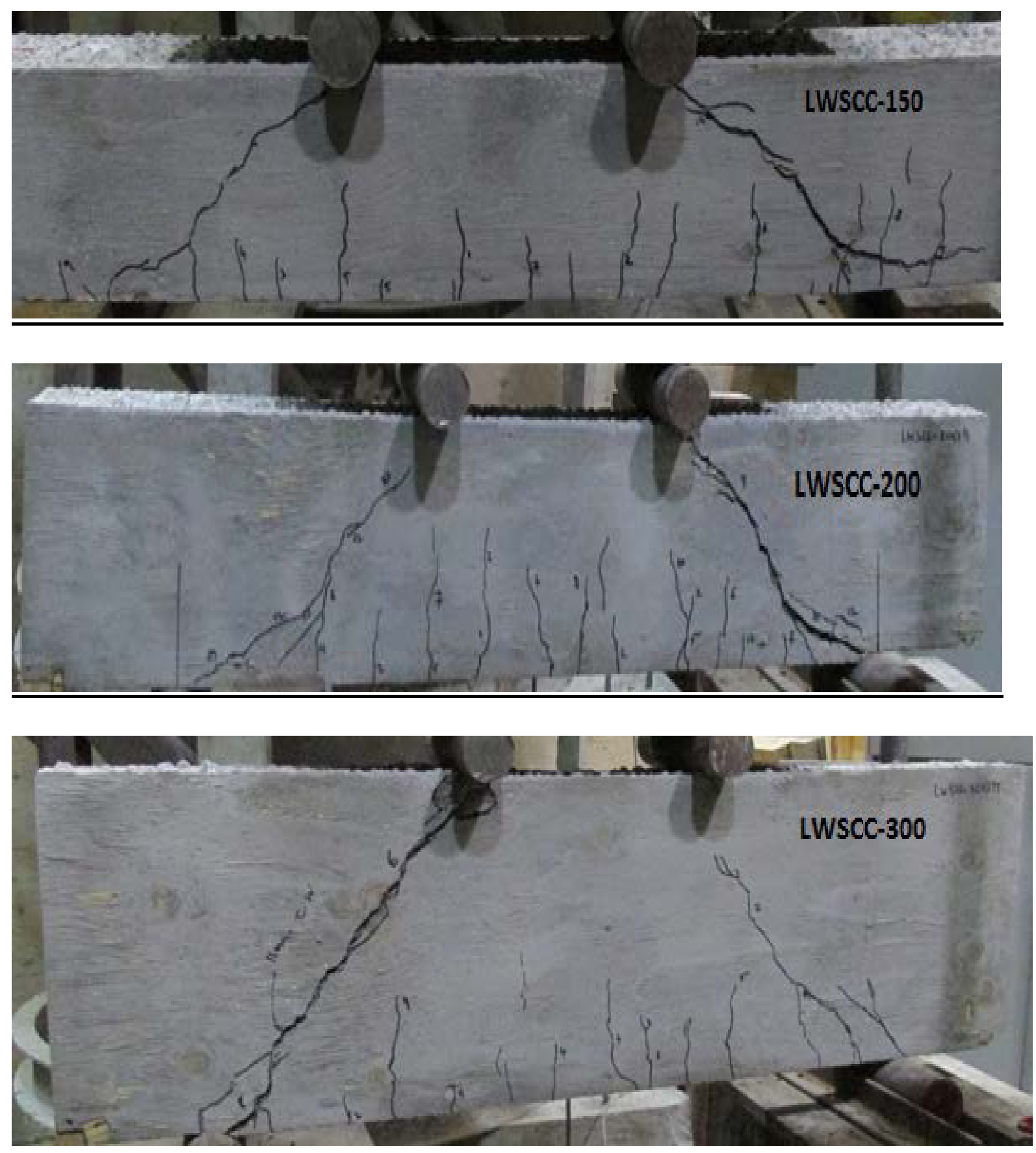

Figure 4.2(a) - Failure modes tested shear LWSCC beams without shear reinforcement 

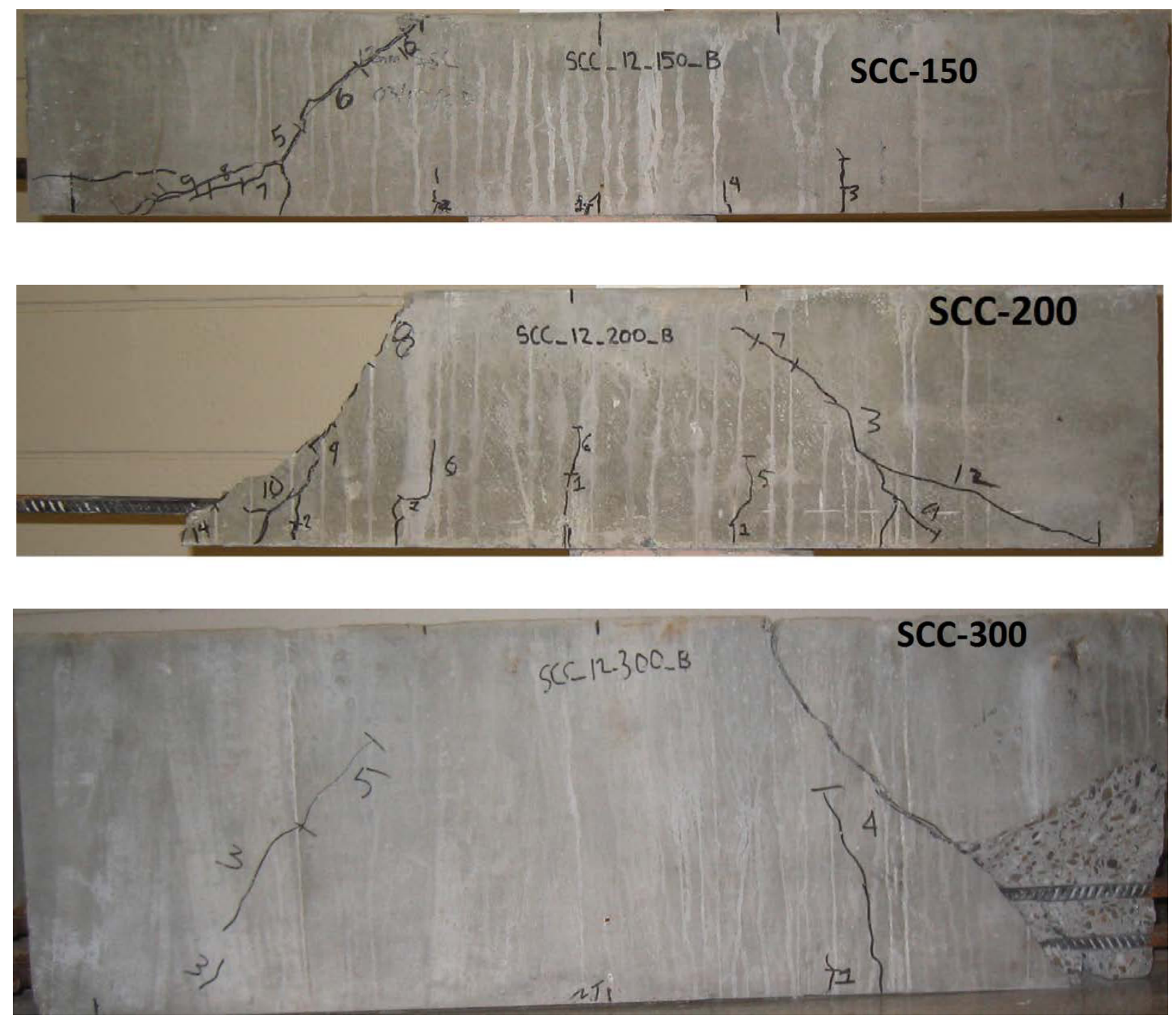

Figure 4.2(b) - Failure modes tested shear SCC beams without shear reinforcement

\subsubsection{Influence of the shear span to depth ratio $(a / d)$ on concrete shear resistance $\left(V_{c}\right)$}

The influence of shear span to depth ratio $(\mathrm{a} / \mathrm{d})$ on the concrete shear resistance capacity $\left(\mathrm{V}_{\mathrm{c}}\right)$ defined as the shear load at first diagonal crack of LWSCC and SCC beams were investigated. LWSCC and SCC beams had a compressive strength of $33.5 \mathrm{MPa}$ and $53 \mathrm{MPa}$, respectively. Figure 4.3 shows the influence of $\mathrm{a} / \mathrm{d}$ on the concrete shear resistance capacity of LWSCC and SCC beams. As expected, shear resistance capacity of LWSCC and SCC beams decreased with the increase of $\mathrm{a} / \mathrm{d}$. The shear resistance capacity of SCC beams was higher than corresponding LWSCC beams. Shear resistance capacity difference between these two concretes increased with the decrease of $\mathrm{a} / \mathrm{d}$. 


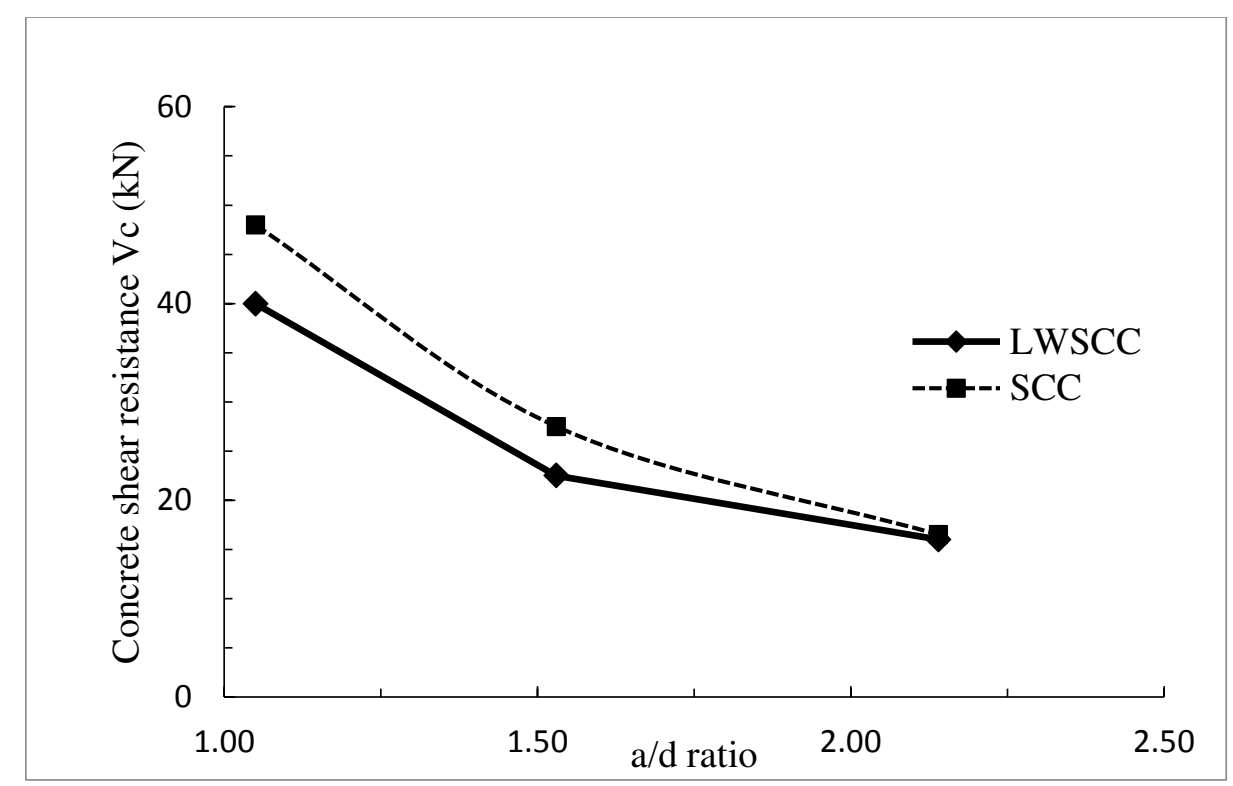

Figure 4.3- Influence of shear span to effective depth ratio on concrete shear resistance $\left(\mathrm{V}_{\mathrm{c}}\right)$

\subsubsection{Post cracking shear resistance, ductility and energy absorption}

Aggregate interlock mechanism and dowel action play significant roles in the increase of shear resistance from $V_{c}$ (shear resistance at the formation of inclined crack) to $V_{u}$ (ultimate shear resistance or peak load). In this study, the shear at the first diagonal crack is denoted as concrete shear resistance $\left(\mathrm{V}_{\mathrm{c}}\right)$ and it was identified from the visual observation during the testing of LWSCC and SCC beams. The ultimate shear resistance $\left(\mathrm{V}_{\mathrm{u}}\right)$ was identified from the maximum load (peak load) that a beam can carry before failure. To characterize the performance of LWSCC and SCC, it is important to analysis the post cracking shear resistance of concrete beams due to aggregate interlock and dowel action. Similar analysis was carried out by previous researchers, Lachimi et al. (2005) and Hassan et al. (2010), by introducing a shear resistance factor (SRF). SRF is defined as the ratio of the failure load to the load at the first diagonal crack $\left(\mathrm{SRF}=\mathrm{V}_{\mathrm{u}} / \mathrm{V}_{\mathrm{c}}\right)$.

To investigate and compare the post cracking shear resistance of LWSCC and SCC beams, the ultimate shear load and diagonal cracking shear load are normalized to account for the difference in compressive strength between LWSCC and SCC. Since the shear strength is proportional to the square root of the compressive strength of concrete ( $\left.\mathrm{f}^{\prime} \mathrm{c}\right)$ according to CSA A23.3 and ACI 318 code based equations, normalized shear loads and SRF were calculated based on the following equations: 
Normalized ultimate shear load: $\quad \mathrm{V}_{\mathrm{nu}}=\frac{\mathrm{V}_{\mathrm{u}}}{\sqrt{\mathrm{f}_{\mathrm{c}}}}$

Normalized inclined cracking shear load: $V_{n c}=\frac{V_{c}}{\sqrt{f_{c}}}$

$\mathrm{SRF}=\frac{\mathrm{V}_{\mathrm{u}}}{\mathrm{V}_{\mathrm{c}}}=\frac{\mathrm{V}_{\mathrm{nu}}}{\mathrm{V}_{\mathrm{nc}}}$

The post cracking shear ductility was defined as the ratio of the deflection at failure load to the deflection at first diagonal crack load by previous researcher Hassan et.al (2010). In this study, ductility of the shear beam is also defined by the ductility factor (DF) as per equation 4.4:

$$
\mathrm{DF}=\mathrm{D}_{\mathrm{u}} / \mathrm{D}_{\mathrm{c}}
$$

Where $D_{u}$ and $D_{c}$ are the deflection at first diagonal crack and peak/failure load, respectively as presented in Table 4.1.

Table 4.2- Shear resistance and ductility factor for the shear beams without shear reinforcement

\begin{tabular}{|l|c|c|c|c|c|c|c|c|}
\hline \multicolumn{1}{|c|}{$\begin{array}{l}\text { Beam } \\
\text { code }\end{array}$} & $\begin{array}{c}\text { Depth } \\
\text { to } \\
\text { width } \\
\text { ratio } \\
(\mathrm{d} / \mathrm{b})\end{array}$ & $\begin{array}{c}\text { Shear } \\
\text { span to } \\
\text { depth } \\
\text { ratio } \\
(\mathrm{a} / \mathrm{d})\end{array}$ & $\begin{array}{c}\text { Concrete } \\
\text { compressive } \\
\text { strength } \\
\left(\mathrm{f}^{\prime} \mathrm{c}\right)\end{array}$ & $\begin{array}{c}\text { Normalized } \\
\text { inclined } \\
\text { cracking } \\
\text { shear load } \\
\left(\mathrm{V}_{\mathrm{nc}}\right)\end{array}$ & $\begin{array}{c}\text { Normalized } \\
\text { ultimate } \\
\text { shear load } \\
\left(\mathrm{V}_{\mathrm{nu}}\right)\end{array}$ & $\begin{array}{c}\text { Shear } \\
\text { resistanc- } \\
\text { e factor } \\
(\mathrm{SRF})\end{array}$ & $\begin{array}{c}\text { Ducti- } \\
\text { lity } \\
\text { factor } \\
(\mathrm{DF})\end{array}$ & $\begin{array}{c}\text { Energy } \\
\text { absorptio } \\
-\mathrm{n} \\
\mathrm{J} / \mathrm{MPa}^{1 / 2}\end{array}$ \\
\hline $\begin{array}{l}\text { LWSCC } \\
-150\end{array}$ & 1.24 & 2.14 & 33.5 & 2.8 & 4.1 & 1.4 & 4.0 & 13.6 \\
\hline $\begin{array}{l}\text { LWSCC } \\
-200\end{array}$ & 1.74 & 1.53 & 33.5 & 3.9 & 6.5 & 1.6 & 2.5 & 14.7 \\
\hline $\begin{array}{l}\text { LWSCC } \\
-300\end{array}$ & 2.53 & 1.05 & 33.5 & 6.9 & 14.3 & 2.0 & 2.4 & 27.7 \\
\hline $\begin{array}{l}\text { SCC- } \\
150\end{array}$ & 1.24 & 2.14 & 53 & 2.3 & 3.4 & 1.5 & 4.7 & 11.5 \\
\hline $\begin{array}{l}\text { SCC- } \\
200\end{array}$ & 1.74 & 1.53 & 53 & 3.8 & 7.3 & 1.9 & 4.5 & 22.4 \\
\hline $\begin{array}{l}\text { SCC- } \\
300\end{array}$ & 2.53 & 1.05 & 53 & 6.6 & 14.1 & 2.1 & 2.3 & 36.1 \\
\hline
\end{tabular}

Normalized shear loads, shear resistance factor and ductility factor for the shear beams without shear reinforcement are shown in Table 4.2. Main portion of the shear is transferred through aggregate interlock mechanism and dowel action in the post-cracking stage. When considering the aggregate interlock mechanism, coarse aggregate content and it's quality affect the post-cracking 
-stage shear transfer capacity. Table 4.2 show that SCC beams had a higher SRF than their LWSCC counterparts to weaker aggregate interlock mechanism in the LWSCC beams. It is also noted that SRF increased with the decrease of $a / d$ and with the increase of $d / b$ for both SCC and LWSCC beams.

Shear ductility (defined by DF) of SCC beams was found to be higher than corresponding LWSCC beams except for $300 \mathrm{~mm}$ height beam. This can be attributed to the brittle nature of porous lightweight aggregate compared to normal weight aggregate as suggested by Gerritse (1981). Overall, shear ductility increased with the increase of a/d for both SCC and LWSCC beams (Table 4.2).

To investigate and compare the energy absorption of SCC and LWSCC beams, the shear load is normalized to accommodate for the difference in compressive strength between SCC and LWSCC. Equation 4.1 is used to normalize the shear loads. Normalized shear load - deflection curves for the beams are shown in Figure 4.3. Energy absorption was calculated by area under the normalized shear deflection curve up to the post peak shear of $85 \%$ of the ultimate shear load $\left(\mathrm{V}_{\mathrm{u}}\right)$ and presented in Table 4.2.

Energy absorption capacity increased with the decrease of beam a/d for both SCC and LWSCC beams. That can be attributed to the louder sound at failure for the higher depth beams compared to smaller depth ones. SCC beams exhibited higher energy absorption capacity compared to LWSCC beams for higher depth beam (height of 200 and $300 \mathrm{~mm}$ ) or $\mathrm{d} / \mathrm{b}$ or lower $\mathrm{a} / \mathrm{d}$. But higher $\mathrm{a} / \mathrm{d}$ or lower $\mathrm{d} / \mathrm{b}$ beam (height of $150 \mathrm{~mm}$ ), energy absorption capacity was found higher for LWSCC beam than SCC beam. 


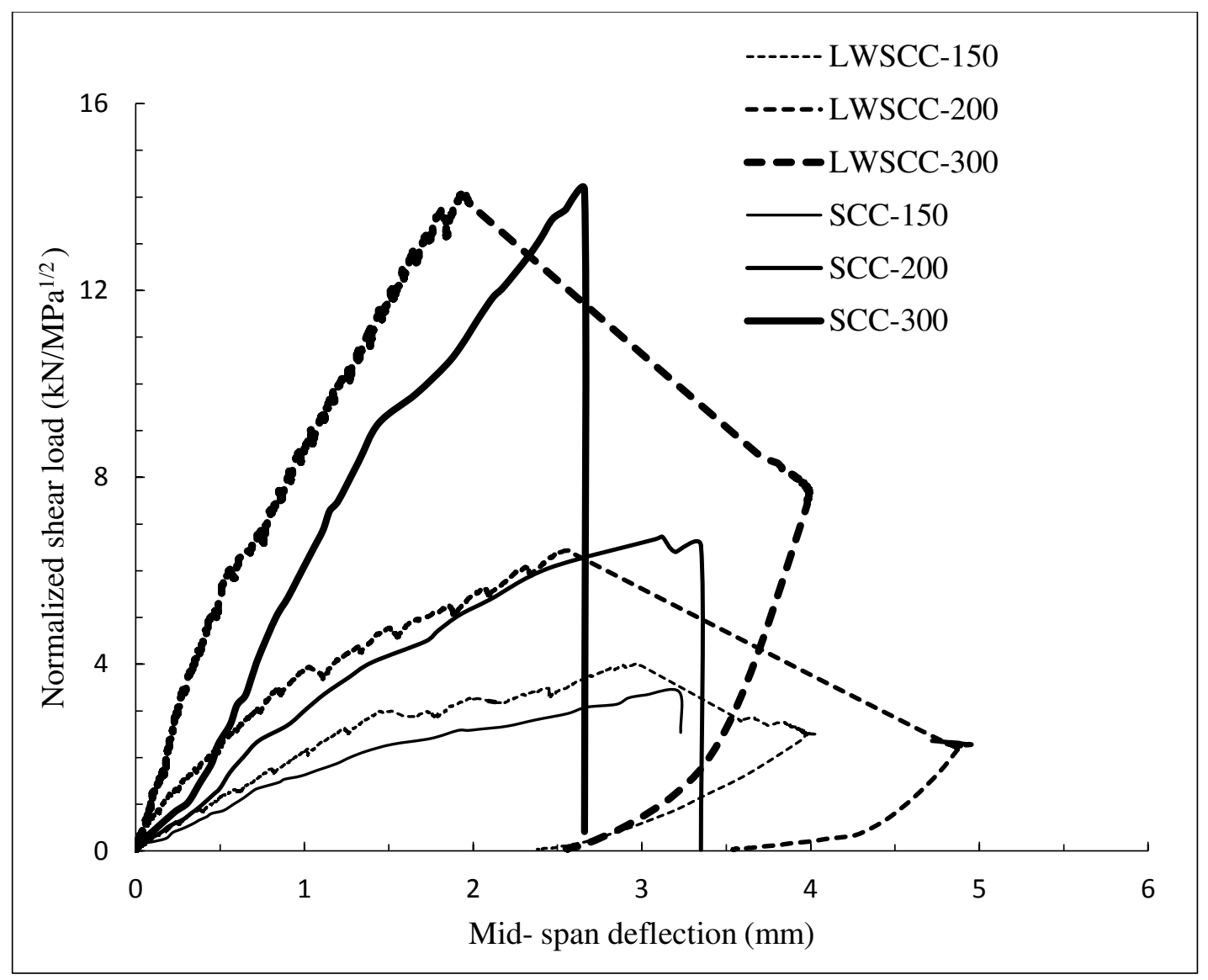

Figure 4.4- Normalized shear load-deflection responses for shear beams without shear reinforcement

\subsection{LWSCC shear beams with shear reinforcement}

Three shear beams with shear reinforcement were tested under four point loading arrangement. Shear span to effective depth ratio were $1.05,1.53$ and 2.14 for 156, 206, $306 \mathrm{~mm}$ height beams, respectively. The respective flexural reinforcement ratio were $1.6 \%, 1.15 \%$ and $1.57 \%$. Shear reinforcement was provided within the shear span of the beam at $133 \mathrm{~mm}$ of center to center spacing but no shear reinforcement was provided within the zero shear region.

\subsubsection{Load deflection behavior}

Load-mid span deflection responses for the beams with shear reinforcements are shown in Figure 4.5. The initial straight line segment of the curve shows that prior to flexural cracking, stiffness of the beams was constant similar to beams without shear reinforcement. After formation of inclined crack, a small reduction in the slope was observed but reduction in the slope was high in beams 
without shear reinforcement. This indicates that the beams with shear reinforcement were stiffer than those without shear reinforcement after the formation of inclined cracks. Even after the formation of inclined crack, deflection curve was almost straight line prior to failure or until yielding of reinforcement. The beams with shear reinforcement failed at a much higher load and had significantly higher deflection than those without shear reinforcement, as expected. The LWSCC beams with shear reinforcement exhibited more ductile behavior in terms of higher deflection development compared to beams without shear reinforcement at failure (Figure 4.1a and Figure 4.5).

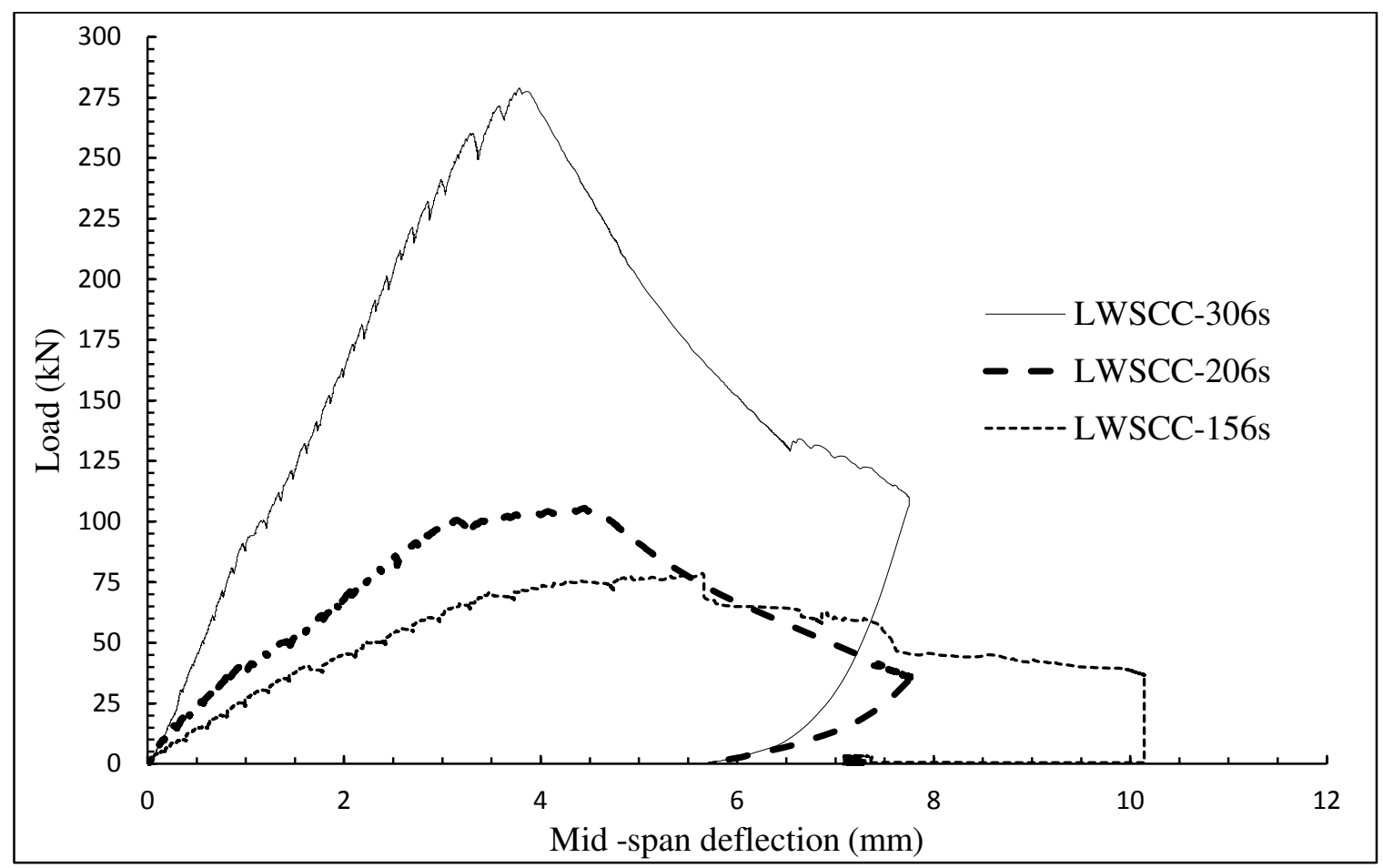

Figure 4.5-Load-mid span deflection responses for beams with shear reinforcement

\subsubsection{Failure mode and cracking behavior}

Figure 4.6 shows the cracking pattern in the LWSCC beams with shear reinforcement. Table 4.3 summarizes experimental results indicating concrete compressive strength, failure modes, shear loads at first flexure/diagonal crack, deflection at first diagonal crack, peak shear load, peak load deflection and angle of diagonal crack. The crack pattern of LWSCC beams with shear reinforcement is almost similar to those without shear reinforcement until the formation of diagonal cracks. But beams with shear reinforcement showed higher load carrying capacity after 
the formation of diagonal crack until failure. The angle of dominant diagonal crack was approximately within the range of 40-50 degree since the inclined cracks in the beams with shear reinforcement were almost straight line instead of curved ones exhibited by the beams without shear reinforcement. Inclined cracks intersected through many shear reinforcement.

Table 4.3 - Experimental results summary for tested shear beams with shear reinforcement

\begin{tabular}{|l|c|c|c|c|c|c|c|c|}
\hline Beam & $\begin{array}{c}\text { Concrete } \\
\text { Strength } \\
(\mathrm{MPa})\end{array}$ & $\begin{array}{c}\text { Failure } \\
\text { pattern }\end{array}$ & $\begin{array}{c}\text { Shear at } \\
\text { first } \\
\text { flexure } \\
\mathrm{V}_{\mathrm{fl}}(\mathrm{kN})\end{array}$ & $\begin{array}{c}\text { Deflection } \\
\text { at first } \\
\text { diagonal } \\
\text { crack } \\
\mathrm{D}_{\mathrm{c}}(\mathrm{mm})\end{array}$ & $\begin{array}{c}\text { Shear at } \\
\text { first } \\
\text { diagonal } \\
\text { crack } \\
\mathrm{V}_{\mathrm{c}}(\mathrm{kN})\end{array}$ & $\begin{array}{c}\text { Peak/ } \\
\text { failure } \\
\text { shear } \\
\mathrm{V}_{\mathrm{u}} \\
(\mathrm{kN})\end{array}$ & $\begin{array}{c}\text { Deflection at } \\
\text { peak shear } \\
\text { load } \\
\mathrm{D}_{\mathrm{u}}(\mathrm{mm})\end{array}$ & $\begin{array}{c}\text { Diagonal } \\
\text { crack } \\
\text { angle } \\
\text { (Degree) }\end{array}$ \\
\hline $\begin{array}{l}\text { LWSCC } \\
-156 \mathrm{~s}\end{array}$ & 36 & Shear & 4.0 & 1.8 & 20.0 & 39.0 & 5.7 & 40 \\
\hline $\begin{array}{l}\text { LWSCC } \\
-206 \mathrm{~s}\end{array}$ & 36 & Shear & 7.5 & 1.4 & 25.0 & 52.5 & 4.5 & 44 \\
\hline $\begin{array}{l}\text { LWSCC } \\
-306 \mathrm{~s}\end{array}$ & 36 & Shear & 14.0 & 1.2 & 50.0 & 136.5 & 3.6 & 50 \\
\hline
\end{tabular}

Immediately after the inclined crack, shear reinforcement picked up the load. Properly spaced shear reinforcement keeps the inclined crack together without further opening of shear crack. The crack width was smaller in LWSCC-306s beam than LWSCC-206s and LWSCC156s beams at failure. This can be attributed to the fact that the shear reinforcement spacing in since LWSCC206s and LWSCC156s beams exceeded the minimum requirement as per ACI 318-05 (2005) and CSA A23.3-04.(2004)codes. These two beams, provided shear spacing were not enough to keep the inclined crack together without further opening after formation of inclined crack.

In LWSCC-156s and LWSCC-206s beams, concrete crushing occurred near the loading point at ultimate stage and final failure mechanism was shear compression failure. For LWSCC-306s beam, concrete spalling occurred near the support at ultimate stage and ultimate failure mode was shear tension (Figure 4.6).

During the testing, the diagonal crack was identified by two methods. One was by visual inspection on cracking and the other was by strain data in the shear reinforcement. Diagonal shear cracking loads varied from 36 to $51 \%$ of ultimate loads for LWSCC beams with shear reinforcement and 48.1 to $68 \%$ of ultimate loads for LWSCC without shear reinforcement. Beams with and without 
shear reinforcement showed same diagonal cracking load capacity but ultimate load capacity was higher for beams with shear reinforcement, as expected. LWSCC beams with shear reinforcement had developed about 12 to 17 cracks at failure (Figure 4.6).
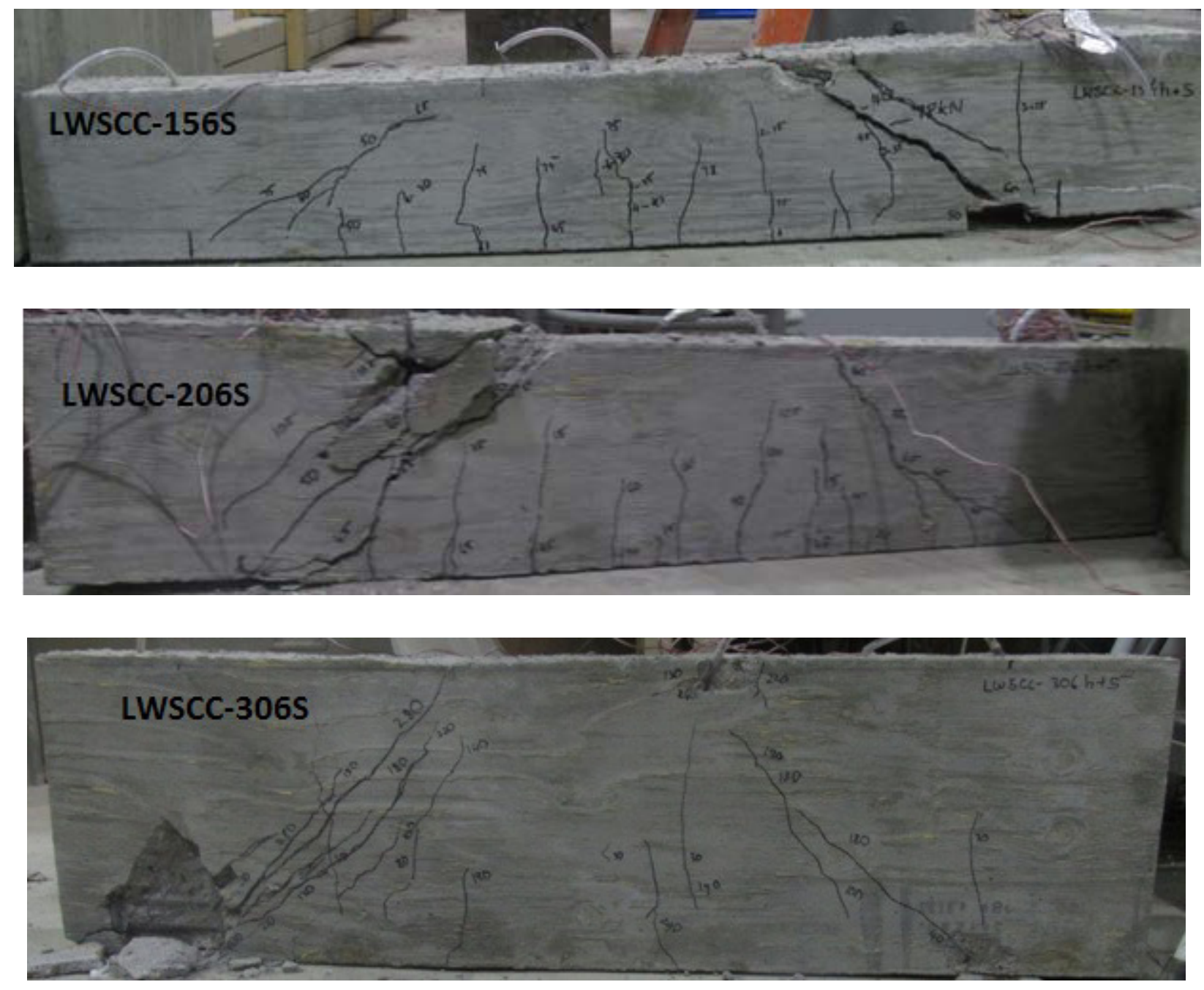

Figure 4.6- Failure modes of tested shear beams with shear reinforcement.

\subsubsection{Strain development in the flexural and shear reinforcement}

Load-rebar strain curves for shear beams with shear reinforcement are shown in Figure 4.7(a-c). Table 4.4 summarizes the values of strain at first inclined cracking in shear and flexural rebars as well as loads at which shear and flexural re-bars yielded. For LWSCC-156s and LWSCC-206s beams, the yielding of bottom flexural reinforcement occurred between diagonal cracking and failure (Figure 4.7a-b). As a result yielding of flexural reinforcement did not affect the load at first 
inclined crack, but it affected the ultimate/failure shear load capacity of both beams. Even though flexural reinforcement yielded first in these two beams (Figure 4.7a-b), ultimate failure mode was shear due to larger shear reinforcement spacing - as this spacing was not enough to keep the inclined crack together without further widening. Therefore, failure of these beams (LWSCC-156s and LWSCC-206s) occurred before yielding of shear reinforcement by widening of the inclined crack following concrete crushing at the loading point (Figure 4.6). In LWSCC-306s beam, after inclined crack occurred, shear reinforcement yielded (at $109 \mathrm{kN}$ ) before the yielding of flexural reinforcement (which occurred at $135 \mathrm{kN}$ ) as shown in Figure 4.7(c).

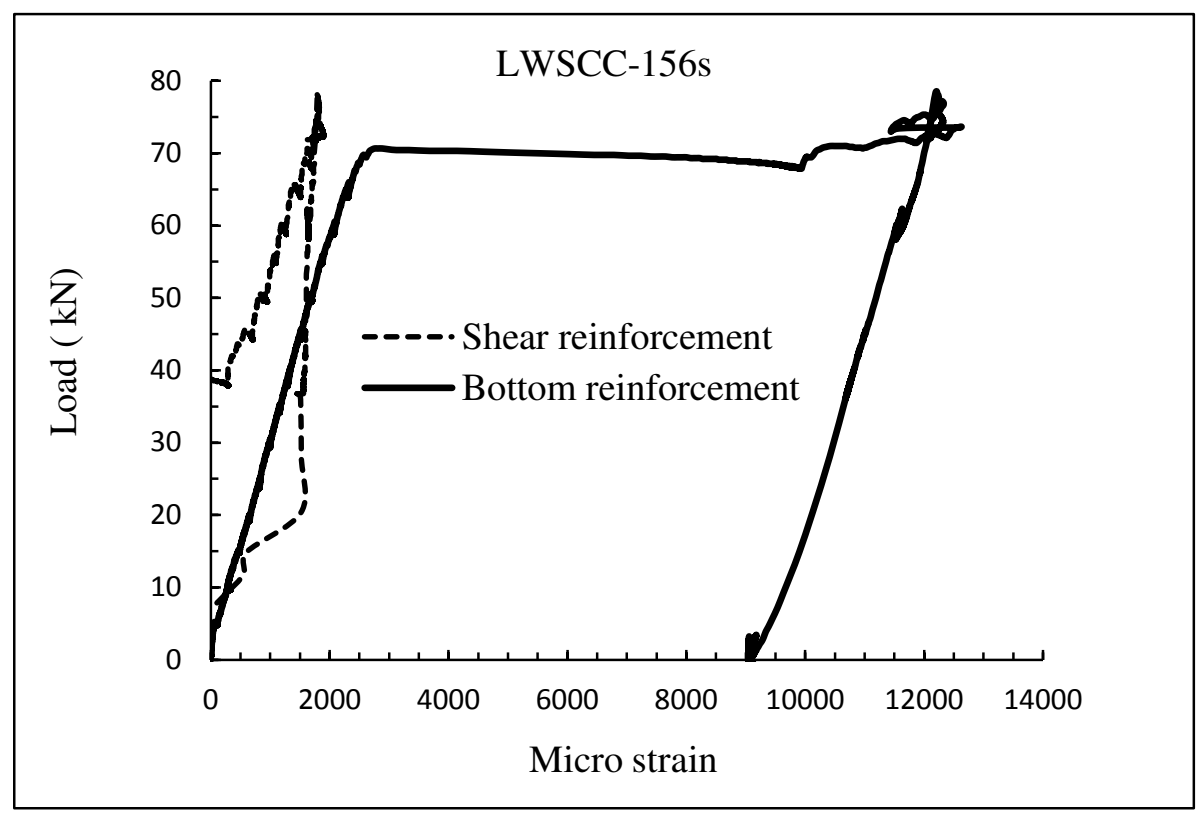

Figure 4.7(a)-Load -rebar strain curves for beams with shear reinforcement 


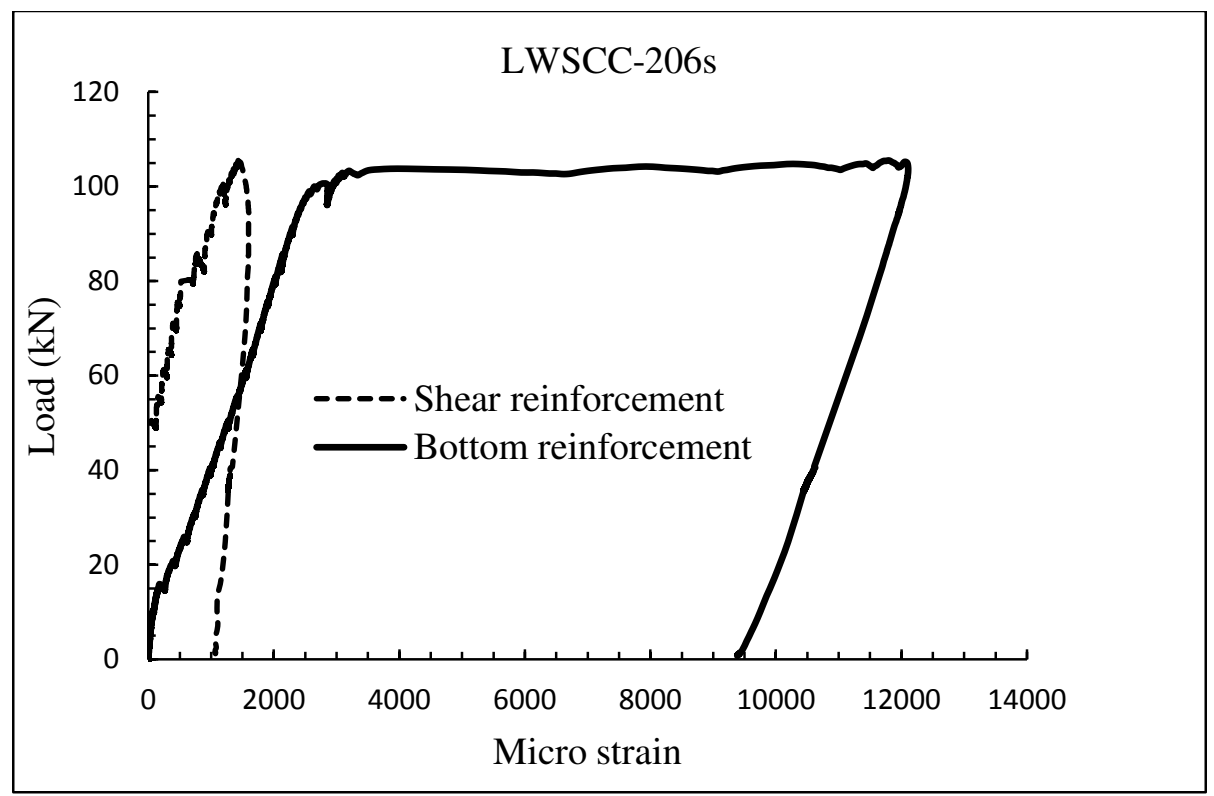

Figure 4.7(b) - Load-rebar strain curves for shear beams with shear reinforcement

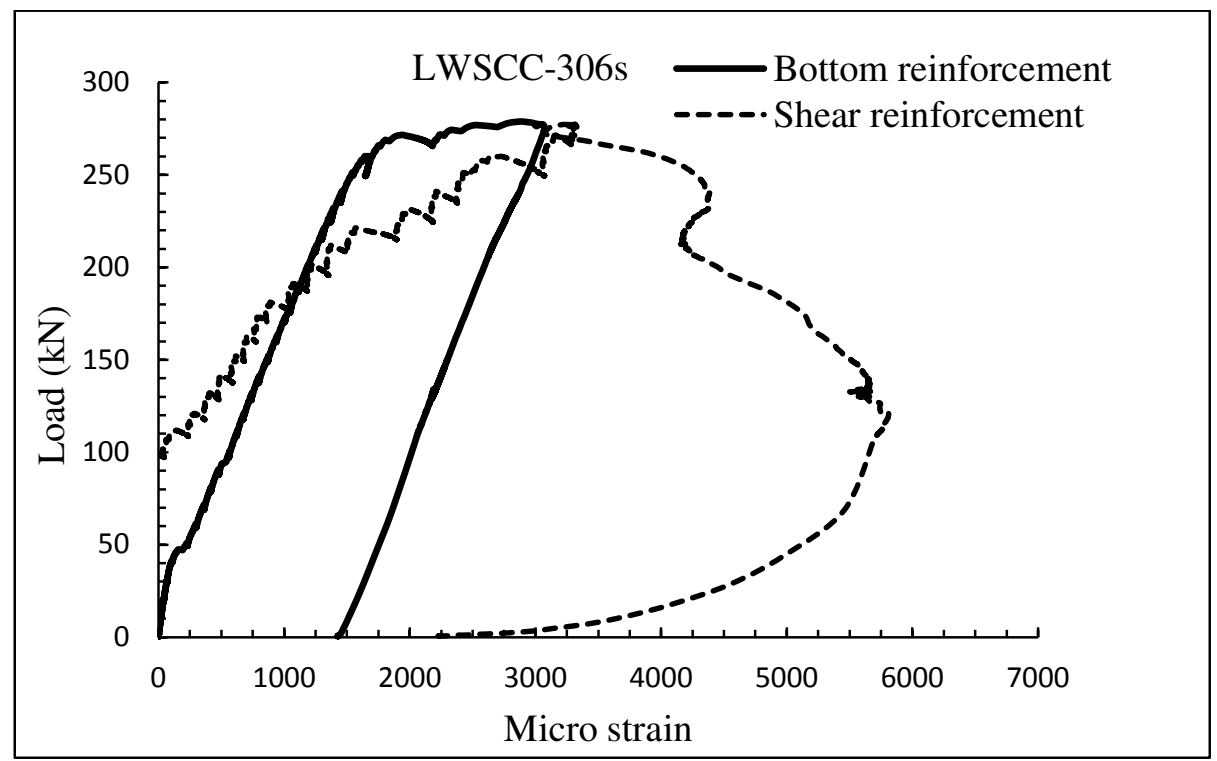

Figure 4.7(c) - Load-rebar strain curves for shear beams with shear reinforcement 
Table 4.4- Experimental strain values of tested shear beams with shear reinforcement

\begin{tabular}{|c|c|c|c|c|c|c|c|}
\hline Beam code & Failure & \multicolumn{4}{|c|}{ Steel strain } & \multicolumn{2}{c|}{ Shear load (kN) } \\
\cline { 3 - 7 } & mode & \multicolumn{2}{|c|}{ Stirrup (micro-strain) } & \multicolumn{2}{c|}{$\begin{array}{c}\text { Bottom flexural re- } \\
\text { bar (micro-strain) }\end{array}$} & \multicolumn{2}{|c|}{} \\
\cline { 3 - 8 } & & $\begin{array}{c}\text { At first } \\
\text { diagonal } \\
\text { cracking } \\
\text { stage }\end{array}$ & $\begin{array}{c}\text { At ultimate } \\
\text { stage }\end{array}$ & $\begin{array}{c}\text { At first } \\
\text { diagonal } \\
\text { cracking } \\
\text { stage }\end{array}$ & $\begin{array}{c}\text { At } \\
\text { ultimate } \\
\text { stage }\end{array}$ & $\begin{array}{c}\text { At } \\
\text { stirrup } \\
\text { yielding }\end{array}$ & $\begin{array}{c}\text { At bottom } \\
\text { flexural } \\
\text { rebar } \\
\text { yielding }\end{array}$ \\
\hline LWSCC-156s & Shear & 83 & 1810 & 1310 & 12228 & - & 35.0 \\
\hline LWSCC-206s & Shear & 40 & 1444 & 1310 & 12105 & - & 49.7 \\
\hline LWSCC-306s & Shear & 33 & 3238 & 567 & 3107 & 109 & 135.0 \\
\hline
\end{tabular}

\subsubsection{Influence of the shear span to depth ratio $(\mathrm{a} / \mathrm{d})$ on concrete shear resistance $\left(\mathrm{V}_{\mathrm{c}}\right)$}

According to Figure 4.8, concrete shear resistance $\left(\mathrm{V}_{\mathrm{c}}\right)$ of shear beams with shear reinforcement is found to decrease with the increase of a/d - similar trend was also observed in LWSCC beams without shear reinforcement. LWSCC beams with shear reinforcement had little bit higher concrete shear resistance capacity than those without shear reinforcement. This may attributed to the higher LWSCC compressive strength of $36 \mathrm{MPa}$ compared to $33.5 \mathrm{MPa}$ of beams without shear reinforcement. It is obvious that an increase in LWSCC compressive strength will increase the shear resistance capacity. It can also be noted that the beams with and without shear reinforcement showed the same diagonal cracking strength and hence, shear reinforcement did not affect the concrete shear resistance capacity until the formation of diagonal crack.

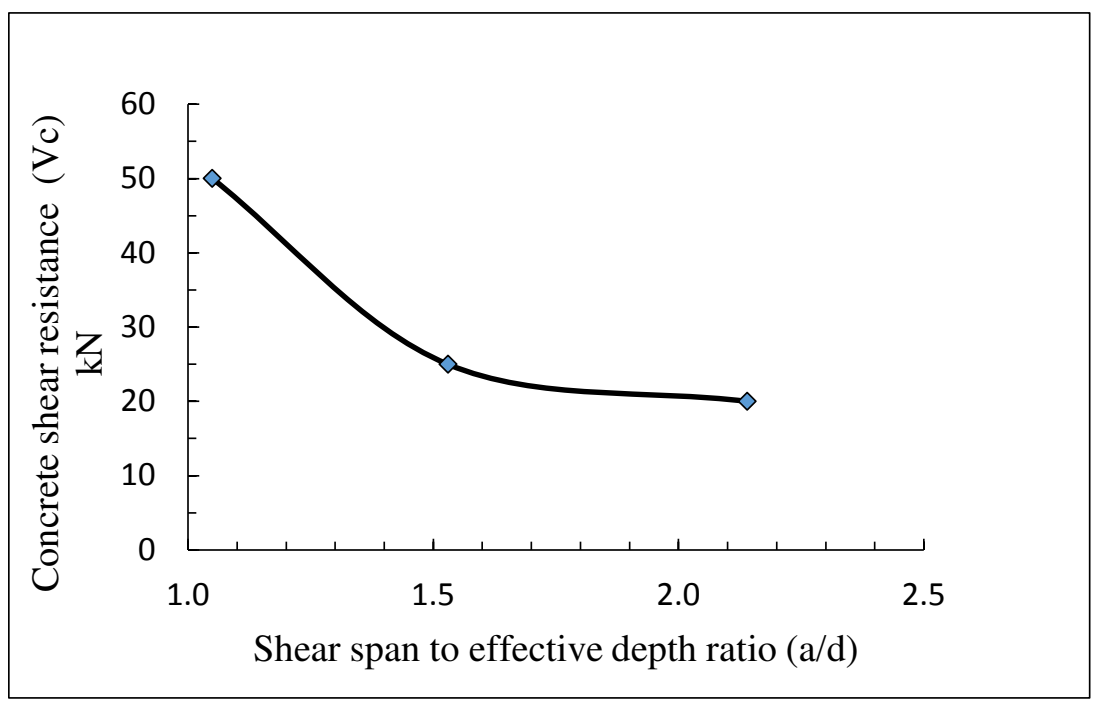

Figure 4.8- Influence of shear span to effective depth ratio on concrete shear resistance of beams with shear reinforcement 


\subsection{Flexural LWSCC beams}

\subsubsection{General}

Two singly reinforced and one doubly reinforced LWSCC beams were tested under four point loading. Shear span to effective depth ratio (a/d) was kept constant at 5.75 for each of the beams. The flexural reinforcement ratios for the beams were $0.66 \%, 1 \%$ and $1.7 \%$ for the F1s, F2s and F3d beams, respectively. Adequate shear reinforcement was provided within the beam except at the zero shear region of $700 \mathrm{~mm}$ (pure bending region). Details of these beams are discussed in Chapter Three.

\subsubsection{Load deflection behavior}

Figures 4.9 (a-c) show the experimental load-deflection curves for singly and doubly reinforced LWSCC beams. Total span of the beam was $3000 \mathrm{~mm}$ and deflection was recorded at 3 different locations - at mid span $(\mathrm{x}=1500 \mathrm{~mm})$, at $750 \mathrm{~mm}$ from the left support $(\mathrm{x}=750)$ and at $2250 \mathrm{~mm}$ from the left support $(x=2250 \mathrm{~mm})$. In all three beams, responses were closely linear (constant slope) up to the first flexural crack. After the formation of flexural cracks, change in slope of the load deflection curves was identified and the slope of the post cracking response remained reasonably linear until yielding of the reinforcements. Stiffness of the beam changed dramatically, when yielding of reinforcement occurred. LVDTs close the left and right supports $(\mathrm{x}=750 \mathrm{~mm}$ and $2250 \mathrm{~mm}$ ) recorded same deflection until yielding of reinforcement, as expected. Mid span deflection was about two times higher than those recorded near the supports (Figure 4.9) until reinforcement yielding. 

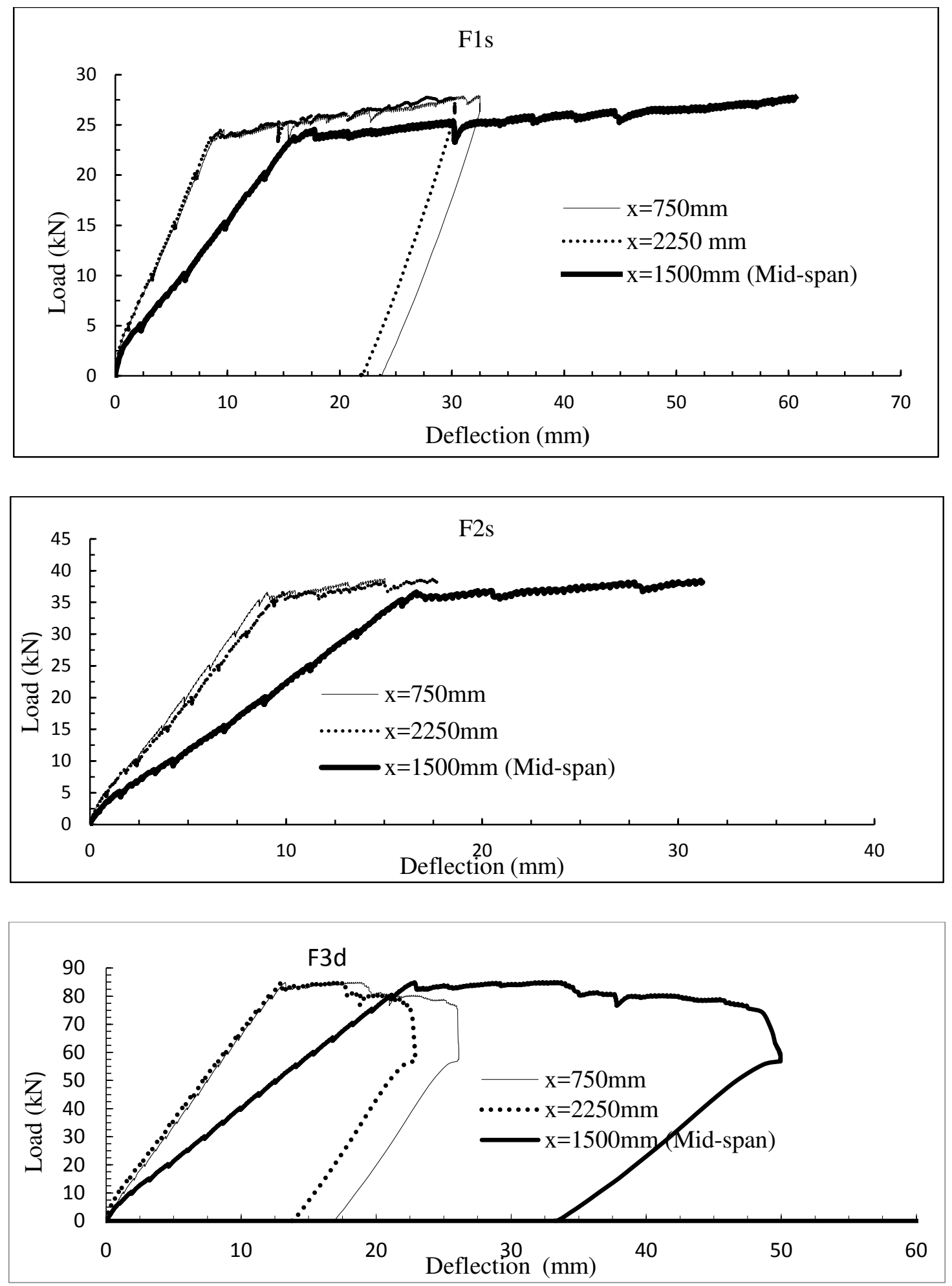

Figure 4.9 - Load deflection curves for tested flexural beams 


\subsubsection{Failure mode, crack pattern and ultimate load capacity}

During testing crack formations were marked on the beam at every load interval. Figures 4.10(ac) show the crack pattern and failure modes of LWSCC flexural beams. All beams exhibited flexure model of failure showing the development of flexural cracks. First hairline vertical flexural cracks were formed within the mid span of all three beams (zero shear region). Table 4.5 summarizes experimental results indicating concrete compressive/flexural strength, failure modes, and loads at first flexure/diagonal crack, ultimate load and number of cracks. For the singly reinforced beams (F1s and F2s), initial vertical flexural crack occurred at about 14 to $20 \%$ of the ultimate load, whereas crack formed approximately at $12 \%$ of the ultimate load for the doubly reinforced beams. This indicates that for higher reinforcement ratio the first crack occurred at lower percentage of ultimate load. Similar result was identified with the previous lightweight flexural beams tested by Teo et al. (2006).

Further increase in load, new hairlines cracks were formed within the zero shear (maximum moment) regions and in the shear span. At the same time with the increase in load, the existing cracks were propagated from the bottom of the beam towards the top. At the failure stage, critical cracks propagated to the top of the beam within the mid span region and failure also occurred within the same region showing flexural failure (Figure 4.10 a-c).

No shear crack was identified in the singly reinforced beams up to the failure but web shear cracks were formed in the doubly reinforced beam at about $85 \%$ of the ultimate load. All of the LWSCC beams failure occurred by crushing of the concrete long after the yielding of steel. The total ultimate load (moment) at beam failure were $25.0 \mathrm{kN}(14.7 \mathrm{kNm}), 42.6 \mathrm{kN}(25 \mathrm{kNm})$ and $84 \mathrm{kN}$ $(49.4 \mathrm{kNm})$ for F1s, F2s and F3d, respectively. Amount of tensile reinforcement had a significant influence on the ultimate load/moment capacity of the flexural beams. 
Table 4.5- Summary of loads, moment and failure modes of LWSCC flexural beams

\begin{tabular}{|l|c|c|c|c|c|c|c|}
\hline $\begin{array}{l}\text { Beam } \\
\text { code }\end{array}$ & $\begin{array}{c}\text { Concrete } \\
\text { Compressive } \\
\text { strength } \\
(\mathrm{MPa})\end{array}$ & $\begin{array}{c}\text { Concrete } \\
\text { modulus } \\
\text { of rupture/ } \\
\text { flexural } \\
\text { strength } \\
(\mathrm{MPa})\end{array}$ & $\begin{array}{c}\text { Failure } \\
\text { mode }\end{array}$ & $\begin{array}{c}\text { First } \\
\text { flexural } \\
\text { crack } \\
\text { load* }(\mathrm{kN})\end{array}$ & $\begin{array}{c}\text { First } \\
\text { web shear } \\
\text { crack } \\
\text { load* } \\
(\mathrm{kN})\end{array}$ & $\begin{array}{c}\text { Ultimate } \\
\text { load* } \\
(\text { Moment }) \\
\mathrm{kN}(\mathrm{kNm})\end{array}$ & $\begin{array}{c}\text { Number } \\
\text { of } \\
\text { cracks } \\
\text { at } \\
\text { failure }\end{array}$ \\
\hline F1s & 40.5 & 3.3 & Flexural & 5 & - & $25.0(14.7)$ & 24 \\
\hline F2s & 41.0 & 3.6 & Flexural & 6 & - & $42.6(25.0)$ & 30 \\
\hline F3d & 42.5 & 3.8 & Flexural & 10 & 68 & $84.0(49.4)$ & 28 \\
\hline a/d: constant at 5.75; b/d: 0.75; flexural reinforcement ratios: $0.66 \%, 1 \%$ and $1.7 \%$ for F1s, F2s and F3d, respectively; \\
*load: total load; Shear load: half of the load; Corresponding moment = load*a/2 (a = 1175 mm $)$
\end{tabular}
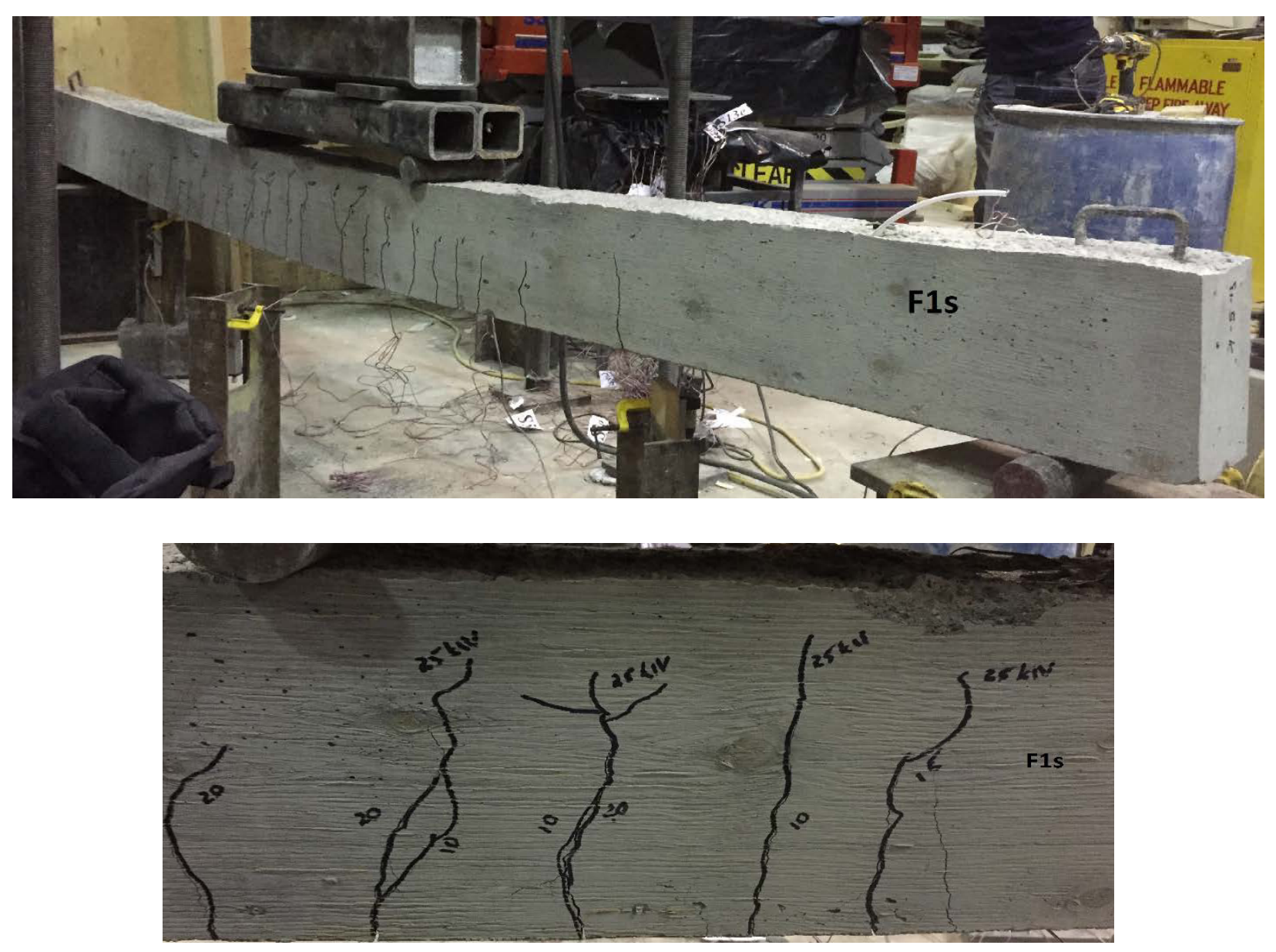

Figure 4.10(a) - Crack pattern and failure mode of singly reinforced F1s flexural beam 

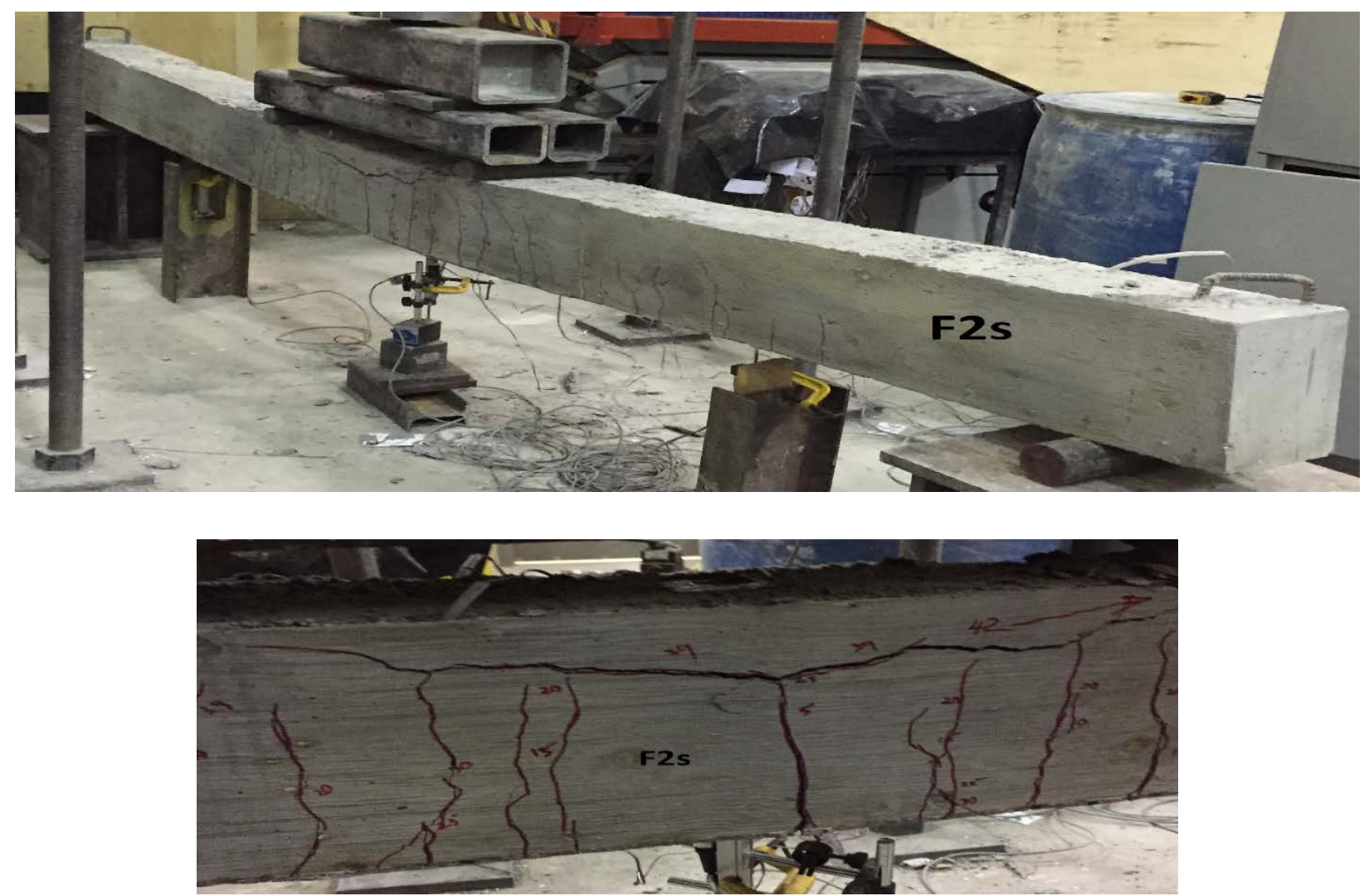

Figure 4.10(b) - Crack pattern and failure mode of singly reinforced F2s flexural beam
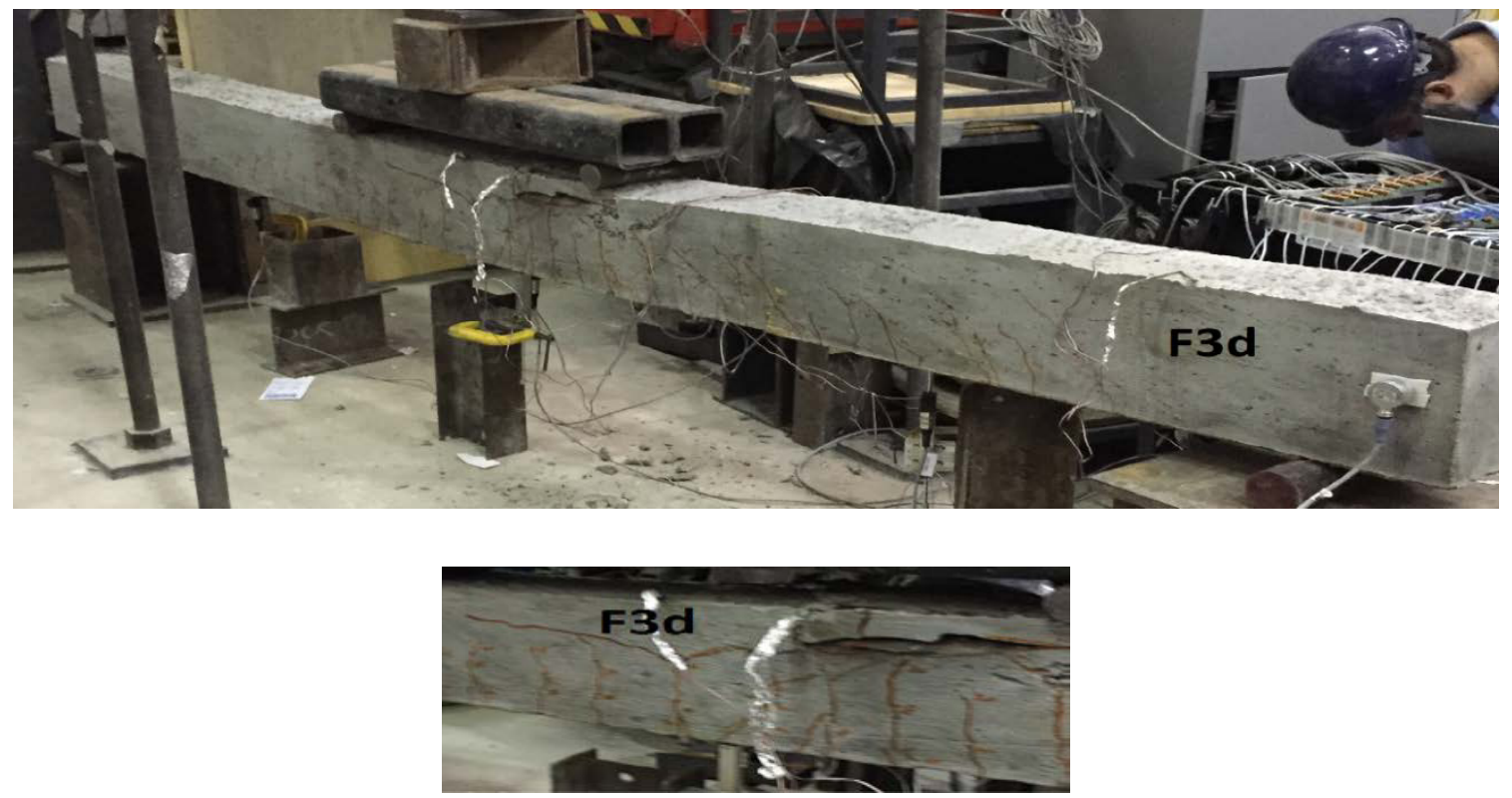

Figure 4.10(c) - Crack pattern and failure mode of doubly reinforced F3s flexural beam 


\subsubsection{Strain development in concrete and flexural/shear reinforcements}

Figures 4.11(a-c) show the strain development in flexural and shear reinforcements as well as in concrete throughout the loading history for LWSCC flexural beams. In singly reinforced F1s and F2s beams, tensile strain in bottom flexural reinforcement gradually increased with the increase in load up to the yielding (Figures 4.11a-b). Flexural reinforcement yielded in both beams at failure, as expected. Compression strain in concrete at the top of beam also increased gradually before showing large strain development at failure. There was no shear cracks observed in the singly reinforced beams until failure and strain in the shear reinforcement was very small during the test. Strain development in these beams confirmed flexure failure due to yielding of bottom flexural reinforcement.

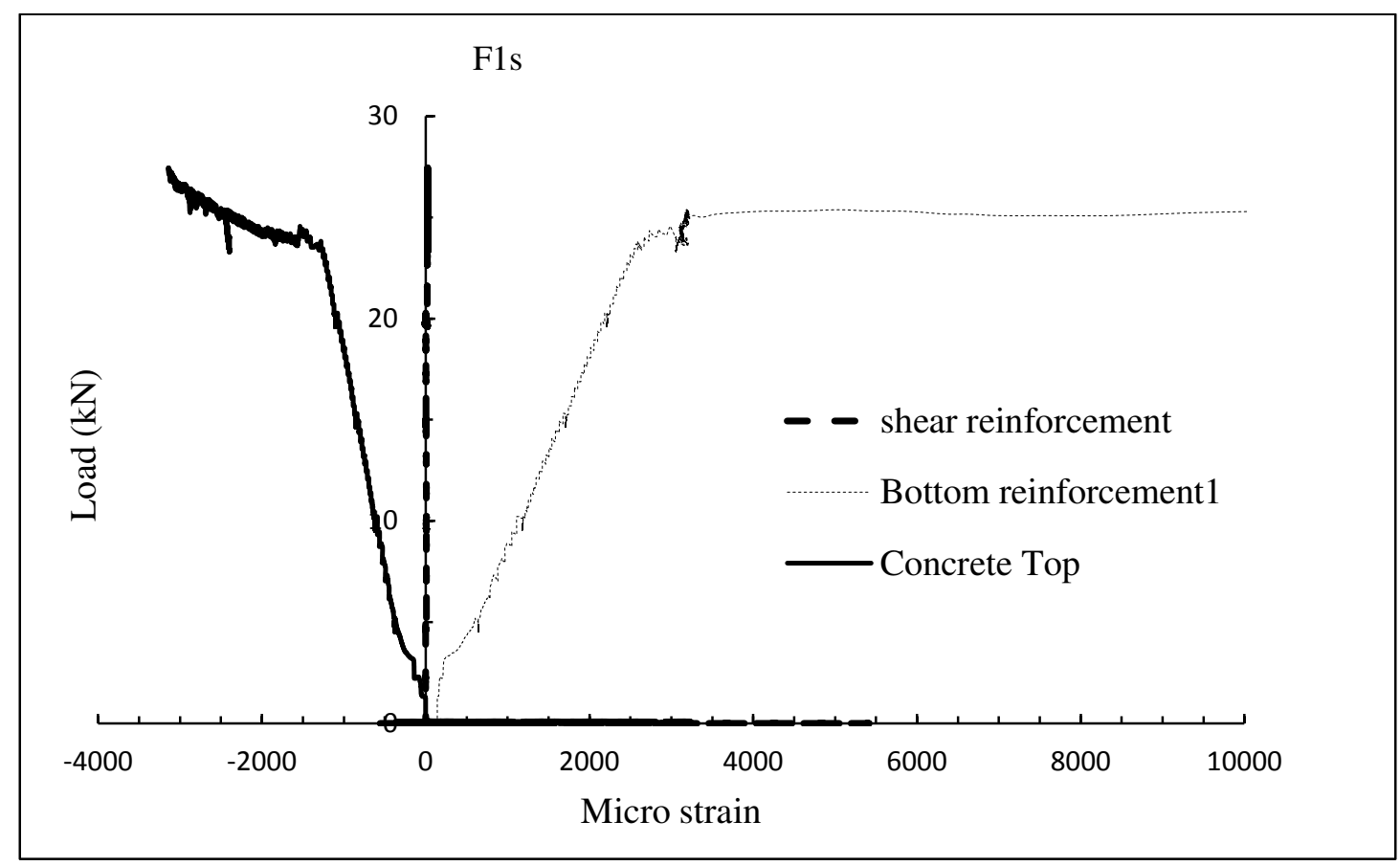

Figure 4.11(a) - Load-strain responses for tested singly reinforced LWSCC flexural beam (F1s) 


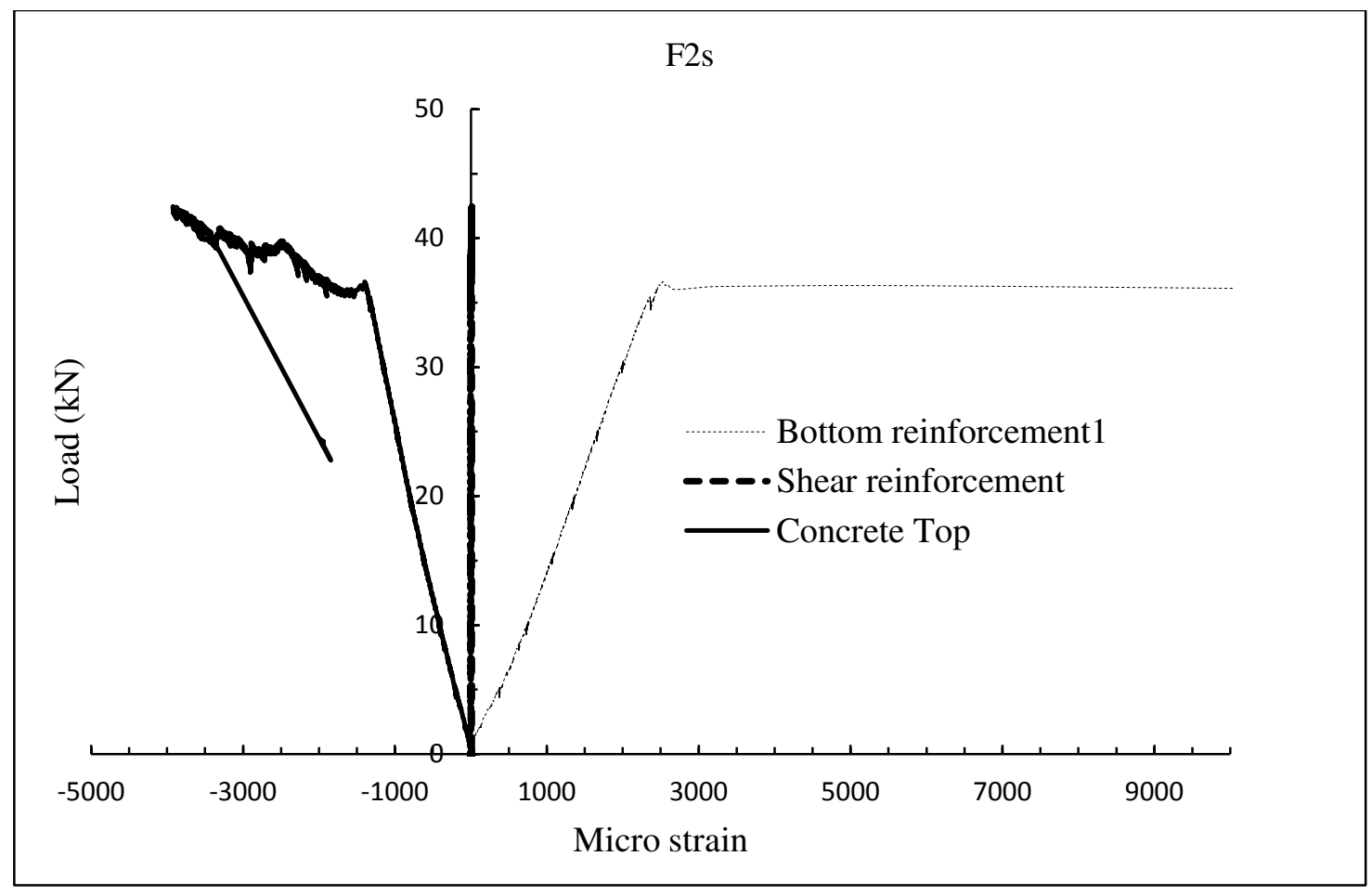

Figure 4.11(b) - Load-strain responses for tested singly reinforced LWSCC flexural beam (F2s)

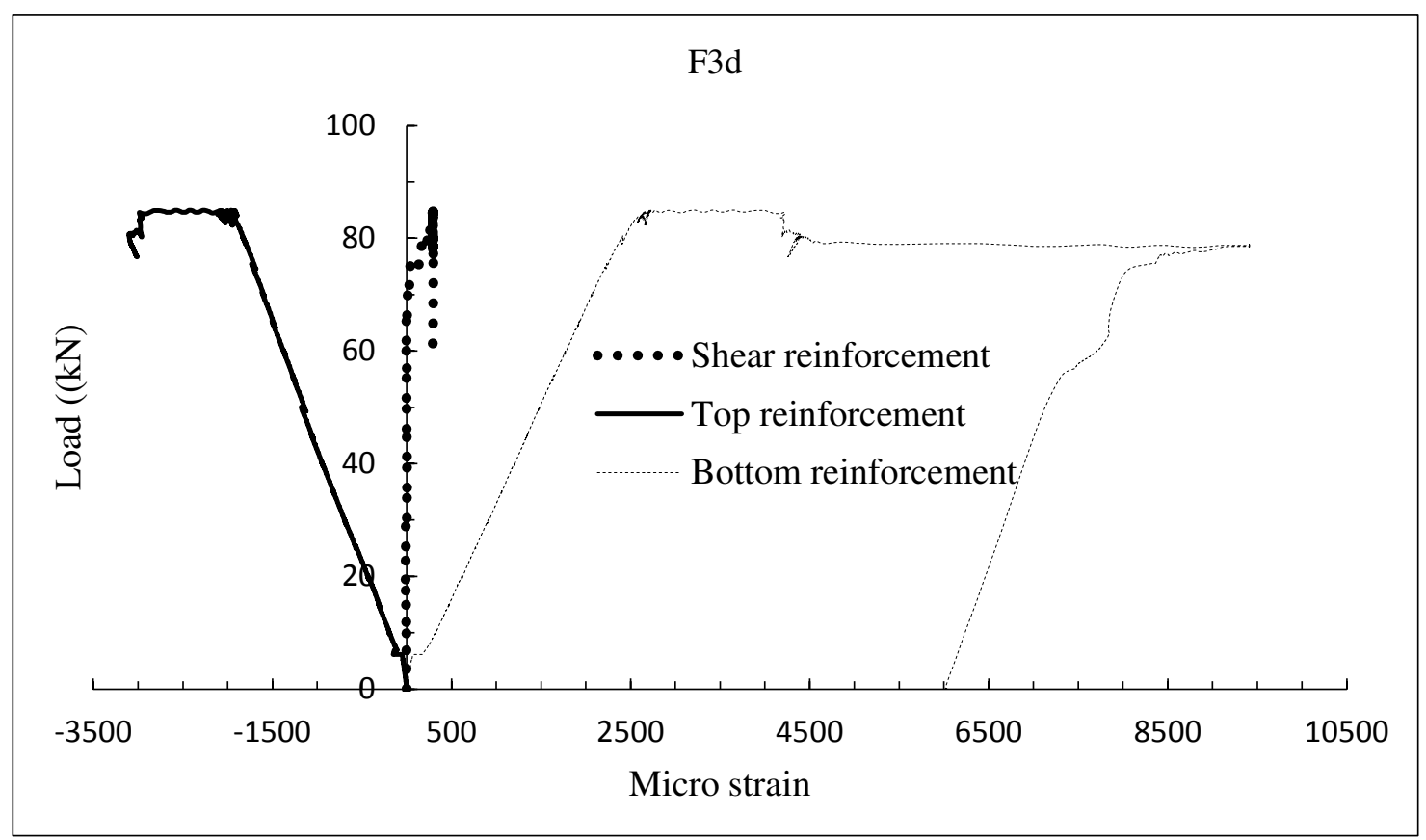

Figure 4.11(c) - Load-strain responses for tested doubly reinforced LWSCC flexural beam (F3d) 
In doubly reinforced LWSCC beam F3d, both top and bottom flexural reinforcements yielded under compression and tension, respectively before failure with bottom reinforcement reaching yielding first (Figure 4.11c). However, compression flexural reinforcement reached yielding before crushing of concrete. After formation of web-shear crack in doubly reinforced beam, strain in the shear reinforcement dramatically started to increase, however, shear reinforcement strain remained less than yield strain up to the failure of the beam (Figure 4.11c). Strain development in concrete and steel confirmed the flexural failure of doubly reinforced LWSCC beam F3d.

Table 4.6 summarizes the first steel yielding load, failure load, strain values at the onset of large strain development and failure strain for the LWSCC flexure beams. Maximum compressive strain at top concrete for the beams was found to be ranging between 2951 and 3872 micro strain at the ultimate stage. CSA A23.3-04.(2004) standard specified a limiting compressive strain equal to 3500 micro strain at ultimate stage. Ultimate stage concrete strain for the LWSCC beams under flexural loading were within the limit of 0.0035 as specified by the CSA A23.3Code. Bottom flexural reinforcement yielded before crushing of concrete which is evident from the fact that during bottom steel yielding stage, concrete compression strain ranged from 1254 to 1899 micro strain (less than 0.0035).

Table 4.6- Yield load, ultimate load/moment and strain at different ages for flexural beams

\begin{tabular}{|c|c|c|c|c|c|c|c|c|}
\hline \multirow[t]{2}{*}{ Beam } & \multirow{2}{*}{$\begin{array}{l}\text { Load at } \\
\text { first } \\
\text { steel } \\
\text { yielding } \\
(\mathrm{kN})\end{array}$} & \multicolumn{3}{|c|}{$\begin{array}{c}\text { Yielding stage (beginning of } \\
\text { large strain development) } \\
\text { (micro strain) }\end{array}$} & \multicolumn{3}{|c|}{$\begin{array}{l}\text { Ultimate/failure stage strain } \\
\text { (micro strain) }\end{array}$} & \multirow{2}{*}{$\begin{array}{l}\text { Ultimate } \\
\text { Load/moment } \\
\mathrm{kN}(\mathrm{kNm})\end{array}$} \\
\hline & & $\begin{array}{c}\text { Tension } \\
\text { rebar }\end{array}$ & $\begin{array}{c}\text { Concrete } \\
\text { top }\end{array}$ & Stirrup & $\begin{array}{c}\text { Tension } \\
\text { rebar }\end{array}$ & $\begin{array}{c}\text { Concrete } \\
\text { top }\end{array}$ & Stirrup & \\
\hline F1s & 23.6 & 2320 & 1254 & 0 & 9143 & 3040 & 0 & $25.0(14.7)$ \\
\hline $\mathrm{F} 2 \mathrm{~s}$ & 36.3 & 2425 & 1366 & 0 & 10037 & 3872 & 0 & $42.6(25.0)$ \\
\hline F3d & 84.0 & 2684 & 1899 & 290 & 9386 & 2951 & 296 & $84.0(49.4)$ \\
\hline
\end{tabular}




\subsubsection{Bending moment and beam end rotation development}

The moment-rotation curves of LWSCC flexural beams are shown in Figure 4.12. The curves show linear behavior similar to load-deflection response until yielding of steel reinforcement. After steel yielding of steel (flexural), beam rotation suddenly increased while insignificant amount of increase in the moment was observed. For LWSCC beams, end rotation was within the range of 2.6 -4.9 degrees prior to failure. Similar rotation angle was observed in the lightweight concrete beams made with oil palm shell aggregate by Teo et al. (2006). The moment capacity and rotation capacity increased and deceased, respectively with the increase of reinforcement ratio. (F3d had the highest reinforcement ratio followed by F2s and F1s having the same $a / d$ and d/b ratio).

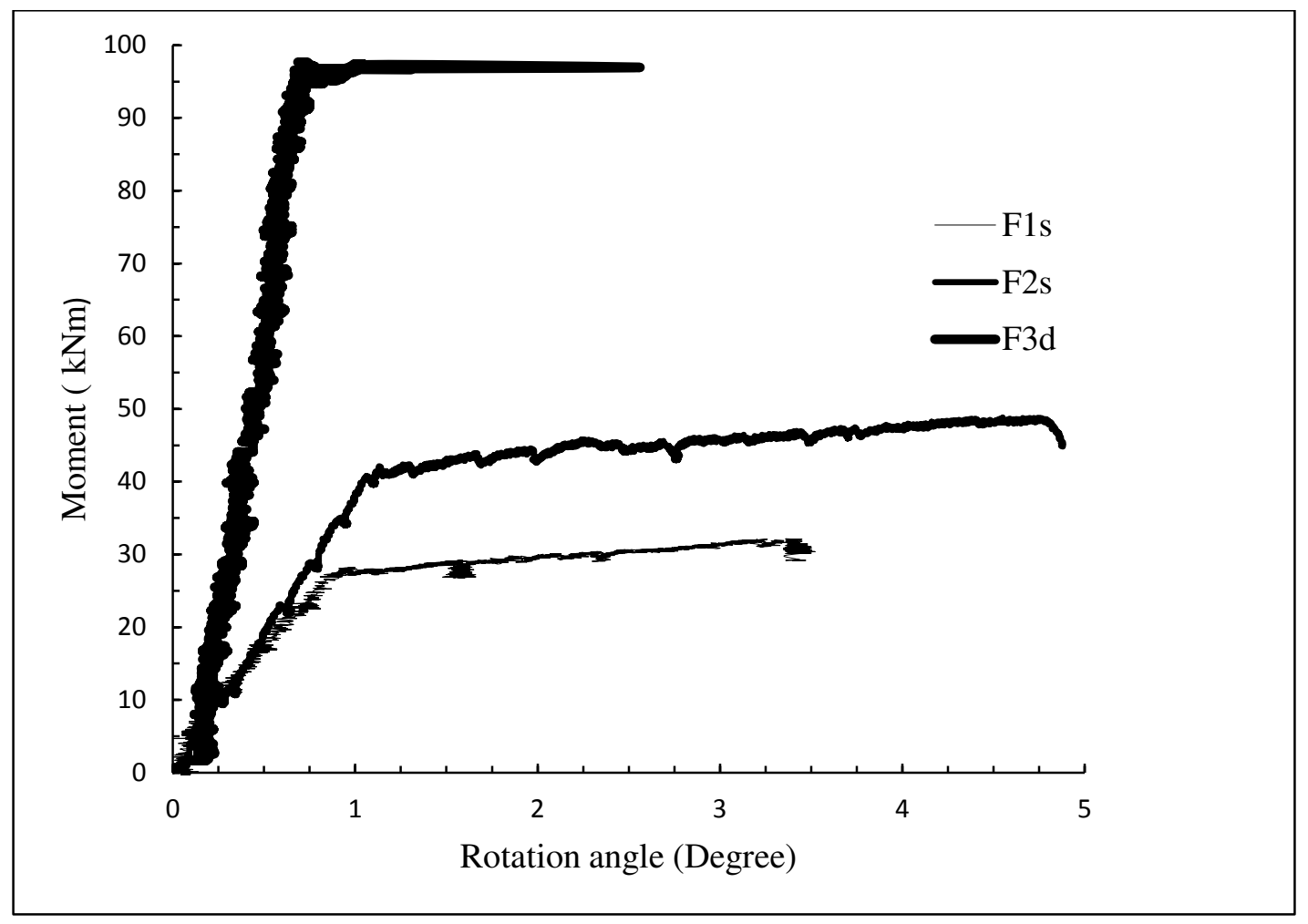

Figure 4.12-Experimental end rotations for tested flexural beams

\subsubsection{Ductility behavior of LWSCC flexural beams}

The ability of a member to deform without a significant loss of its strength is called as ductility. The ductility is defined by the curvature ductility index (DI). Here DI is assumed to be the ratio of deflection at failure/ultimate stage $\left(D_{u}\right)$ to that at first yielding of steel $\left(D_{y}\right)$. Table 4.7 presents the 
DI values for LWSCC flexural beams calculated based on $\mathrm{D}_{\mathrm{y}}$ and $\mathrm{D}_{\mathrm{u}}$ obtained from load deflection responses shown in Figure 4.9. In general, curvature ductility index is strongly affected by the crushing strain of concrete. LWSCC beams showed good ductility with a DI value of greater than 2.0. All three beams had shear reinforcements in the shear region only. The DI values could be increased by providing at least nominal shear reinforcement within the mid span or zero shear region. Increasing of tension reinforcement ratio resulted in the less ductile behavior, as the beam F1s with lowest reinforcement ratio exhibited the highest DI value of 3.8. Similar trend of decreasing ductility with the increase of reinforcement ration was observed for oil palm shell lightweight aggregate concrete beams by Teo et al. (2006).

Table 4.7-Curvature ductility index of LWSCC flexural beams.

\begin{tabular}{|l|c|c|c|c|c|}
\hline \multirow{2}{*}{$\begin{array}{l}\text { Beam } \\
\text { code }\end{array}$} & \multicolumn{2}{|c|}{ First steel yielding } & \multicolumn{2}{c|}{ Ultimate stage } & Ductility index (DI) \\
\cline { 2 - 5 } & $\begin{array}{c}\text { Load } \\
(\mathrm{kN})\end{array}$ & $\begin{array}{c}\text { Deflection } \\
\mathrm{D}_{\mathrm{y}}(\mathrm{mm})\end{array}$ & $\begin{array}{c}\text { Load } \\
\mathrm{kN}\end{array}$ & $\begin{array}{c}\text { Deflection } \\
\mathrm{D}_{\mathrm{u}}(\mathrm{mm})\end{array}$ & \\
\hline F1s & 23.6 & 16.8 & 25 & 64.9 & 3.8 \\
\hline F2s & 36.3 & 16.7 & 42.6 & 33.5 & 2.0 \\
\hline F3d & 84 & 22.9 & 85 & 49.9 & 2.2 \\
\hline \multicolumn{2}{|l|}{ a/d: constant at 5.75; b/d: $0.75 ;$ flexural reinforcement ratios: $0.66 \%, 1 \%$ and $1.7 \%$ for F1s, F2s and F3d, respectively; } \\
\\
*load: total load; Shear load: half of the load; Corresponding moment = load*a/2 $(\mathrm{a}=1175 \mathrm{~mm})$
\end{tabular}

\subsection{Summary}

The shear and flexure performance of LWSCC beams are described based on experimental results. Formation of first flexural crack was observed at lower loads among the LWSCC beams without shear reinforcement compared to their SCC counterparts. Angle of diagonal shear crack tend to increase with the increase of the height/depth of both LWSCC and SCC beams. Diagonal shear crack load varied from 48.1 to $68 \%$ of ultimate load for LWSCC beams compared to 51.8 to $69.5 \%$ of SCC beams. LWSCC beams had about 14 to 17 numbers of cracks at failure while around 6 to 9 numbers of cracks were observed for SCC beams. LWSCC beams showed more crack than SCC beams at failure. Shear resistance capacity of both LWSCC and SCC beams without shear reinforcement decreased with the increase of shear span to depth ratio $(\mathrm{a} / \mathrm{d})$. 
For LWSCC beams with shear reinforcement, diagonal shear crack load varied from 36 to $51 \%$ of ultimate loads for LWSCC and 48.1 to $68 \%$ of ultimate load. LWSCC with and without shear reinforcement had almost same diagonal cracking load capacity but ultimate load capacity was higher for beams with shear reinforcement.

All LWSCC flexural beams showed typical structural behavior in flexure, since the beams were under-reinforced. Yielding of the tensile reinforcement happened before crushing of the compression concrete in the pure bending region. The ultimate load of the beam increased with the increase of steel reinforcement ratio. LWSCC beams showed good ductility behavior since all the beams had shown significant amount of deformation before failure. 


\section{CHAPTER FIVE}

\section{THEORITICAL ANALYSIS OF SHEAR AND FLEXURAL CAPACITIES OF EXPERIMENTAL BEAMS}

\subsection{Introduction}

This Chapter compares the experimental shear capacities of lightweight self-consolidating concrete (LWSCC) beams with/without shear reinforcement and self-consolidating concrete (SCC) beams without shear reinforcement with those obtained from Code based equations/procedures namely ACI 318-05 (2005), CSA A23.3-04 (2004) and BS8110-97 (1997), In addition, experimental shear capacities of concretes made with six different types of lightweight aggregates from previous research studies are also compared with those obtained from above three Codes. Shear resistance capacity and shear transfer mechanism in different types of lightweight aggregate concrete beams are also investigated. The experimental cracking and ultimate moment capacities of LWSCC flexural beams are compared with those obtained from CSA A23.3-04 Code.

\subsection{Codes and the prediction of shear capacity of beams}

An accepted rational physical method does not yet exist (specifically for lightweight or lightweight self-consolidating concrete) due to the complex nature of the shear failure mechanism in reinforced concrete beams. Most design codes use empirical equations to calculate the shear capacity of the reinforced normal concrete beams and introduce some factors/modifications to be applicable to lightweight concrete (LWC). Codes normally use reduction factor to take into account weaker LWC with lower tensile strength. Therefore, it is important to study the performance of such Code based equations/procedures in predicting SCC especially LWSCC beams with lower volume of aggregate. For reinforced concrete beam with shear reinforcement, the total shear resistance $\left(\mathrm{V}_{\mathrm{n}}\right)$ can be calculated by adding concrete shear resistance $\left(V_{c}\right)$ to the transverse shear reinforcement contribution $\left(\mathrm{V}_{\mathrm{s}}\right)$.

$$
\mathrm{V}_{\mathrm{n}}=\mathrm{V}_{\mathrm{c}}+\mathrm{V}_{\mathrm{s}}
$$


In this study, the performance of American (ACI 318-05 2005) Canadian (CSA A23.3-04 2004) and British (BS8110 1997) Codes in predicting the shear and flexure resistance of LWC/LWSCC beams based on experimental results of current and previous research studies. These Codes are already introduced in Chapter Two, however, they are reintroduced again in this section.

ACI 318-05 (2005) presents the following basic equations (in SI units) for the shear resistance of concrete and shear reinforcement:

$\mathrm{V}_{\mathrm{c}}=\lambda\left(\sqrt{\mathrm{f}_{\mathrm{c}}^{\prime}}+120 \mathrm{p}_{\mathrm{w}} \frac{\mathrm{V}_{\mathrm{u}} \mathrm{d}}{\mathrm{M}_{\mathrm{u}}}\right) \frac{\mathrm{b}_{\mathrm{w}} \mathrm{d}}{7} \leq 0.3 \sqrt{\mathrm{f}_{\mathrm{c}}^{\prime}} \mathrm{b}_{\mathrm{w}} \mathrm{d}$

$V_{s}=\frac{A_{v} f_{y t} d}{s}$

$\chi$ is the reduction factor (equal to 0.75 for all- lightweight concrete, 0.85 for sand lightweight concrete and 1.0 for normal weight concrete).

According to Canadian Code (CSA A23.3-04, 2004) based on modified compression field theory, $\mathrm{V}_{\mathrm{c}}$ and $\mathrm{V}_{\mathrm{s}}$ can be obtained from the following equations:

$\mathrm{V}_{\mathrm{C}}=\lambda \beta \sqrt{\mathrm{f}_{\mathrm{c}}^{\prime}} \mathrm{b}_{\mathrm{w}} \mathrm{d}_{\mathrm{v}}$

The value of $\beta$ shall be determined from:

$$
\begin{aligned}
\beta & =\frac{520}{\left[\left(1+1500 \varepsilon_{\mathrm{x}}\right)\left(1000+\mathrm{S}_{\mathrm{ze}}\right)\right]} \\
\mathrm{S}_{\mathrm{ze}} & =\frac{35 \mathrm{~s}_{\mathrm{z}}}{15}+\mathrm{a}_{\mathrm{g}} \leq 0.85 \mathrm{~S}_{\mathrm{z}} \\
\varepsilon_{\mathrm{X}} & =\frac{\frac{\mathrm{M}_{\mathrm{f}}}{\mathrm{d}_{\mathrm{v}}}+\mathrm{V}_{\mathrm{f}}}{2 \mathrm{~A}_{\mathrm{s}} \mathrm{E}_{\mathrm{s}}} \\
\mathrm{V}_{\mathrm{s}} & =\frac{\mathrm{A}_{\mathrm{v}} \mathrm{f}_{\mathrm{y}} \mathrm{d}_{\mathrm{v}}}{\mathrm{s}}
\end{aligned}
$$

$\chi$ is the reduction factor equal to 0.75 for low density concrete (with an air dry density less than $1850 \mathrm{~kg} / \mathrm{m}^{3}$ ), 0.85 for semi lightweight concrete (with an air dry density between 1850 and 2150 $\mathrm{kg} / \mathrm{m}^{3}$ ) and 1.0 for normal weight concrete (with air dry density between 2150 and $2500 \mathrm{~kg} / \mathrm{m}^{3}$ ). According to British standards (BS8110-part1 1997), $\mathrm{V}_{\mathrm{c}}$ and $\mathrm{V}_{\mathrm{s}}$ can be calculated from:

$$
\begin{aligned}
& \mathrm{V}_{\mathrm{C}}=\lambda 0.79\left(\frac{100 \mathrm{~A}_{\mathrm{S}}}{\mathrm{bd}}\right)^{\frac{1}{3}}\left(\frac{400}{\mathrm{~d}}\right)^{\frac{1}{4}}\left(\frac{\mathrm{f}_{\mathrm{cu}}}{25}\right)^{\frac{1}{3}} \\
& \mathrm{~V}_{\mathrm{S}}=\frac{\mathrm{A}_{\mathrm{sv}}}{\mathrm{S}_{\mathrm{v}}} 0.95 \mathrm{f}_{\mathrm{yv}} \mathrm{d}
\end{aligned}
$$

$\chi$ is the reduction factor equal to 0.8 for lightweight concretes and 1.0 for normal weight concrete. 


\subsubsection{Shear strength prediction of slag aggregate beams without shear reinforcement}

Shear resistances of LWSCC beams (with slag aggregate) without shear reinforcement from current experiments and various code based predictions are compared in Table 5.1. It can be observed that all design codes were conservative in predicting the ultimate shear strength of LWSCC beams. ACI 318 provided the highest safety margin (ratio ranged between 1.5 and 1.9 for all tested LWSCC beams compared to CSA A23.3 (ratio ranged between 1.4 and 1.8) and BS8110 (ratio ranged between 1.2 and 1.8). CSA-A23.3 and BS8110 codes estimated the shear capacity of SCC-200 and SCC-300 beams reasonably but overestimated SCC-150 beam. In both type of beams (LWSCC and SCC), all codes predictions were conservative and conservativeness increased with the increase of beam depth or decrease in shear span to depth ratio $(\mathrm{a} / \mathrm{d})$. It should be noted that conservativeness was higher of LWSCC beams compared to normal weight SCC beams even after the use of reduction factors specified in the Codes. However, the predicted shear capacity differences for similar beams between the Codes were not significant. For the calculation of lightweight concrete shear capacity, ACI 318 and CSA A23.3 Codes use the reduction factor of 0.75 but BS8110 use the reduction factor of 0.8 , Therefore, BS8110 predictions were higher than those of CSA A23.3 and ACI 318.

Table 5.1- Shear resistance of beams without shear reinforcement from experiment and code based predictions

\begin{tabular}{|c|c|c|c|c|c|c|c|}
\hline \multirow{3}{*}{$\begin{array}{l}\text { Beams } \\
\text { (Authors } \\
\text { research) }\end{array}$} & \multicolumn{4}{|c|}{ Total shear resistance, $\mathrm{V}_{\mathrm{n}}=\mathrm{V}_{\mathrm{c}}(\mathrm{kN})$} & \multirow{2}{*}{\multicolumn{3}{|c|}{$\begin{array}{l}\text { Ratio of experimental to Code predicted } \\
\text { shear }\end{array}$}} \\
\hline & \multirow{2}{*}{$\begin{array}{l}\text { Experiment } \\
\text { (Exp) }\end{array}$} & \multicolumn{3}{|c|}{ Code-based predictions } & & & \\
\hline & & ACI & CSA & BS8110 & Exp/ACI & Exp/CSA & Exp/BS8110 \\
\hline LWSCC-150 & 16.0 & 10.2 & 10.7 & 12.5 & 1.5 & 1.4 & 1.2 \\
\hline LWSCC-200 & 22.5 & 13.3 & 13.4 & 14.4 & 1.6 & 1.6 & 1.5 \\
\hline LWSCC-300 & 40.0 & 20.8 & 21.4 & 21.3 & 1.9 & 1.8 & 1.8 \\
\hline SCC-150 & 16.5 & 16.3 & 17.9 & 17.9 & 1.0 & 0.9 & 0.9 \\
\hline SCC-200 & 27.5 & 21.4 & 20.3 & 20.6 & 1.2 & 1.3 & 1.3 \\
\hline SCC-300 & 48.0 & 33.1 & 33.5 & 30.4 & 1.4 & 1.4 & 1.5 \\
\hline
\end{tabular}




\subsubsection{Shear strength prediction of slag aggregate LWSCC beams with shear reinforcement}

Shear resistances of LWSCC beams (with slag aggregate) with shear reinforcement from experiment and Code predictions are compared in Table 5.2. It can be observed that all design codes had a higher margin of safety in predicting concrete shear strength $\left(\mathrm{V}_{\mathrm{c}}\right)$. Mean ratio of experimental to code predicted concrete shear resistance were 2.02, 2.11 and 1.71 for ACI 318, CSA-A23.3 and BS8110, respectively. BS8110 had shown better predictability (in terms of ratio of experimental to predicted) than other two codes because it adopts a reduction factor of 0.8 while ACI 318 and BS8110 use a reduction factor of 0.75 in the LWC lightweight concrete shear resistance calculation.

Table 5.2- Shear resistance of beams shear reinforcement from experiment and code based predictions

\begin{tabular}{|c|c|c|c|c|c|c|c|}
\hline \multirow[t]{3}{*}{ Beam } & \multicolumn{4}{|c|}{ Concrete shear resistance, $\mathrm{V}_{\mathrm{c}}(\mathrm{kN})$} & \multirow{2}{*}{\multicolumn{3}{|c|}{$\begin{array}{c}\text { Ratio of experimental to Code } \\
\text { predicted shear }\end{array}$}} \\
\hline & \multirow{2}{*}{$\begin{array}{l}\text { Experiment } \\
\quad(\text { Exp) }\end{array}$} & \multicolumn{3}{|c|}{ Code-based predictions } & & & \\
\hline & & ACI & CSA & BS8110 & $\mathrm{Exp} / \mathrm{ACI} /$ & $\mathrm{Exp} / \mathrm{CSA}$ & Exp/BS8110 \\
\hline LWSCC-156s & 20.0 & 10.5 & 10.0 & 13.8 & 1.90 & 2.00 & 1.40 \\
\hline LWSCC-206s & 25.0 & 13.7 & 13.3 & 15.9 & 1.80 & 1.80 & 1.50 \\
\hline \multirow[t]{4}{*}{ LWSCC-306s } & 50.0 & 21.4 & 20.3 & 23.5 & 2.30 & 2.40 & 2.10 \\
\hline & \multicolumn{4}{|c|}{ Stirrups shear resistance, $\mathrm{V}_{\mathrm{s}}(\mathrm{kN})$} & \multirow{2}{*}{\multicolumn{3}{|c|}{$\begin{array}{l}\text { Ratio of experimental to Code } \\
\text { predicted shear }\end{array}$}} \\
\hline & $\begin{array}{l}\text { Experiment } \\
\quad(\text { Exp) }\end{array}$ & \multicolumn{3}{|c|}{ Code-based prediction $* *$} & & & \\
\hline & & $\mathrm{ACI}$ & CSA & BS8110 & Exp/ACI & Exp/CSA & Exp/BS8110 \\
\hline LWSCC-156s* & 19.0 & 23.7 & 23.7 & 22.5 & - & - & - \\
\hline LWSCC-206s* & 27.5 & 33.2 & 33.2 & 31.6 & - & - & - \\
\hline LWSCC-306s & 86.5 & 48.3 & 48.3 & 45.9 & 1.20 & 1.20 & 1.30 \\
\hline \multicolumn{8}{|c|}{$*$ shear reinforcement not yielded; ** considering yielding of sh } \\
\hline 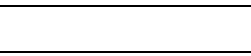 & \multicolumn{4}{|c|}{ Beam shear resistance, $V_{n}=\left(V_{c}+V_{s}\right) k N$} & \multirow{2}{*}{\multicolumn{3}{|c|}{$\begin{array}{l}\text { Ratio of experimental to Code } \\
\text { predicted shear }\end{array}$}} \\
\hline (n) & $\begin{array}{l}\text { Experiment } \\
(\operatorname{Exp})\end{array}$ & \multicolumn{3}{|c|}{ Code-based prediction** } & & & \\
\hline & & $\mathrm{ACI}$ & CSA & BS8110 & Exp/ACI & Exp/CSA & Exp/BS8110 \\
\hline LWSCC-156s & 39.0 & 34.2 & 33.7 & 36.3 & 1.14 & 1.16 & 1.07 \\
\hline LWSCC-206s & 52.5 & 46.9 & 46.5 & 47.5 & 1.12 & 1.13 & 1.11 \\
\hline LWSCC-306s & 136.5 & 69.7 & 68.6 & 69.4 & 1.96 & 1.99 & 1.97 \\
\hline
\end{tabular}


LWSCC-156s and LWSCC-206s beams failed in shear but without yielding of shear reinforcement. Hence, the ratio of experimental (shear reinforcement not yielded) to Code predicted (assuming yielding of shear reinforcement) values were low (ranging between 1.07 and 1.16) - still codes are safe but with low factor of safety. Only LWSCC-306s beam failed by yielding of shear reinforcement prior to shear failure, so this beam's experimental shear capacity can be a true measure of the performance of the Codes. LWSCC-306S beam's predicted total shear resistance $\left(\mathrm{V}_{\mathrm{c}}+\mathrm{V}_{\mathrm{s}}\right)$ capacities by CI 318, CSA-A23.3 and BS8110 were very close (Table 5.2). All three codes underestimated the shear capacity of this beam and the safety margin of the code predictions ranged between 1.96 and 1.99 .

Overall, current reduction factors suggested by the Codes for lightweight concrete can be increased for the prediction of shear resistance of LWSCC beams. This is reasonable considering the lower volume of weak lightweight aggregate (hence higher volume of strong paste) in LWSCC compared to lightweight concrete.

\subsection{Analysis of previous experimental studies on shear resistance of lightweight concrete beams and Performance of existing Codes}

Data from author's research and previous research studies were used to analyze the shear resistance of LWSCC and LWC beams and to assess the predictive ability of ACI 318 (2005), CSA-A23.3 (2004) and BS110 (1997) Codes. Forty rectangular LWC beams without shear reinforcement and twenty rectangular LWC beams with shear reinforcement were selected from previous research studies conducted by researchers as shown in Table 5.4 in addition to six LWSCC beams tested in the current research. These beams were made of six different types of lightweight aggregates such as Phyllite (P), palm oil clinker (POC), Palm kernel shell (PKS), coconut shell (CS), Expanded clay (EC), Expanded shale (ES) and blast furnace slag (Table 5.3). The parameters affecting the shear resistance had wide range such as: concrete compressive strength ( $f^{\prime} \mathrm{c}$ ) ranged between $23 \mathrm{MPa}$ and $68.5 \mathrm{MPa}$, shear span to depth ratio $(\mathrm{a} / \mathrm{d})$ ranged between 1.0 and 4.0 and longitudinal reinforcement ratio $(\rho)$ ranged between $0.3 \%$ and $3.4 \%$ as shown in the Table 5.4. For the beam with the shear reinforcement, information on shear reinforcement spacing, yield strength of rebar and rebar diameter were also collected 
Table 5.3- Data summary for the lightweight concrete beams

\begin{tabular}{|c|c|c|c|c|c|c|}
\hline \multirow[t]{2}{*}{ Researchers } & \multirow{2}{*}{$\begin{array}{l}\text { Lightweight } \\
\text { aggregate } \\
\text { types }\end{array}$} & \multirow{2}{*}{$\begin{array}{c}\text { Concrete } \\
\text { compressive } \\
\text { strength (f'c) } \\
(\mathrm{MPa})\end{array}$} & \multirow{2}{*}{$\begin{array}{l}\text { Shear } \\
\text { span to } \\
\text { depth } \\
\text { ratio }(\mathrm{a} / \mathrm{d})\end{array}$} & \multirow{2}{*}{$\begin{array}{l}\text { Percentage of } \\
\text { longitudinal } \\
\text { reinforcement } \\
(\rho)\end{array}$} & \multicolumn{2}{|c|}{$\begin{array}{c}\text { Number } \\
\text { of beam specimen }\end{array}$} \\
\hline & & & & & $\begin{array}{l}\text { Without } \\
\text { stirrups }\end{array}$ & $\begin{array}{c}\text { With } \\
\text { stirrups }\end{array}$ \\
\hline \multicolumn{7}{|c|}{ LWC beams } \\
\hline $\begin{array}{l}\text { Adom and } \\
\text { Afrifa (2013) }\end{array}$ & Phyllite (P) & $23.0-23.5$ & 2.4 & $1.0-2.0$ & 10 & 6 \\
\hline $\begin{array}{l}\text { Mohammed } \\
\text { et al. (2013) }\end{array}$ & $\begin{array}{c}\text { Palm oil } \\
\text { clinker (POC) }\end{array}$ & $20.3-39.8$ & $1.0-3.0$ & $0.3-3.4$ & 7 & - \\
\hline $\begin{array}{l}\text { Alengaram } \\
\text { et al. (2011) }\end{array}$ & $\begin{array}{l}\text { Palm kernel } \\
\text { shell (PKS) }\end{array}$ & $32.6-37.9$ & $1.44-2.15$ & $0.7-3.70$ & 2 & 2 \\
\hline $\begin{array}{l}\text { Gunasekaran } \\
\text { et al. (2013) }\end{array}$ & $\begin{array}{l}\text { Coconut shell } \\
\text { (CS) }\end{array}$ & 26.7 & 4.0 & $0.52-0.75$ & 2 & 2 \\
\hline Juan (2011) & $\begin{array}{l}\text { Expanded clay } \\
\text { (EC) }\end{array}$ & $42.6-69.8$ & $1.5-3.5$ & 0.63 & 15 & - \\
\hline Ahmed (2011) & $\begin{array}{l}\text { Expanded } \\
\text { shale (ES) }\end{array}$ & $39.5-68.5$ & $1.5-4.0$ & $1.1-2.2$ & 4 & 12 \\
\hline \multicolumn{7}{|c|}{ LWSCC beams } \\
\hline Author & $\begin{array}{l}\text { Blast furnace } \\
\text { slag (slag) }\end{array}$ & $33.5-36.0$ & $1.05-2.14$ & $1.15-1.6$ & 3 & 3 \\
\hline
\end{tabular}

\subsubsection{Analysis of the influence of aggregate type on the post-cracking and ultimate shear resistance}

Aggregate interlock mechanism and dowel action contribute significantly to the post-cracking shear resistance (that ranges from $V_{c}$ to $V_{u}$ ) of reinforced concrete beams without shear reinforcement. To characterize the performance of aggregate during the post diagonal cracking shear transfer stage, shear resistance factor (SRF) was introduced in Chapter Four. SRF was defined as the ratio of the failure load $\left(\mathrm{V}_{\mathrm{u}}\right)$ to the load at the first diagonal crack $\left(\mathrm{V}_{\mathrm{c}}\right)$ :

$\mathrm{SRF}=\frac{\mathrm{V}_{\mathrm{u}}}{\mathrm{V}_{\mathrm{c}}}$

Shear strength of all LWC and LWSCC beams having different cross-sections and concrete compressive strength $\left(f^{\prime}\right.$ c) was converted into normalized shear stress $\left(V_{n c z}\right)$ to analyze and compare the performance in terms aggregate types as follows ( $b$ and $\mathrm{d}$ are the width and effective depth of the beam, respectively):

Normalized shear stress, $\quad \mathrm{V}_{\mathrm{ncz}}=\frac{\mathrm{v}_{\mathrm{c}}}{\mathrm{bd} \sqrt{f_{c}^{\prime}}}$ 
Table 5.4- Shear resistance factor and nominalized shear stress for beams without shear reinforcement

\begin{tabular}{|c|c|c|c|c|c|}
\hline $\begin{array}{c}\text { Beam } \\
\text { designations }\end{array}$ & $\begin{array}{l}\text { Aggregate } \\
\text { type }\end{array}$ & $\begin{array}{c}\text { Shear load at } \\
\text { first } \\
\text { diagonal } \\
\text { crack }(\mathrm{Vc})(\mathrm{kN})\end{array}$ & $\begin{array}{c}\text { Shear load at } \\
\text { failure } \\
(\mathrm{Vu})(\mathrm{kN})\end{array}$ & $\begin{array}{c}\text { Shear resistance } \\
\text { factor }(\mathrm{SRF}= \\
\left.\mathrm{V}_{\mathrm{u}} / \mathrm{V}_{\mathrm{c}}\right)\end{array}$ & $\begin{array}{c}\text { Normalized } \\
\text { shear stress } \\
\left(\mathrm{V}_{\mathrm{ncz}}\right)\end{array}$ \\
\hline \multicolumn{6}{|c|}{ Author } \\
\hline LWSCC-150 & Slag & 16 & 23.5 & 1.47 & 0.22 \\
\hline LWSCC-200 & Slag & 22.5 & 37.5 & 1.67 & 0.22 \\
\hline LWSCC-300 & Slag & 40 & 83.0 & 2.08 & 0.27 \\
\hline \multicolumn{6}{|c|}{ Alengaram et al. (2011) } \\
\hline PKSC-P1 & PKS & 27 & 67.0 & 2.48 & 0.15 \\
\hline PKSC-P2 & PKS & 28 & 59.0 & 2.11 & 0.16 \\
\hline \multicolumn{6}{|c|}{ Mohammed et al. (2013) } \\
\hline AD-3 & POC & 23 & 27.5 & 1.20 & 0.10 \\
\hline AD-1 & POC & 16 & 19.5 & 1.22 & 0.07 \\
\hline WC-1 & POC & 13 & 21.5 & 1.65 & 0.07 \\
\hline WC-3 & POC & 14 & 25.0 & 1.79 & 0.06 \\
\hline SR-1 & POC & 14 & 30.5 & 2.18 & 0.07 \\
\hline SR-3 & POC & 7 & 12.5 & 1.79 & 0.03 \\
\hline \multicolumn{6}{|c|}{ Gunasekaran et al. (2013) } \\
\hline $\mathrm{AD} / \mathrm{WC} / \mathrm{SR}-2$ & $\mathrm{CS}$ & 10.0 & 23.0 & 2.30 & 0.05 \\
\hline WOS1-CSAC & $\mathrm{CS}$ & 15.7 & 22.5 & 1.43 & 0.11 \\
\hline WOS2-CSAC & $\mathrm{CS}$ & 17.4 & 23.3 & 1.34 & 0.13 \\
\hline \multicolumn{6}{|c|}{ Juan (2011) } \\
\hline S.B 1.5 & $\mathrm{EC}$ & 37.5 & 67.0 & 1.79 & 0.20 \\
\hline S.B 2 & $\mathrm{EC}$ & 33.5 & 42.7 & 1.27 & 0.18 \\
\hline S.B 3 & $\mathrm{EC}$ & 34.3 & 36.1 & 1.05 & 0.18 \\
\hline S.B 3.5 & $\mathrm{EC}$ & 27.5 & 28.3 & 1.03 & 0.15 \\
\hline SB C50 1.5 & $\mathrm{EC}$ & 65.0 & 74.0 & 1.14 & 0.33 \\
\hline SB C50 2.0 & $\mathrm{EC}$ & 37.0 & 56.7 & 1.53 & 0.19 \\
\hline SB C50 3.0 & $\mathrm{EC}$ & 30.0 & 30.3 & 1.01 & 0.15 \\
\hline SB C50 3.5 & $\mathrm{EC}$ & 31.5 & 34.3 & 1.09 & 0.16 \\
\hline $\begin{array}{l}\text { SB C50 P0.78 } \\
3.0\end{array}$ & $\mathrm{EC}$ & - & 17.8 & - & 0.16 \\
\hline SA C50 3.0 & $\mathrm{EC}$ & 32.5 & 37.8 & 1.16 & 0.15 \\
\hline SG C50 3.0 & $\mathrm{EC}$ & 35.0 & 35.3 & 1.01 & 0.16 \\
\hline SB C70 1.5 & $\mathrm{EC}$ & 67.5 & 72.5 & 1.07 & 0.28 \\
\hline SB C70 2.0 & $\mathrm{EC}$ & 40.0 & 57.2 & 1.43 & 0.17 \\
\hline SB C70 3.0 & $\mathrm{EC}$ & 33.0 & 39.4 & 1.19 & 0.14 \\
\hline SB C70 3.5 & $\mathrm{EC}$ & 31.3 & 31.4 & 1.00 & 0.13 \\
\hline \multicolumn{6}{|c|}{ Ahmed (2011) } \\
\hline B4C7.40S0 & ES & 35.0 & 49.4 & 1.41 & 0.16 \\
\hline B3C7.40S0 & ES & 43.0 & 59.9 & 1.39 & 0.10 \\
\hline B2C7.40S0 & ES & 52.0 & 64.5 & 1.24 & 0.06 \\
\hline B2.C7.40S0-2 & ES & 58.0 & 69.2 & 1.19 & 0.07 \\
\hline
\end{tabular}


Table 5.4 Continue

\begin{tabular}{|l|l|l|l|l|l|}
\hline \multicolumn{7}{|c|}{ Adom and Afrifa (2013) } \\
\hline P1 & P & 40.0 & 68.0 & 1.70 & 0.23 \\
\hline P2 & P & 60.0 & 78.0 & 1.30 & 0.35 \\
\hline P3 & P & 44.0 & 66.0 & 1.50 & 0.31 \\
\hline P4 & P & 66.0 & 80.0 & 1.21 & 0.46 \\
\hline P5 & P & 28.0 & 50.0 & 1.79 & 0.30 \\
\hline P6 & P & 46.0 & 50.0 & 1.09 & 0.49 \\
\hline P7 & P & 24.0 & 40.0 & 1.67 & 0.33 \\
\hline P8 & P & 28.0 & 46.0 & 1.64 & 0.38 \\
\hline P9 & P & 18.0 & 28.0 & 1.56 & 0.38 \\
\hline P10 & P & 24.0 & 40.0 & 1.67 & 0.51 \\
\hline
\end{tabular}

The post diagonal cracking resistance capacity of LWSCC and LWC beams with different aggregates is described using SRF. Shear resistance factor and normalized shear strength values of all LWSCC and LWC beams from various researchers are shown in Table 5.4

Mean shear resistance factor and mean normalized shear strength of LWSCC (from author) and LWC (from previous researchers) beams with different types of lightweight aggregates are shown in Figure 5.1. Mean shear resistance factor (SRF) for palm kernel shell (PKS) LWC beams is found to be higher than those made with other types of lightweight aggregates with POC showing the lowest.

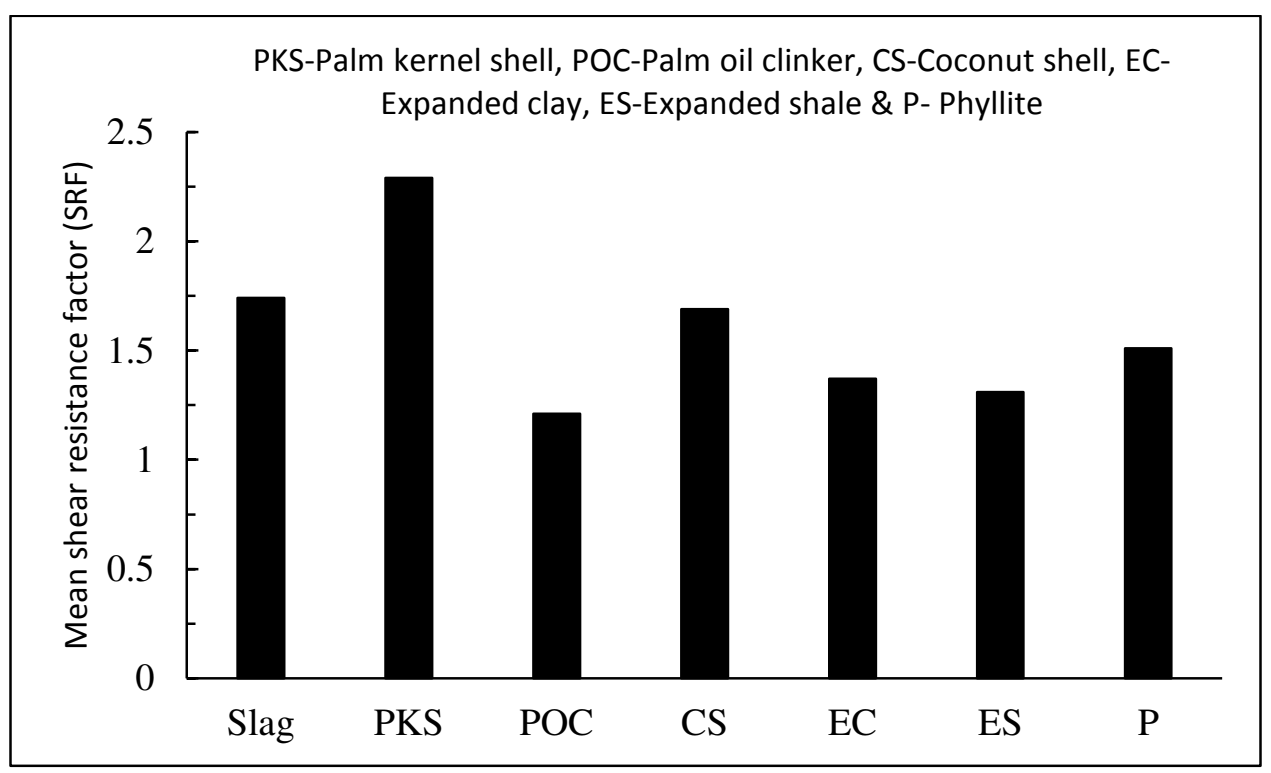

Figure 5.1-Mean shear resistance factor for LWSCC/LWC beams with different types of aggregate 


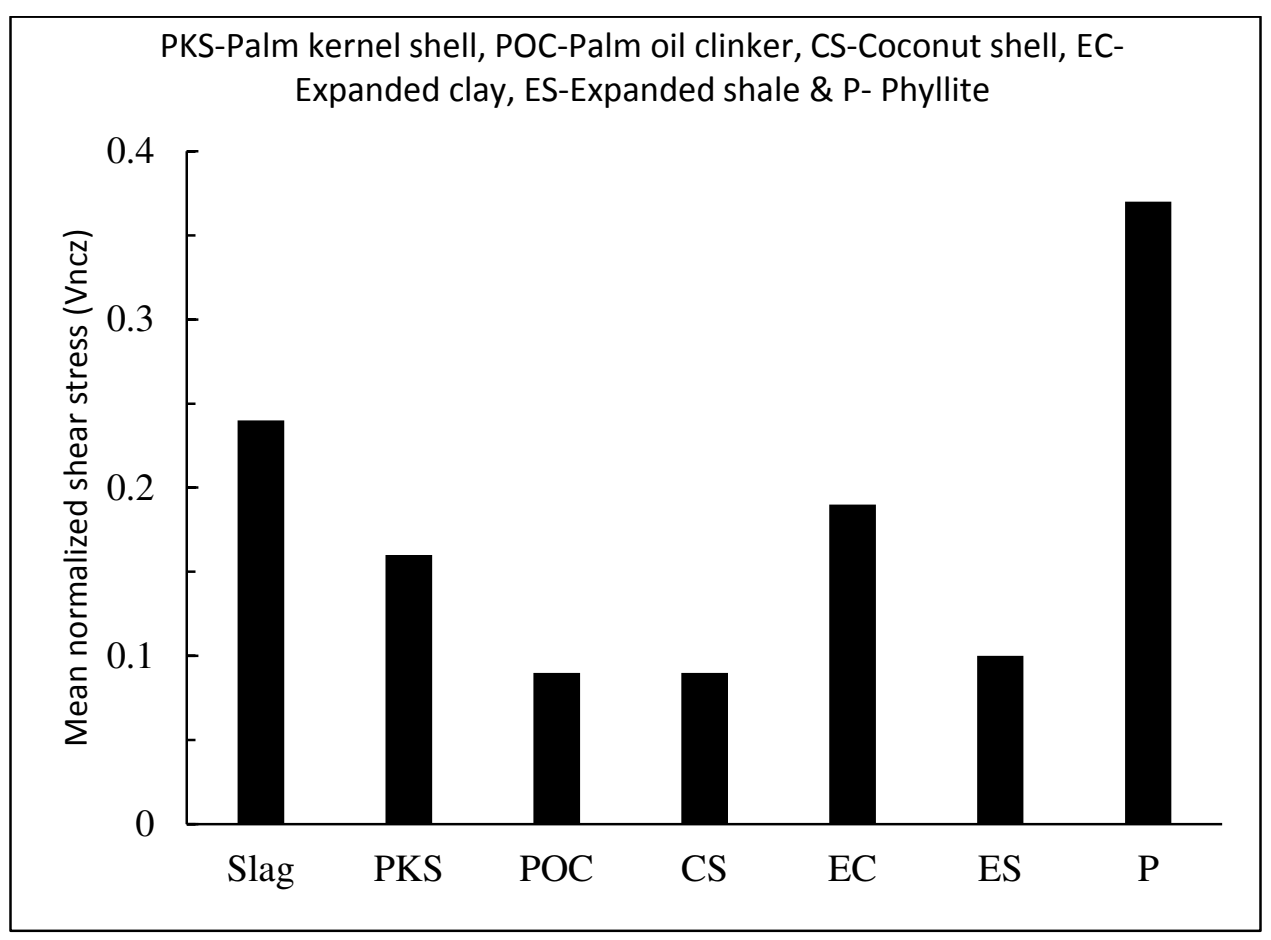

Figure.5.2- Mean normalized shear stress of LWSCC/LWC beams with different types of aggregates

According to Figure 5.2, phyllite lightweight aggregate beams had the highest mean normalized shear strength and those with palm oil clinker (POC) showing the lowest. The mean normalized shear strengths of palm oil clinker and coconut shell (CS) aggregate beams were found to be the lowest. The high shear resistance of phyllite aggregate LWC can be attributed to the enhanced the aggregate interlock mechanism due to the elongated aggregate particles with diverse size.

LWSCC beams with slag aggregate exhibited second highest shear resistance factor and normalized shear strength and can be suitable to use as a structural lightweight aggregate. However, it should be noted that comparison between LWSCC and LWC beams to judge the influence of aggregate types on shear resistance is not practical due to high paste to aggregate volume ratio in LWSCC. 


\subsubsection{Code based analyses of LWC beams and performance of Codes}

Code based analyses of LWSCC beams with slag aggregate with and without shear reinforcement are presented in section 5.2. Shear resistances of LWSCC beams were found to be under predicted by the ACI 318, CSA A23.3 and BS8110 Codes. In this section, shear resistance of LWC beams with and without shear reinforcement are predicted by the three Codes to differentiate Code's performance between LWSCC and LWC.

Table 5.5 summarizes experimental and Code predicted shear strength values of LWC beams (without shear reinforcement) made of different types of lightweight aggregates from previous research studies. ACI 318, CSA A23.3 and BS8110 codes underestimated the shear capacity of the experimental beams made of the following type of lightweight aggregates: palm kernel shell (PKS), coconut shell (CS), expanded clay (EC) and phyllite (P). Most conservative prediction was found for the LWC beams with palm kernel shell (PKS) and phyllite (P) aggregates. However, for most of the LWC beams produced with expanded shale (ES) and palm oil clinker (POC) aggregates, all three codes overestimated the shear resistance capacity and are found to be not safe.

Shear resistance of LWC beams with shear reinforcement made of different aggregates obtained from experiments and Code based predictions are compared in Table 5.6. Shear strength of all LWC beams except one with coconut shell aggregate and one with expanded shale aggregate, were found to be conservatively predicted by ACI 318, CSA A23.3 and BS8110 Codes. In general, all three Codes underestimated the shear strength of LWC beams with shear reinforcement made of CS, ES and P aggregates and all three Codes are found safe

Code based predictions are found to be more conservative for beams with shear reinforcement than beams without shear reinforcement. Similar trend was observed for LWSCC beams produced with slag aggregate. 
Table 5.5 - Shear resistance of lightweight concrete beams without shear reinforcementexperiment and code based predictions

\begin{tabular}{|c|c|c|c|c|c|c|c|}
\hline \multirow[t]{3}{*}{ Beam } & \multicolumn{4}{|c|}{ Shear resistance $V_{u}=V_{c}(k N)$} & \multirow{2}{*}{\multicolumn{3}{|c|}{$\begin{array}{c}\text { Ratio of experimental to predicted } \\
\text { shear }\end{array}$}} \\
\hline & \multirow{2}{*}{$\begin{array}{l}\text { Experiment } \\
\text { (Exp) }\end{array}$} & \multicolumn{3}{|c|}{ Code-based prediction } & & & \\
\hline & & ACI & CSA & BS8110 & Exp/ACI & Exp/CSA & Exp/BS8110 \\
\hline \multicolumn{8}{|c|}{ Alengaram et al. (2011): PKS } \\
\hline PKSC-P1 & 67.1 & 33.3 & 23.8 & 35.6 & 2.01 & 2.81 & 1.88 \\
\hline PKSC-P2 & 58.9 & 33.6 & 30.8 & 35.6 & 1.75 & 1.91 & 1.65 \\
\hline \multicolumn{8}{|c|}{ Mohammed et al. (2013): (POC)Palm oil clinker } \\
\hline AD-3 & 27.5 & 28.7 & 39.7 & 27.6 & 0.96 & 0.69 & 0.99 \\
\hline AD-1 & 19.5 & 28.7 & 39.7 & 27.6 & 0.68 & 0.49 & 0.70 \\
\hline WC-1 & 21.5 & 24.0 & 31.8 & 23.9 & 0.89 & 0.67 & 0.90 \\
\hline WC-3 & 25.0 & 31.6 & 44.6 & 29.9 & 0.79 & 0.56 & 0.84 \\
\hline SR-1 & 30.5 & 39.0 & 37.9 & 40.2 & 0.78 & 0.80 & 0.76 \\
\hline SR-3 & 12.5 & 25.5 & 36.2 & 18.7 & 0.49 & 0.34 & 0.67 \\
\hline \multicolumn{8}{|c|}{ Gunasekaran et al. (2013): (CS)Coconut shell } \\
\hline $\mathrm{AD} / \mathrm{WC} / \mathrm{SR}-2$ & 23.0 & 28.7 & 35.7 & 27.6 & 0.80 & 0.64 & 0.83 \\
\hline WOS1-CSAC & 22.5 & 16.9 & 22.4 & 15.9 & 1.34 & 1.01 & 1.41 \\
\hline WOS2-CSAC & 23.3 & 17.7 & 26.7 & 18.0 & 1.31 & 0.87 & 1.29 \\
\hline \multicolumn{8}{|c|}{ Juan (2011):(EC)Expanded clay } \\
\hline S.B 1.5 & 37.5 & 22.7 & 20.0 & 24.8 & 1.66 & 1.87 & 1.51 \\
\hline S.B 2 & 33.5 & 22.7 & 21.7 & 24.8 & 1.48 & 1.54 & 1.35 \\
\hline S.B 3 & 34.3 & 22.7 & 21.3 & 24.8 & 1.51 & 1.60 & 1.38 \\
\hline S.B 3.5 & 27.5 & 22.7 & 25.0 & 24.8 & 1.21 & 1.10 & 1.11 \\
\hline SB C50 1.5 & 65.0 & 23.7 & 13.6 & 25.7 & 2.74 & 4.78 & 2.53 \\
\hline SB C50 2.0 & 37.0 & 23.7 & 21.2 & 25.7 & 1.56 & 1.74 & 1.44 \\
\hline SB C50 3.0 & 30.0 & 23.7 & 24.7 & 25.7 & 1.27 & 1.21 & 1.17 \\
\hline SB C50 3.5 & 31.5 & 23.7 & 23.9 & 25.7 & 1.33 & 1.32 & 1.22 \\
\hline SB C50 P0.78 3.0 & - & 25.0 & 27.0 & 28.2 & 1.20 & 1.11 & 1.06 \\
\hline SA C50 3.0 & 32.5 & 25.1 & 24.8 & 26.8 & 1.30 & 1.31 & 1.21 \\
\hline SG C50 3.0 & 35.0 & 25.8 & 24.3 & 26.8 & 1.35 & 1.44 & 1.30 \\
\hline SB C70 1.5 & 67.5 & 28.3 & 16.0 & 26.8 & 2.38 & 4.21 & 2.51 \\
\hline SB C70 2.0 & 40.0 & 28.3 & 24.4 & 26.8 & 1.41 & 1.64 & 1.49 \\
\hline SB C70 3.0 & 33.0 & 28.3 & 28.1 & 26.8 & 1.17 & 1.17 & 1.23 \\
\hline SB C70 3.5 & 31.3 & 28.3 & 29.2 & 26.8 & 1.11 & 1.07 & 1.16 \\
\hline \multicolumn{8}{|c|}{ Ahmed (2011):(ES) Expanded shale } \\
\hline B4C7.40S0 & 35.0 & 27.3 & 34.6 & 29.4 & 1.28 & 1.01 & 1.19 \\
\hline B3C7.40S0 & 43.0 & 54.5 & 69.3 & 49.4 & 0.79 & 0.62 & 0.87 \\
\hline B2C7.40S0 & 52.0 & 109.0 & 138.6 & 83.2 & 0.48 & 0.37 & 0.62 \\
\hline B2.C7.40S0-2 & 58.0 & 109.0 & 138.6 & 83.2 & 0.53 & 0.42 & 0.70 \\
\hline \multicolumn{8}{|c|}{ Adom and Afrifa (2013) (P) Phyllite } \\
\hline P1 & 40.0 & 23.4 & 33.8 & 22.9 & 1.71 & 1.18 & 1.74 \\
\hline $\mathrm{P} 2$ & 60.0 & 28.5 & 27.7 & 28.9 & 2.11 & 2.16 & 2.07 \\
\hline P3 & 44.0 & 19.7 & 24.8 & 20.1 & 2.24 & 1.77 & 2.18 \\
\hline $\mathrm{P} 4$ & 66.0 & 23.9 & 28.6 & 25.4 & 2.76 & 2.30 & 2.60 \\
\hline $\mathrm{P} 5$ & 28.0 & 12.7 & 15.9 & 13.7 & 2.20 & 1.75 & 2.04 \\
\hline P6 & 46.0 & 15.5 & 17.7 & 17.2 & 2.96 & 2.60 & 2.66 \\
\hline P7 & 24.0 & 10.1 & 11.5 & 11.5 & 2.38 & 2.08 & 2.09 \\
\hline P8 & 28.0 & 12.3 & 13.2 & 14.4 & 2.28 & 2.11 & 1.93 \\
\hline P9 & 18.0 & 6.5 & 6.2 & 7.8 & 2.79 & 2.90 & 2.30 \\
\hline P10 & 24.0 & 7.9 & 8.0 & 9.8 & 3.05 & 2.99 & 2.43 \\
\hline
\end{tabular}


Table 5.6- Shear resistance of lightweight concrete beams with shear reinforcement- experiment and code based predictions

\begin{tabular}{|c|c|c|c|c|c|c|c|}
\hline \multirow[t]{3}{*}{ Beam } & \multicolumn{4}{|c|}{$\begin{array}{c}\text { Beam shear resistance } \mathrm{V}_{\mathrm{u}}=\mathrm{V}_{\mathrm{c}+} \mathrm{V}_{\mathrm{s}} \\
(\mathrm{kN})\end{array}$} & \multirow{2}{*}{\multicolumn{3}{|c|}{ Ratio of experimental to predicted shear capacity }} \\
\hline & \multirow{2}{*}{$\begin{array}{c}\text { Experi } \\
\text { ment } \\
\text { (Exp) }\end{array}$} & \multicolumn{3}{|c|}{ Code-based prediction } & & & \\
\hline & & $\mathrm{ACI}$ & CSA & $\begin{array}{c}\text { BS811 } \\
0\end{array}$ & Exp/ACI & Exp/CSA & Exp/BS8110 \\
\hline \multicolumn{8}{|c|}{ Alengaram et al. (2011): (PKS) Palm kernel shell } \\
\hline PKSC-L1 & 57.5 & 25.8 & 24.2 & 28.1 & 2.23 & 2.38 & 2.05 \\
\hline PKSC-L2 & 110.0 & 47.7 & 47.1 & 47.4 & 2.31 & 2.34 & 2.32 \\
\hline \multicolumn{8}{|c|}{ Gunasekaran et al. (2013): (CS)Coconut shell } \\
\hline WS1-CSAC & 51.2 & 43.3 & 43.3 & 42.3 & 1.18 & 1.18 & 1.21 \\
\hline WS2-CSAC & 27.2 & 44.2 & 43.3 & 44.5 & 0.62 & 0.63 & 0.61 \\
\hline \multicolumn{8}{|c|}{ Adom and Afrifa (2013):( P )Phyllite } \\
\hline P11 & 106.0 & 36.2 & 35.1 & 39.1 & 2.92 & 3.02 & 2.71 \\
\hline P12 & 86.0 & 36.2 & 35.0 & 39.1 & 2.37 & 2.46 & 2.20 \\
\hline P13 & 96.0 & 44.9 & 43.5 & 47.4 & 2.14 & 2.21 & 2.03 \\
\hline P14 & 114.0 & 44.9 & 43.3 & 47.4 & 2.54 & 2.63 & 2.41 \\
\hline P15 & 128.0 & 55.8 & 54.0 & 57.7 & 2.30 & 2.37 & 2.22 \\
\hline P16 & 118.0 & 55.8 & 53.8 & 57.7 & 2.12 & 2.19 & 2.05 \\
\hline \multicolumn{8}{|c|}{ Ahmed (2011):(ES)Expanded Shale } \\
\hline B4C9.96S12 & 148.0 & 93.5 & 110.4 & 97.4 & 1.58 & 1.34 & 1.52 \\
\hline B4C8.48S12 & 146.6 & 90.2 & 104.4 & 94.1 & 1.62 & 1.40 & 1.56 \\
\hline B4C7.40S12 & 132.0 & 87.7 & 99.6 & 91.5 & 1.51 & 1.32 & 1.44 \\
\hline B1.5C5.7S10 & 170.9 & 82.4 & 85.5 & 82.4 & 2.07 & 2.00 & 2.07 \\
\hline B1.5C5.7S9 & 160.5 & 87.1 & 89.9 & 86.9 & 1.84 & 1.79 & 1.85 \\
\hline B1.5C5.7S8 & 157.1 & 93.2 & 95.8 & 92.7 & 1.68 & 1.64 & 1.69 \\
\hline B1.5C5.7S7 & 161.8 & 100.8 & 103.0 & 99.9 & 1.61 & 1.57 & 1.62 \\
\hline B1.5C6.12S5 & 233.6 & 126.6 & 128.9 & 124.3 & 1.85 & 1.81 & 1.88 \\
\hline B1.5C6.12S3.5 & 197.9 & 163.3 & 165.3 & 159.2 & 1.21 & 1.20 & 1.24 \\
\hline B1.5C6.12S2.5 & 200.1 & 211.3 & 212.9 & 204.7 & 0.95 & 0.94 & 0.98 \\
\hline
\end{tabular}




\subsection{Code based prediction of flexural capacity of LWSCC beams}

\subsubsection{Theoretical cracking moment of the LWSCC flexural beams}

When the tensile stress of concrete reaches modulus of the rupture $\left(f_{r}\right)$, the beam section is considered to be cracked. The theoretical cracking moment (Mcr) of the beam at the onset of first flexural crack can be determined by using the equation 5.15 recommended by ACI 318 (2005) and CSA A23.3 (2004) codes. Flexural equations are already introduced in Chapter Two, however, they are reintroduced again in this section

$\mathrm{M}_{\mathrm{cr}}=\frac{\mathrm{f}_{\mathrm{r}} \mathrm{I}_{\mathrm{g}}}{y_{t}}$

Experimental and theoretical first flexural cracking moments for the LWSCC beams are compared in Table 5.7. For singly reinforced beams, predicted cracking moments were reasonably close to those obtained from experiments as the ratio of experimental to predicted (theoretical) ranges between 1.03 and 1.16. However for doubly reinforced beam (F3d), Eq. 5.15 conservatively estimated the cracking moment due to compression reinforcement playing a significant factor in increasing the cracking load compared to singly reinforced beams (F1s and F2s).

Table 5.7 - Experimental and theoretical cracking moment comparison

\begin{tabular}{|l|c|c|c|}
\hline $\begin{array}{l}\text { Beam } \\
\text { code }\end{array}$ & $\begin{array}{c}\text { Experimental cracking } \\
\text { moment } \\
\mathrm{M}_{\mathrm{cr}(\mathrm{exp})}(\mathrm{kNm})\end{array}$ & $\begin{array}{c}\text { Theoretical cracking } \\
\text { moment } \\
\mathrm{M}_{\mathrm{cr}(\text { the })} \mathrm{kNm}\end{array}$ & $\begin{array}{c}\text { Ratio of experimental to } \\
\text { theoretical cracking moment }\end{array}$ \\
\hline F1s & 2.8 & 2.7 & 1.03 \\
\hline F2s & 3.5 & 3.0 & 1.16 \\
\hline F3d & 5.7 & 3.1 & 1.83 \\
\hline
\end{tabular}

\subsubsection{Theoretical ultimate moment of the LWSCC flexural beams}

In engineering practice, it is often required to evaluate the ultimate flexural capacity of a beam. At ultimate stage, concrete reaches its maximum compressive strain which is equal to 0.0035 according to CSA A23.3 (2004) Code. At ultimate state, the tensile steel reinforcement could be either in elastic or plastic state. If the section is over reinforced, concrete-controlled failure by crushing of concrete can happen and the nature of such failure is brittle and therefore, undesirable. 
If the section is under-reinforced, steel controlled failure by yielding of the tensile reinforcement occurs and the nature of such failure is ductile, therefore favored by designers.

Section provided with tension and compression reinforcement is called doubly reinforced beam. This type of section is preferred for earthquake resistance, controlling the long term deformation, ductility improvement and architectural constraints.

As per CSA A23.3 (2004), the ultimate moment capacity $\left(\mathrm{M}_{\mathrm{u}}\right)$ for singly reinforced beam can be obtained by using Eqs. 5.16 and 5.17:

$\mathrm{M}_{\mathrm{u}}=\mathrm{f}_{\mathrm{y}} \mathrm{A}_{\mathrm{s}}\left(\mathrm{d}-\frac{\mathrm{a}}{2}\right)$

$\mathrm{a}=\frac{\mathrm{f}_{\mathrm{y}} \mathrm{A}_{\mathrm{s}}}{\alpha_{1} \mathrm{f}_{\mathrm{c}}^{\prime} \mathrm{b}}$

Also as per CSA A23.3 (2004), the ultimate moment capacity $\left(\mathrm{M}_{\mathrm{u}}\right)$ for doubly reinforced beam can be obtained by using Eqs. 5.18 and 5.19:

$\mathrm{M}_{\mathrm{u}}=\left(\mathrm{f}_{\mathrm{y}} \mathrm{A}_{\mathrm{s}}-\mathrm{f}_{\mathrm{y}}^{\prime} \mathrm{A}_{\mathrm{s}}^{\prime}\right)\left(\mathrm{d}-\frac{\mathrm{a}}{2}\right)+\mathrm{f}_{\mathrm{y}}^{\prime} \mathrm{A}_{\mathrm{s}}^{\prime}\left(\mathrm{d}-\mathrm{d}^{\prime}\right)$

$\mathrm{a}=\frac{\mathrm{f}_{\mathrm{y}} \mathrm{A}_{\mathrm{s}}-\mathrm{f}_{\mathrm{y}}^{\prime} \mathrm{A}_{\mathrm{s}}^{\prime}}{\alpha_{1} \mathrm{f}_{\mathrm{c}}^{\prime} \mathrm{b}}$

Theoretical ultimate moment capacities of LWSCC beams as per CSA A23.3 (2004) code are compared with those obtained from experiments in Table 5.8. It can be noted that the CSA A23, 3 based methods predicted the ultimate moment capacity of both singly and doubly reinforced LWSCC beams with good accuracy as the ratios of experimental to code predicted values ranged between 1.06 and 1.13 .

Table 5.8- Comparison of experimental and theoretical ultimate moments of LWSCC beans

\begin{tabular}{|l|c|c|c|}
\hline $\begin{array}{l}\text { Beam } \\
\text { code }\end{array}$ & $\begin{array}{c}\text { Experimental ultimate } \\
\text { moment } \\
\mathrm{M}_{\mathrm{u}(\exp )}(\mathrm{kNm})\end{array}$ & $\begin{array}{c}\text { Theoretical ultimate } \\
\text { moment } \\
\mathrm{M}_{\mathrm{u}(\text { the })}(\mathrm{kNm})\end{array}$ & $\begin{array}{c}\text { Ratio of experimental to theoretical } \\
\text { ultimate moment }\end{array}$ \\
\hline F1s & 18.1 & 16 & 1.13 \\
\hline F2s & 26.5 & 24.5 & 1.08 \\
\hline F3d & 51.2 & 48.3 & 1.06 \\
\hline
\end{tabular}




\subsection{Summary}

ACI 318, CSA A23.3 and BS8110 design codes were conservative in predicting the ultimate shear strength of LWSCC beams without shear reinforcement. Higher margin of safety was identified in predicting the concrete shear resistance LWSCC beams with shear reinforcement than those without shear reinforcement.

From the analysis of sixty six experimental beams (current and from previous research) with six types of lightweight aggregates, those with slag aggregate incorporated LWSCC showed the second highest normalized shear strength and shear resistance factor, This proves the suitability of using slag aggregate to produce structural lightweight concrete with good shear resistance capacity and post-cracking shear resistance.

CSA A23.3 code also very accurately predicted the cracking moment and ultimate moment capacities of LWSCC beams. 


\section{CHAPTER SIX}

\section{CONCLUSIONS}

\subsection{Introduction}

This research studied the shear and flexural strength of lightweight self-consolidating concrete (LWSCC) beams made of blast furnace slag aggregate. The variables of this experimental and theoretical (Code based) research included shear span to depth ration (a/d), types of concrete (LWSCC and normal weight self-consolidating concrete'SCC'), longitudinal(flexural) reinforcement ratio, presence or absence of shear reinforcement, singly or doubly reinforced beams (for flexure behavior only) and types of aggregate (for Code based analyses only).

\subsection{Shear resistance of $L W S C C$ beams}

The test results of six LWSCC/SCC beams (three from each) without shear reinforcement and three LWSCC beams tested under four point monotonic static loading to failure are described. In addition, six types of lightweight aggregate concrete (LWC) shear beams (with and without shear reinforcement) from previous experimental research studies were collected and investigated from the perspective of the effect of aggregate types on shear capacity/shear transfer mechanism and the performance of existing Canadian, American and British Codes. Within the scope of the investigation, the following conclusions are drawn:

- Shear strength of LWSCC (with and without shear reinforcement) and SCC beams having nominal flexural reinforcement increased with the decrease of shear span to depth ratio $(\mathrm{a} / \mathrm{d})$.

- The shear resistance capacity of SCC beams (without shear reinforcement) was higher than corresponding LWSCC beams. Shear resistance capacity difference between these two concretes increased with the decrease of a/d.

- SCC beams without shear reinforcement had higher post-cracking shear resistance (defined by shear resistance factor 'SRF) than their LWSCC counterparts. SRF increased with the decrease of $\mathrm{a} / \mathrm{d}$ and increase of width to depth ratio (b/d) for both SCC and LWSCC beams. This was attributed to the weaker aggregate interlock mechanism resulting from partially 
fractured coarse aggregate along the failure surface, higher number of cracks and wider final crack width at failure than normal weight SCC beams.

- LWSCC beams with shear reinforcement behaved similar manner to LWSCC beams without shear reinforcement until formation of diagonal crack - showed the same diagonal cracking strength and hence, shear reinforcement did not affect the concrete shear resistance capacity until the formation of diagonal crack.

- As expected, LWSCC beams with shear reinforcement had higher stiffness, higher ultimate load carrying capacity and higher ductility than LWSCC beams without shear reinforcement.

- All structural design codes found to be conservatively predicted the shear capacity of the LWSCC beams. For all design codes, experimental to predicted shear strength ratios were high and these ratios ranged from 1.27 to 1.92 for LWSCC beams without shear reinforcement and 1.44 to 2.34 for LWSCC beams with shear reinforcement.

- In both type of beams (LWSCC and SCC), all code predictions were conservative and conservativeness increased with the increase of beam depth or decrease in shear span to depth ratio $(\mathrm{a} / \mathrm{d})$. It should be noted that overestimation was higher of LWSCC beams compared to normal weight SCC beams even after the use of reduction factors specified in the Codes. However, the predicted shear capacity differences for similar beams between the Codes were not significant.

- Overall, current reduction factors suggested by the Codes for lightweight concrete can be increased for the prediction of shear resistance of LWSCC beams. This is reasonable considering the lower volume of weak lightweight aggregate (hence higher volume of strong paste) in LWSCC compared to lightweight concrete.

- From the analysis from the previous experimental data, LWSCC with slag aggregate showed good shear resistance characteristics during pre and post cracking stages compared to those made of other six types of lightweight aggregates.

- On the contrary, design Codes were found to over or under predict (depending on the types of aggregates) the shear capacity of the LWC beams with and without shear reinforcement. Current code adopted LWC reduction factors were unsafe for some lightweight aggregate 
types. It is necessary to suggest reduction factors to address different variety of lightweight aggregates in the shear strength prediction.

\subsection{Flexural LWSCC beams}

The results of three flexural LWSCC beams (made of slag aggregate) tested to failure under four point monotonic loading are discussed along with Canadian Code based (CSA.A23.3-04 2004) prediction of cracking and ultimate moment resistances. The following conclusions are drawn:

- All LWSCC flexural beams showed typical structural behavior in flexure, since the beams were under-reinforced. Yielding of the tensile reinforcement happened before crushing of the compression concrete in the pure bending region. The ultimate load of the beam increased with the increase of steel reinforcement ratio.

- LWSCC beams showed good ductility behavior since all the beams had shown significant amount of deformation before failure.

- CSA A23.3 code accurately predicted the cracking moment and ultimate moment capacities of LWSCC beams.

\subsection{Recommendations for future research studies}

The following recommendations are made for future research studies:

- Investigate experimentally and theoretically (using various code based analyses) shear and flexure capacities of LWSCC beams with different types of lightweight aggregates such as expanded shale, expanded clay, volcanic pumice/scoria and others.

- Perform durability studies of LWSCC beams with different types of lightweight aggregates under aggressive environments quantifying reinforcement corrosion and over strength degradation.

- Perform strength and durability studies of LWSCC structural elements (such as columns, shear panels, slabs etc,) made different types of lightweight aggregates,

- Develop or modify Code based procedures/specifications for structural design and durability requirements for various LWSCC structural elements. 


\section{REFERENCES}

ACI Committee 211 (1981). Standard Practice for Selecting Proportions of Structural Lightweight

Concrete (ACI 211.2-81). American Concrete Institute, Detroit, USA.

ACI Committee 213 (2003). Guide for Structural Lightweight-Aggregate Concrete (ACI 213R03), American Concrete Institute, Farmington Hills, Michigan, pp.38.

ACI Committee (2005). Building Code Requirements for Structural Concrete (ACI 318-05) and Commentary (ACI 318R-05). American Concrete Institute.

Adom A.M.and Afrifa R.O. (2013).Shear Behavior of Reinforced Phyllite Concrete Beams, Materials and Design, Vol.43, pp.438-446.

Adom A.M.and Afrifa R.O. (2011). Investigation on the Flexural Behavior of Reinforced Concrete Beams Using Phyllite Aggregates from Mining Waste. Materials and Design, Vol.32, No.10, pp.5132-5140.

Ahmed A.N. (2011). Flexural and Shear Performance of High Strength Lightweight Reinforced Concrete Beams, Doctoral Dissertation, Department of Civil and Environmental Engineering University of Illinois at Chicago, USA.

Aïcin P.C (1998). High-Performance Concrete, CRC-Press, London: EandFN Spon, pp. 510-526. Alengaram U. J., Jumaat M. Z., Mahmud. H. and Fayyadh M. M. (2011). Shear Behavior of

Reinforced Palm Kernel Shell Concrete Beams, Construction and Building Materials, Vol.25, No.6, pp.2918-2927

Andiç-Çakır Ö.and Hızal S. (2012). Influence of Elevated Temperatures on the Mechanical

Properties and Microstructure of Self-consolidating Lightweight Aggregate Concrete, Construction and Building Materials, Vol. 34, pp. 575-583.

ASTM C39/C39M (2003). Standard Test Method for Compressive Strength of Cylindrical Concrete Specimens American Society for Testing and Materials, West Conshohocken, Pennsylvania, USA, pp.1-7.

ASTM C78/C78M (2010). Standard Test Method for Flexural Strength of Concrete (Using Simple Beams with Third-Point Loading), Cement Standards and Concrete Standards, pp.1-7. ASTM C330 (2014). Standard Specification for Lightweight Aggregates for Structural Concrete, ASTM International, West Conshohocken, PA, USA, WWW.astm.org. 
Bai Y, Ibrahim R. and Muhammed Basheer P. A. M. (2004). Properties of Lightweight Concrete Manufactured with Fly Ash, Furnace Bottom Ash, and Lytag, International Workshop on Sustainable Development and Concrete Technology, Beijing, China, pp.77-88.

Bamforth P.B. (1987). The Properties of High Strength Lightweight Concrete, Concrete, Vol. 21, No. 4, pp. 8-9.

Bentur A., Igarashi S. and Kovler K. (2001). Prevention of Autogenous Shrinkage in High-strength Concrete by Internal Curing using Wet Lightweight Aggregates, Cement and Concrete Research, Vol. 31, No. 11, pp.1587-91.

Bogas J.A.j., Gomes A. and Pereira M.F.C. (2012). Self-compacting Lightweight Concrete Produced with Expanded Clay Aggregate, Construction and Building Materials, Vol. 35, Pp.1013-1022.

British Standards Institute. (1997). BS 8110-Part1:1997 Structural Use of Concrete, Code of Practice for Design and Construction, British Standards Institute, London.

Chaallal O. and Lachemi M. (2010). Reinforced Concrete Structures, Design according to CSA A23.3-04, Presses de I' University du Quebec, Canada, pp.465.

Choi Y.W., KimY.J., Shin H.C., Shin H.C. and Moon H.Y. (2006). An Experimental Research on the Fluidity and Mechanical Properties of High-Strength Lightweight Self-compacting, Concrete, Cement and Concrete Research, Vol. 36, No. 9, pp.1595-602.

CIP 36 (2003). - Concrete in Practice - What, why and how? Structural lightweight concrete, National Ready Mix Concrete Association (NRMCA), MD, USA, http://www.nrmca.org/aboutconcrete/cips/36p.pdf

CSA Standard A23.3-04. (2004). Canadian Standard Association (CSA), Design of Concrete Structures, CSA Standard A23.3-04. Rexdale, Ontario.

Curcio F., Galeota D., Gallo A. and Giammatteo M. M. (1998). High-Performance Lightweight Concrete for the Precast Prestressed Concrete Industry, CANMET/ACI/JCI, Tokushima, Japan, Vol. SP179-24, No. 1, pp. 389-406.

Dymond B. Z. (2007). Shear Strength of a PCBT-53 Girder Fabricated with Lightweight, SelfConsolidating Concrete, Master's thesis, Virginia Polytechnic Institute and State University, USA.

EFNARC (2005).The European Guidelines for Self-Compacting Concrete, Specification, Production and Use the Self-Compacting Concrete European Project Group, pp. 63 
CEB-FIP (1983). Federation International de la Precontraine (FIP). FIP Manual of Lightweight Aggregate Concrete, Halsted Press, New York, pp.259.

Gastebled O. J. and May I. M. (2001). Reinforced Concrete Beams Without Stirrups, ACI Structural Journal, Vol.98, No.18.

Gerritse A. (1981). Design Considerations for Reinforced Lightweight Concrete, International Journal of Cement Composites and Lightweight Concrete, Vol. 3, No.1, pp. 57-69.

Gunasekaran K., Annadurai R. and Kumar P.S. (2013). Study on Reinforced Lightweight Coconut Shell Concrete Beam Behavior under Shear. Material and Design, Vol. 50, pp.293-301.

Hanson J.A. (1968). Effect of Curing and Environments on Splitting Tensile Strength, ACI Journal Proceedings, Vol.65, No.7, pp535-543.

Hassan A. A., Lachemi M. and Hossain K. M.A (2012). Effect of Metakaolin and Silica Fume on the Durability of Self-Consolidating Concrete, Cement and Concrete Composites, Vol. 34, No. 6, pp.801-807

Hassan A. A. A., Hossain K.M.A. and Lachemi M. (2010a). Strength, Cracking and Deflection Performance of Large-Scale Self-Consolidating Concrete Beams Subjected to Shear Failure, Engineering Structures, Vol. 32, No.5, pp.1262-1271.

Hassan A. A. A., Hossain K. M. A. and Lachemi M. (2010b). Structural Assessment of Corroded Self-Consolidating Concrete Beams. Engineering Structures, Vol. 32, No.3, pp.874-885.

Hassan A.A.A, Hossain K.M.A. and Lachemi M. (2008). Behaviour of Full -Scale Self Consolidating Concrete Beams in Shear, Cement and Concrete Composites, Vol. 30, No.7, pp.588-596.

Holm T.A. (1980). Performance of Structural Lightweight Concrete in a Marine Environment, Performance of Concrete in Marine Environment, SP-65, V. M. Malhotra, Edited, American Concrete Institute, Farmington Hills, Michigan, pp. 589 - 608.

Hossain K.M.A. (1997). Properties of Volcanic Ash and Pumice Concrete, IABSE Report, Vol. 81, pp. 145-150 (ISBN 974-331-139-4).

Hossain K.M.A. and Lachemi M. (2009). Fresh, Mechanical, and Durability Characteristics of Self-consolidating Concrete Incorporating Volcanic Ash. Journal of Materials in Civil Engineering, Vol.22, No.7, pp. 651-657. 
Hossain K. M. A. (2009a). Influence of Extreme Curing Conditions on Compressive Strength and Pulse Velocity of Lightweight Pumice Concrete, Computers and Concrete, Vol.6, No.6, pp. 437-450.

Hossain K. M. A. (2009b). Resistance of Scoria-Based Blended Cement Concrete against Deterioration and Corrosion in Mixed Sulfate Environment, ASCE Journal of Materials in Civil Engineering, Vol. 21, No. 7, pp. 299-308.

Hossain K. M.A. and Ahmed S. (2010). Lightweight Concrete Incorporating Volcanic Ash-Based Blended Cement and Pumice Aggregate. Journal of Materials in Civil Engineering, Vol.23, No.4, pp.493-498.

Hossain K.M.A. and Lachemi M. (2007a). Mixture Design, Strength, Durability, and Fire Resistance of Lightweight Pumice Concrete. ACI Materials Journal, Vol.104, No.5, pp. 449457.

Hossain K.M.A. and Lachemi M. (2007b). Characteristics of Self-Consolidating Concrete Incorporating Volcanic Ash, 32nd Conference on Our World in Concrete and Structures, Singapore, August 27-29, 217-224.

Hossain K. M. A. and Anwar M.S. (2015), Influence of Foundry Sand and Natural Pozzolans on the Mechanical, Durability and Micro-structural Properties of Lightweight Concrete, British Journal of Applied Science and Technology, Vol.10, No.4, pp.1-12.

Hossain K. M. A. (2008). Bond Characteristics of Plain and Deformed Bars in Lightweight Pumice Concrete. Construction and Building Materials, Vol.22, No.7, pp.1491-1499

Hossain K.M.A., Lachemi M. and Sammour M. (2010). Influence of Polyvinyl Alcohol and Metallic Fibres on Fresh and Rheological Properties of Self-Consolidating Concrete, $6^{\text {th }}$ International RILEM Symposium on Self-consolidating Concrete, 26-29 Sept, Montreal. Canada.

Hossain K.M.A.(2012).Lightweight Concrete Incorporating Volcanic Materials, ICEConstruction Materials Journal, Vol. 165, No. 2, pp.111-120.

Hossain K. M. A., Ahmed S. and Lachemi M. (2011). Lightweight Concrete Incorporating Pumice Based Blended Cement and Aggregate, Mechanical and Durability Characteristics, Construction and Building Materials, Vol.25, No.3, pp.1186-1195. 
Hossain K.M.A., Julkarnine K.M.Y. and Anwar M. S. (2015). Evolution of Strength and Durability of Scoria Concrete In Sea Environment. Evolution, Journal of Multidisciplinary Engineering Science and Technology, (JMEST), Vol.2, No. 6, pp.1268-1275.

Hossain K.M.A. (2004a). Properties of Volcanic Pumice Based Cement and Lightweight Concrete, Cement and Concrete Research, Vol. 34, No. 2, pp. 283-291.

Hossain K.M.A. (2004b). Properties of Volcanic Scoria Based Lightweight Concrete, Magazine of Concrete Research, Vol. 56, No. 2, pp. 111-120.

Hossain K.M.A. (2006). Blended Cement and Lightweight Concrete Using Scoria Mix Design, Strength, Durability and Heat Insulation Characteristics, International Journal of Physical Sciences (IJPS), Vol.1, No. 1, pp. 5-16.

Hossain K.M.A. (2015). Lightweight Self-Consolidating Concrete with Volcanic and Other Natural Materials, ICE Journal of Construction Materials, Vol .168, No 1, 24-35.

Hossain K.M.A. (2013). Effect of Air Entrainment and Volcanic Ash on The Properties of SelfConsolidating Concrete, European Journal of Scientific Research, Vol.95,No.3, pp.387-399. Hubertova M. and Hela R. (2007). The Effect of Metakaolin and Silica Fume on the Properties of Lightweight Self-Consolidating Concrete, ACI Special Publication, SP-243, No.3, pp. 3548.

Hwang C.L. and Hung M.F. (2005).Durability Design and Performance of Self-Consolidating Lightweight Concrete, Construction and Building Materials, Vol. 19, No. 8, pp.619-626.

Hwang C.L., Bui L.A.T., Lin K.L. and Lo C.T. (2012). Manufacture and Performance of Lightweight Aggregate from Municipal Solid Waste Incinerator Fly Ash and Reservoir Sediment for Self-consolidating Lightweight Concrete. Cement and Concrete Composites, Vol. 34, No. 10, pp. 1159-1166.

IStructE. (1987). Guide to the Structural Use of Lightweight Aggregate Concrete, The institution of Structural Engineers and The Concrete Society, London, pp.58.

Juan K. Y. (2011). Cracking Mode and Shear Strength of Lightweight Concrete Beams, Doctoral Dissertation. Department of Civil and Environmental Engineering, National University of Singapore, Singapore.

Karahan O, Hossain K. M.A., Ozbay E., Lachemi M. and Sancak E. (2012). Effect of Metakaolin Content on the Properties Self-Consolidating Lightweight Concrete. Construction and Building Materials, Vol. 31, No. 6, pp.320-325. 
Karahan O., Hossain K.M.A., Ozbay E., Lachemi M. and Sancak E. (2012a). Effect of Metakaolin Content on the Properties Self-Consolidating Lightweight Concrete, Construction and Building Materials, Vol. 31, No. 6, pp. 320-325

Karahan O., Ozbay E., Hossain K. M.A., Lachemi M. and Atis C. D. (2012b). Fresh, Mechanical, Transport, and Durability Properties of Self-Consolidating Rubberized Concrete. ACI Materials Journal, Vol. 109, No.4, pp.413-420.

Kiliç A., Atis C.D., Yasar E. and Özcan F. (2003). High-Strength Lightweight Concrete Made with Scoria Aggregate Containing Mineral Admixtures, Cement and Concrete Research, Vol. 33, No. 10, pp.1595-9.

Kim Y. H., Hueste M. B. D., Trejo D. and Cline D. B. (2010). Shear Characteristics and Design for High-Strength Self-Consolidating Concrete, Journal of Structural Engineering, Vol. 136, No.8, pp.989- 1000.

Kim Y.J., Choi Y.W. and Lachemi M. (2010). Characteristics of Self-Consolidating Concrete Using Two Types of Lightweight Coarse Aggregates, Construction and Building Materials, Vol. 24, No. 1, pp.11-16.

Lachemi M., Hossain K.M.A and Lambros V. (2005). Shear Resistance of Self-Consolidating Concrete Beams-Experimental Investigations. Canadian journal of Civil Engineering, Vol.32, No.6, ppl.1103-1113.

Lachemi M., Hossain K.M.A., Lambros V. and Bouzoubaa N. (2003a). Development of CostEffective Self-Compacting Concrete Incorporating Fly Ash, Slag Cement or Viscosity Modifying Admixtures, ACI Materials Journal, Vol.100, No.5, pp. 419-425.

Lachemi M., Hossain K.M.A., Lambros V., Nkinamubanzi P.C. and Bouzoubaa N. (2003b). Performance of New Viscosity Modifying Admixtures in Enhancing the Rheological Properties of Cement Paste, Vol.34, No.2, pp. 185-193.

Lachemi M., Bae S., Hossain K.M.A. and Sahmaran M. (2009). Steel-Concrete Bond Strength of Lightweight Self-Consolidating Concrete, Materials and Structures, Vol. 42, No. 7, pp.10151023.

LaRue H. A. (1946). Modulus of Elasticity of Aggregates and Its Effect on Concrete, ASTM Proceeding, Volume .46, pp. 1298 - 1310. 
Lee J.Y. and Watanabe F. (2000). Shear Design of Reinforced Concrete Beams with Shear Reinforcement Considering Failure Modes, American Concrete Institute Structural Journal, Vol.97, No.3.

Lee J. Y. and Watanabe F. (2000). Shear Design of Reinforced Concrete Beams with Shear Reinforcement Considering Failure Modes, American Concrete Institute Structural Journal, Vol. 97, No.3, pp.323-331.

Lim H. S., Wee T. H., Mansur M. A. and Kong K. H. (2006). Flexural Behavior of Reinforced Lightweight Aggregate Concrete Beams, Vol.1, No.15, pp 1-15.

Lo T.Y., Tang P.W.C., Cui H.Z. and Nadeem A. (2007). Comparison of Workability and Mechanical Properties of Self-Compacting Lightweight Concrete and Normal SelfCompacting Concrete. Materials Research Innovations, Vol. 11, No. 1, pp. 45-50.

Lotfy A. (2012). Lightweight Self-consolidating Concrete Statistical Modelling, Mixture Design and Performance Evaluation, $\mathrm{PhD}$ thesis, Ryerson University.

Lotfy A., Hossain K. M. A. and Lachemi M. (2014). Application of Statistical Models in Proportioning Lightweight Self-Consolidating Concrete with Expanded Clay Aggregates, Construction and Building Materials, Vol. 65 (August), pp. 450-469.

Lotfy A., Hossain K. M. A. and Lachemi M. (2015a). Lightweight Self-consolidating Concrete with Expanded Shale aggregates: Modelling and Optimization, International Journal of Concrete Structures and Materials, Vol.9, No.2, pp.185-206.

Lotfy A., Hossain K. M. A. and Lachemi M. (2015b). Statistical Models for the Development of Optimized Furnace Slag Lightweight SCC, Cement and Concrete Composites, Vol. 55 (January), pp. 169-185.

Maghsoudi A. A., Mohamadpour S. and Maghsoudi M. (2011). Mix Design and Mechanical Properties of Self-Compacting Lightweight Concrete. International Journal of Civil Engineering, Vol.9, No. 3, pp. 230-236.

Mohammed B. S., Foo W. L., Hossain K. M. A. and Abdullahi M. (2013). Shear Strength of Palm Oil Clinker Concrete Beams, Materials and Design, Vol. 46, pp.270-276.

Mohammed B. S., Hossain A. M. A, Foo W. L. and Abdullahi M. (2011). Rapid Chloride Permeability Test on Lightweight Concrete Made with Oil Palm Clinker. Journal of Engineering Research and Applications (IJERA) ISSN, Vol.1, No.4, pp. 2248- 9622. 
Mor A. (1993). Steel-Concrete Bond in High-strength Lightweight Concrete, ACI Materials Journal, Vol. 89, No. 1, pp.76-82.

Neville A. M. (1999). Properties of Concrete, Fourth Edition, Longman, Essex, pp.844.

Okamura H. and Ouchi M. (2003). Self-Compacting Concrete, Journal of Advanced Concrete Technology, Vol .1, No.1, pp. 5-15

Papanicolaou C. and Kaffetzakis M. (2009). Pumice Aggregate Self-Compacting Concrete (PASCC), 16th Conference on Concrete Materials and Structures, Technical Chamber of Greece, 21-23 October, Paphos, Cyprus, pp. 21-23.

Pauw A. (1960). Static Modulus of Elasticity of Concrete as Affected by Density, Journal of the American Concrete Institute Proceedings, Vol. 57, No. 6, pp. 679-687.

Shi C. and $\mathrm{Wu}$ Y. (2005). Mixture Proportioning and Properties of Self-Consolidating Lightweight Concrete Containing Glass Powder, ACI Materials Journal, Vol. 102, No. 5, pp.355-63.

Su N. and Miao B. (2003). A New Method for the Mix Design of Medium Strength Flowing Concrete with Low Cement Content. Cement Concrete Composites, Vol. 25, No. 2, pp. 21522.

Taylor H. P. J. (1970). Investigation of the Forces Carried Across Cracks in Reinforced Concrete Beams in Shear by Interlock of Aggregate (No. TR 42.447 Tech. Rpt.).

Taylor R. and Brewer R. S. (1963). The Effect of the Type of Aggregate on the Diagonal Cracking of Reinforced Concrete Beams, Magazine of Concrete Research, Vol. 15, No. 44, pp. 8792.

Teo D. C., Mannan M. A. and Kurian J. V. (2006). Flexural Behavior of Reinforced Lightweight Concrete Beams Made with Oil Palm Shell (OPS),Journal of Advanced Concrete Technology, Vol.4, No.3, pp.459-468.

Topcu I.B. (1997). Semi-Lightweight Concretes Produced by Volcanic Slags, Cement and Concrete Research, Vol. 27, No.1, pp.15-21.

Topçu I.B. and Uygunoğlu T. (2010). Effect of Aggregate Type on Properties of Hardened SelfConsolidating Lightweight Concrete (SCLC), Construction and Building Materials, Vol. 24, No. 7, pp.1286-1295.

Topçu I.B. and Uygunoğlu T. (2007). Properties of Autoclaved Lightweight Aggregate Concrete, Building and Environment, Vol. 42, Issue. 12, pp. 4108-4116. 
Wang H.Y. (2009). Durability of Self-Consolidating Lightweight Aggregate Concrete Using Dredged Silt, Construction and Building Materials, Vol. 23, No. 6, pp. 2332-7.

Wesche K. (1968). Regulations for Reinforced and Prestressed Lightweight Aggregate Concrete in Various Countries, Cement and Concrete Association, Lomdon/UK, Vol.1,pp.225-233.

Wight J.K. and Macgregor J.G. (1997). Reinforced Concrete Mechanics and Design, Sixth Edition Upper Saddle River, NJ, Prentice Hall, U.S.A, pp.1143.

Wu Z., Zhang Y., Zheng J. and Ding Y. (2009). An Experimental Study on the Workability of Self-Compacting Lightweight Concrete, Construction and Building Materials, Vol. 23, No. 5, pp. 2087-2092.

Yahia A., Tanimura M., Shimabukuro A. and Shimoyama Y. (1999). Effect of Rheological Parameter on Self-Compacting of Concrete Containing Various Mineral Admixtures, Proceeding of the First RILEM International Symposium on Self -Compacting Concrete, Stockholm, Sweden, September, pp.523-535.

Ziehl P. H., Rizos, D. C., Caicedo, J. M., Barrios B., Howard R. B. and Colmorgan A. S. (2009), Investigation of the Performance and Benefits of Lightweight SCC Prestressed Concrete Bridge Girders and SCC Materials, The South Carolina Department of Transportation and The Federal Highway Administration, Report No. FHWA-SC-09-02 CEE-SG-0662-01, USA, 282p. 